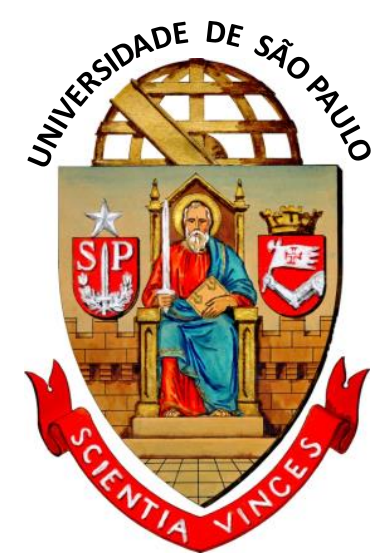

UNIVERSIDADE DE SÃO PAULO

ESCOLA DE ENGENHARIA DE SÃO CARLOS

DEPARTAMENTO DE ENGENHARIA ELÉTRICA

PROGRAMA DE PÓS-GRADUAÇÃO EM ENGENHARIA ELÉTRICA

DANIEL MARCHESI DE CAMARGO NEVES

\title{
Ressoadores WGM Baseados em Grafeno como \\ Plataforma para Moduladores de Eletro-absorção
}

SÃo CARLOS 



\section{DANIEL MARCHESI DE CAMARGO NEVES}

\section{Ressoadores WGM Baseados em Grafeno como \\ Plataforma para Moduladores de Eletro-absorção}

Dissertação apresentada à Escola de Engenharia de São Carlos como parte dos requisitos para obtenção do título de Mestre em Ciências, Programa de Engenharia Elétrica.

Área de Concentração: Telecomunicações

Orientador: Prof. Dr. Ben-Hur Viana Borges

SÃO CARLOS

2015 


\begin{abstract}
AUTORIZO A REPRODUÇÃO TOTAL OU PARCIAL DESTE TRABALHO, POR QUALQUER MEIO CONVENCIONAL OU ELETRÔNICO, PARA FINS DE ESTUDO E PESQUISA, DESDE QUE CITADA A FONTE.
\end{abstract}

Neves, Daniel Marchesi de Camargo
Ressoadores WGM Baseados em Grafeno como Plataforma
para Moduladores de Eletro-absorço / Daniel Marchesi
de Camargo Neves; orientador Ben-Hur Viana Borges. São
Carlos, 2015.
Dissertação (Mestrado) - Programa de Pós-Graduação
em Engenharia Elétrica e Área de Concentração em
Telecomunicações -- Escola de Engenharia de São
Carlos da Universidade de São Paulo, 2015.
1. Eletro-absorção. 2. Grafeno. 3. Moduladores. 4.
Ressoadores. 5. Silicon-on-Insulator (Sol). 6.
Whispering Gallery Modes (WGM). I. Título.




\section{FOLHA DE JULGAMENTO}

Candidato: Bacharel DANIEL MARCHESI DE CAMARGO NEVES.

Título da dissertação: "Ressoadores WGM baseados em grafeno como plataforma para moduladores de eletro-absorção".

Data da defesa: 15/05/2015

Comissão Julgadora:

Prof. Associado Ben-Hur Viana Borges

(Orientador)

(Escola de Engenharia de São Carlos/EESC)

Prof. Dr. Danilo Henrique Spadoti

(Universidade Federal de Itajubá/UNIFEI)

Prof. Dr. Carlos Alberto de Francisco

(Universidade Federal de São Carlos/UFSCar)
Resultado:
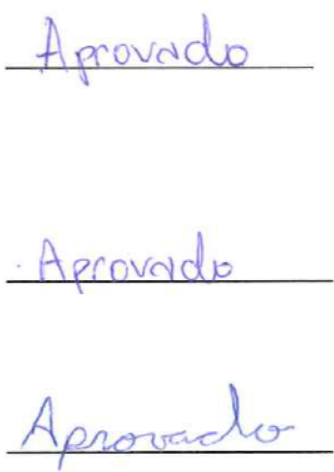

Coordenador do Programa de Pós-Graduação em Engenharia Elétrica: Prof. Associado Luis Fernando Costa Alberto

Presidente da Comissão de Pós-Graduação:

Prof. Associado Paulo César Lima Segantine 



\section{AGRADECIMENTOS}

Aos meus irmãos, André, Raul e Carolina, e em especial aos meus pais, Sonia e Augusto, por todo o apoio e confiança que sempre depositaram em mim, mesmo nos momentos mais difíceis.

À minha namorada, Georgeana, pelo apoio, carinho e ajuda, especialmente nos momentos finais, que me permitiram ânimo para concluir o trabalho.

A os meus amigos de São Carlos, com os quais pude vivenciar momentos que deixarão ótimas lembranças por toda a vida,

Aos meus amigos de Fortaleza e os espalhados pelo mundo, por todas as conversas e o apoio que me deram,

Ao professor Ben-Hur Viana Borges, pela orientação,

À Coordenação de Aperfeiçoamento de Pessoal de Nível Superior (CAPES), pelo suporte financeiro. 



\section{RESUMO}

NEVES, D. M. C. Ressoadores WGM Baseados em Grafeno como Plataforma para Moduladores de Eletro-absorção. 2015. Dissertação (Mestrado) - Escola de Engenharia de São Carlos, Universidade de São Paulo, São Carlos, 2015.

O objetivo deste trabalho é investigar a aplicação ressoadores WGM (Whispering-Gallery Mode) em plataforma SOI (silicon-on-insulator) baseados em grafeno como candidatas potenciais para aplicações como moduladores de eletro-absorção. O grafeno apresenta variação de condutividade considerável quando submetido a uma aplicação de tensão, o que reflete na parte imaginária de seu índice de refração (relacionada às perdas de propagação). Com isso, é possível atribuir estados ligado e desligado (on-off) que conferem ao dispositivo sua característica de modulação óptica. A geometria utilizada é do tipo anel, o que permite uma elevada seletividade em frequência possibilitando, assim, uma grande profundidade de modulação. As simulações foram realizadas no software de elementos finitos COMSOL Multiphysics, o qual é bastante apropriado para a definição das diferentes figuras de mérito a serem utilizadas para a caracterização do desempenho do modulador.

Palavras-chave: WGM, ressoador, baseado em grafeno, modulador, SOI comunicações ópticas, profundidade de modulação, eletro-absorção. 


\begin{abstract}
NEVES, D. M. C. Graphene-based WGM Resonator as a Plataform for Electroabsorption

Modulators. 2015. Dissertation (Master of Science) - Escola de Engenharia de São Carlos, Universidade de São Paulo, São Carlos, 2015.

The goal of this work is to investigate SOI (silicon on insulator) WGM (Whispering-Gallery Modes) resonators based on graphene as potential candidates for electro-absorption modulator applications. Graphene conductivity varies substantially when submitted to an applied voltage, which reflects directly in the imaginary part of its refractive index (responsible for the propagation losses). Therefore, it is possible to assign on-off states that render the device its optical modulation characteristics. The geometry adopted for the design is the ring type, which allows high frequency selectivity and modulation depth. The simulations were carried out in the finite elements software COMSOL Multiphysics, which is quite appropriate for the definition of the different figure of merits to be used in the modulator characterization.
\end{abstract}

Keywords: WGM, Ressonator, Graphene-Based, SOI, Modulator, optical communications, WDM, modulation depth, electro-absorption. 


\section{LISTA DE ILUSTRAÇÕES}

Figura 1 - (a) Vista superior e transversal (b) do modulador proposto por Midrio et al. [20]; (c) parâmetros geométricos e figuras de mérito do modulador.

Figura 2 - Condutividade elétrica e constante dielétrica em função do potencial químico $\mu$ para comprimentos de onda de $1.53 \mu \mathrm{m}(\mathrm{a}, \mathrm{b}), 1.55 \mu \mathrm{m}(\mathrm{c}, \mathrm{d})$ e $1.57 \mu \mathrm{m}(\mathrm{e}, \mathrm{f})$.

Figura 3 - Representação superior (a) e transversal (b) de um modulador de silício que utiliza o efeito de modulação por dispersão em plasma de portadores de cargas livres.

Figura 4 - Densidade de portadores em função do potencial químico.

Figura 5 - Variação da energia (fJ) em função da espessura (a) e área (b) camada dielétrica e variação da tensão de chaveamento em função da espessura da camada dielétrica (c) para valores de potenciais químicos variáveis entre 0,3 à $0,5 \mathrm{eV}$.

Figura 6 - Representação esquemática do acoplamento entre um guia de onda e um ressoador.......22

Figura 7 - Variação da transmissão T em função de $\alpha$.

Figura 8 - (a) Guia de onda de silício com duas camadas de grafeno, de espessura hg $=0,34 \mathrm{~nm}$ e uma camada de alumina de espessura ha $=7 \mathrm{~nm}$; (b) Aproximação de homogeneização da estrutura proposta na figura (a).

Figura 9 - (a) Curvas de dispersão dos índices de refração real para um guia sem grafeno (vermelha) e com grafeno em potenciais químicos ajustados a 0,3 (verde) e 0,5 (azul) eV para uma largura de $\mathrm{W}=600 \mathrm{~nm}$; (b) Curva de dispersão da parte imaginária do índice de refração para um potencial químico de $0,5 \mathrm{eV}$; (d) Curva de variação do índice de refração imaginário em função do potencial químico para um guia de largura $\mathrm{W}=600 \mathrm{~nm}$ e $\lambda_{\text {ress }}=1544,6 \mathrm{~nm}$.

Figura 10 - Distribuição do módulo do campo elétrico normalizado para um guia de onda (azul) e ressoador (verde) para $\mathrm{W}=600 \mathrm{~nm}$ e $\lambda_{\text {ress }}=1544,6 \mathrm{~nm}$.

Figura 11 - Vista superior (a) e secção transversal (b) do modulador.

Figura 12 - (a) Curva de dispersão do modo radial de primeira (verde) e segunda (azul) ordem em função da largura $\mathrm{W}$ do ressoador; Norma do campo elétrico (V/m) para (b) $\mathrm{W}=1 \mu \mathrm{m}, \lambda=1,5617$ $\mu \mathrm{m}$, (c) $\mathrm{W}=1 \mu \mathrm{m}, \lambda=1,548 \mu \mathrm{m}, \quad$ (d) $\mathrm{W}=0,6 \mu \mathrm{m}, \lambda=1,5446 \mu \mathrm{m}$ e (e) $\mathrm{W}=0,6 \mu \mathrm{m}$, $\lambda=1,407 \mu \mathrm{m}$.

Figura 13 - Largura de banda em função da largura W do ressoador.

Figura 14 - Secção angular de grafeno em função da largura w1 do barramento, parametrizado para as distâncias de separação entre barramento e ressoador $\mathrm{g}=80,100$ e $120 \mathrm{~nm}$.

Figura 15 - Mínimo de ressonância do modulador ligado em função da largura w1 do barramento, parametrizado para as distâncias de separação entre barramento e ressoador $\mathrm{g}=80,100$ e $120 \mathrm{~nm}$. 37 
Figura 16 - (a) Curvas de Transmissão para o modulador em seu estado ligado $(\mu=0,5 \mathrm{eV}) \mathrm{e}$ desligado $(\mu=0,3 \mathrm{eV})$ em função do comprimento de onda; (b) Figuras de mérito do modulador.. 39 Figura 17 - Largura de banda do modulador para o desligado $(\mu=0,3 \mathrm{eV})$ em função de W.

Figura 18 - Mínimo de transmissão S21 para o modulador ligado $(\mu=0,5 \mathrm{eV})$ em função de W... 43

Figura 19 - Secção angular contendo grafeno em função de W. ................................................. 44

Figura 20 - Consumo de potência por bit em função da largura $\mathrm{W}$ do ressoador.............................. 44

Figura 21 - FSR em função da largura W do ressoador...............................................................45

Figura 22 - Vista frontal (a) e lateral (b) do modulador..............................................................46

Figura 23 - Largura de banda do modulador ligado em função da secção angular de grafeno no ressoador, parametrizado para barramentos de larguras w1 $=340,370$ e 400nm.

Figura 24 - Mínimo de ressonância do modulador ligado em função da secção angular de grafeno no ressoador, parametrizado para barramentos de larguras $\mathrm{w} 1=340,370$ e $400 \mathrm{~nm}$.

Figura 25 - Distância de separação entre o barramento e ressoador em função secção angular de grafeno no ressoador, parametrizado para barramentos para larguras de $\mathrm{w} 1=340,370$ e $400 \mathrm{~nm}$... 49 Figura 26 - (a) Perfil de transmissão S21 do modulador ligado $(\mu=0,3 \mathrm{eV})$ e desligado $(\mu=0,5$ eV); (b) Figuras de mérito do modulador em termos de footprint, largura de banda, tensão de chaveamento e consumo de potência por bit.

Figura 27 - Mínimo de transmissão do modulador ligado em função da largura W.

Figura 28 - Largura de banda do modulador para o acoplamento crítico em função da largura W. .54 Figura 29 - Separação g entre o ressoador e o barramento para o acoplamento crítico em função da largura W 55

Figura 30 - Consumo de potência em função da largura W. 55 


\section{LISTA DE TABELAS}

Tabela 1 - Parâmetros dos ressoadores simulados em função da largura. ...................................... 41

Tabela 2 - Parâmetros dos ressoadores simulados em função da largura. .......................................52

Tabela 3 - Comparação entre os moduladores das configurações 1,2 e da obtida por Midrio et al. .56 


\section{LISTA DE ACRÔNIMOS}

2D

Two Dimensional (Bi-dimensional)

3D Three Dimensional (Tri-dimensional)

FEM Finite Element Method (Método dos elementos finitos)

FSR Free Spectral Range (Região espectral livre, dada em nm)

LED Light Emitting Diode (Diodo emissor de luz)

Q Quality Factor (Fator de qualidade)

RR Ring Resonator (Ressoador em anel)

SOI Silicon-on-Insulator

TE Transverse Electric

WGM Whispering Gallery Modes 


\section{LISTA DE SÍMBOLOS}

\begin{tabular}{|c|c|}
\hline$n$ & Índice de refração \\
\hline$\varepsilon 0$ & Permissividade elétrica $(\mathrm{F} / \mathrm{m})$ \\
\hline$\varepsilon_{r}$ & Permissividade elétrica relativa $(\mathrm{F} / \mathrm{m})$ \\
\hline$C$ & Capacitância (F) \\
\hline$V_{\mu c}$ & Tensão elétrica para se obter um potencial químico(V) \\
\hline$E_{\mu c}$ & Energia para se obter um potencial químico (fJ) \\
\hline$Q_{\mu c}$ & Quantidade de cargas associado a um potencial químico (C) \\
\hline$\mu$ & Permeabilidade magnética $(\mathrm{H} / \mathrm{m})$ \\
\hline$\theta$ & Ângulo de rotação da polarização de azimute $\left(^{\circ}\right)$ \\
\hline$\lambda$ & Comprimento de onda (nm) \\
\hline$\lambda_{\text {ress }}$ & Comprimento de onda de ressonância (nm) \\
\hline$\Delta \lambda_{-3 \mathrm{~dB}}$ & Largura de banda de $-3 \mathrm{~dB}(\mathrm{~nm})$ \\
\hline$\sigma$ & Condutividade óptica $(\mu \mathrm{S})$ \\
\hline$\omega$ & Frequência angular (rad/s) \\
\hline$\rho$ & Densidade de carga $\left(\mathrm{C} / \mathrm{m}^{3}\right)$ \\
\hline$n_{s}$ & Densidade de portadores $\left(1 / \mathrm{cm}^{2}\right)$ \\
\hline$\Gamma$ & Fração de espalhamento dos elétrons livres (eV) \\
\hline$N_{g}$ & Índice de refração de grupo \\
\hline$n_{g}$ & Índice efetivo do guia \\
\hline$\alpha$ & Coeficiente de perdas do anel \\
\hline$k$ & Coeficiente de acoplamento do barramento ao ressoador \\
\hline$t$ & Coeficiente de transmissão do barramento \\
\hline$\mu_{c}$ & Potencial Químico (eV) \\
\hline hg & Espessura da camada de grafeno $(\mathrm{nm})$ \\
\hline $\mathrm{h} A l$ & Espessura da camada de alumina (nm) \\
\hline $\mathrm{h} S i$ & Espessura da camada de silício (nm) \\
\hline $\mathrm{w} 1$ & Largura do barramento (nm) \\
\hline $\mathrm{W}$ & Largura do ressoador (nm) \\
\hline $\mathrm{g}$ & distância de separação gap (nm) \\
\hline Rext & Raio externo $(\mu \mathrm{m})$ \\
\hline Rint & Raio interno $(\mu \mathrm{m})$ \\
\hline
\end{tabular}


$\mathrm{E}$

$\mathrm{H}$

D

B

$\mathrm{J}$

$\mathrm{S}$

$k_{0}$

$\alpha$

$N_{h}$

$N_{e}$
Vetor intensidade de campo elétrico $(\mathrm{V} / \mathrm{m})$

Vetor intensidade de campo magnético $(\mathrm{A} / \mathrm{m})$

Vetor densidade de fluxo elétrico $\left(\mathrm{C} / \mathrm{m}^{2}\right)$

Vetor densidade de fluxo magnético $\left(\mathrm{Wb} / \mathrm{m}^{2}\right)$

Vetor densidade de corrente $\left(\mathrm{A} / \mathrm{m}^{2}\right)$

Vetor de Poynting

Número de onda

Absorção do material

Concentração de buracos

Concentração de elétrons 


\section{LISTA DE PUBLICAÇÕES}

Daniel M. C. Neves, Daniel B. Mazulquim, Luiz G. Neto, and Ben-Hur V. Borges, "Graphenebased SOI Microdonut Resonator as a Platform for Electro-Absorption Modulators.” in LAOP, Latin America Optics and Photonics Conference (17 a 23 de Novembro de 2014, Cancún, México). 



\section{SUMÁRIO}

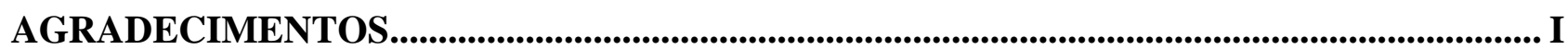

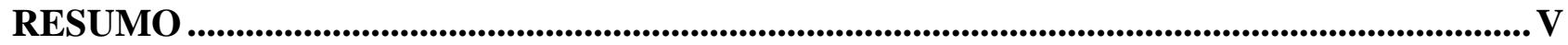

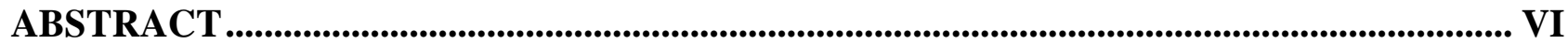

LISTA DE ILUSTRAÇÕES .......................................................................................................VII

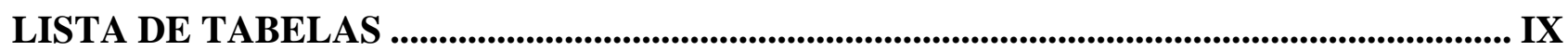

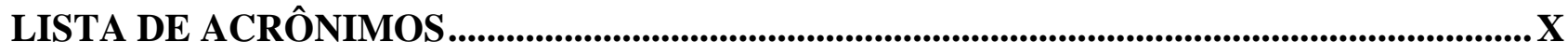

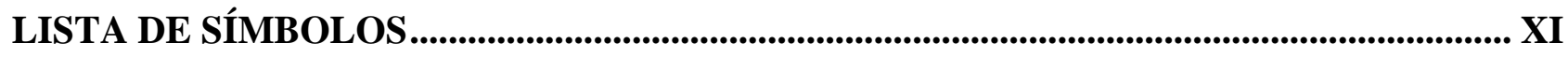

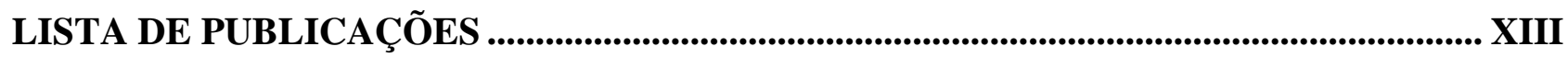

1 INTRODUÇÃ

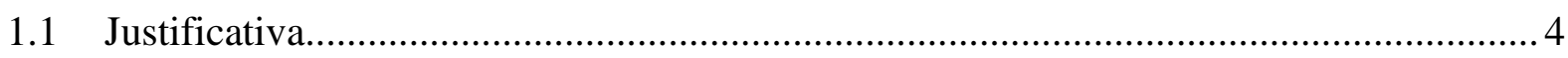

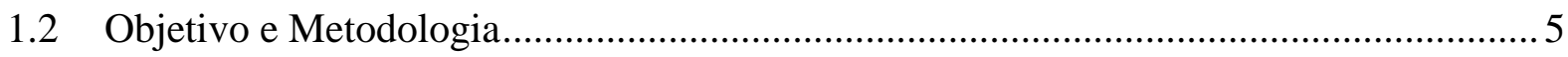

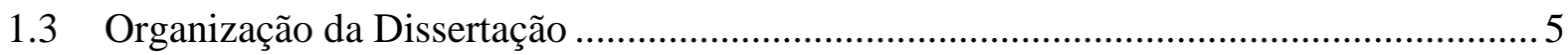

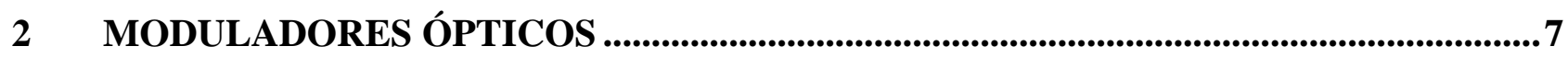

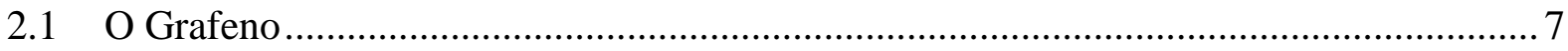

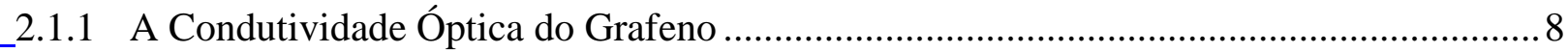

2.2Princípio de Funcionamento dos Moduladores de Eletro-Absorção Baseados em Grafeno 12

3 MICROCAVIDADES RESSOADORAS WGM .................................................................. 18

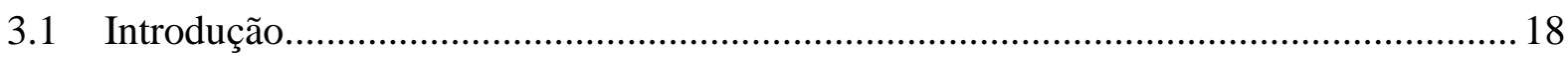

3.2 Parâmetros Caracterizadores dos Ressoadores ............................................................ 19

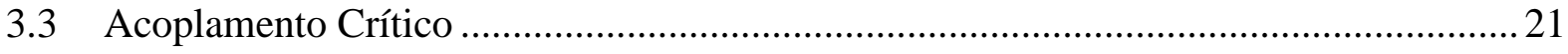

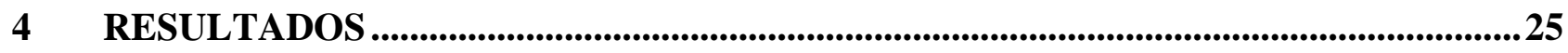

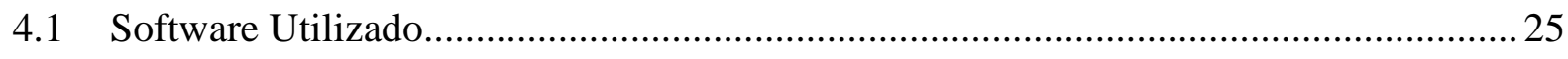

4.2 Estruturas de Moduladores Investigadas .............................................................. 25

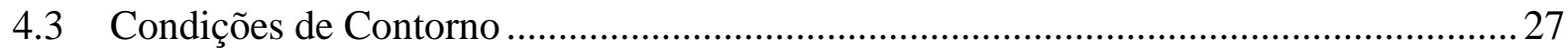

4.4 Obtenção da Condição de Acoplamento Crítico ......................................................... 27

4.5 Secção Transversal e Aproximação de Homogenização............................................... 28

4.6 Acoplamento Crítico Ajustado para um Potencial Químico de 0,3 eV ........................ 32 
4.7 Otimização Geométrica do Ressoador ..................................................................... 33

4.8 Acoplamento Crítico Ajustado para um Potencial Químico de 0,5 eV ....................... 45

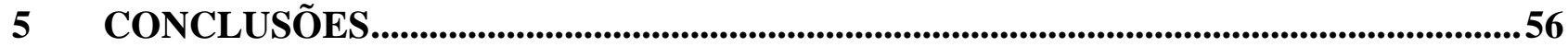

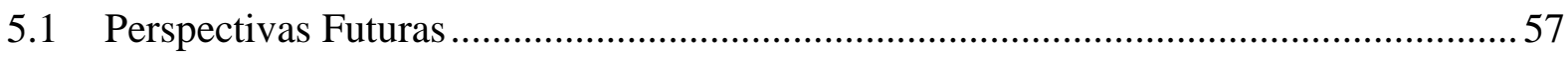

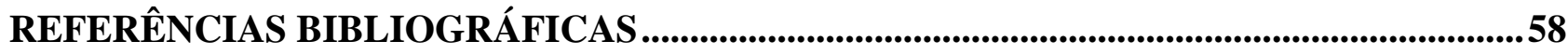


Os moduladores ópticos são dispositivos de sistemas opto-eletrônicos capazes de alterar as características de uma onda eletromagnética que se propaga por eles. Dessa forma, é possível modular um sinal óptico por meio desse dispositivo. Inicialmente, a técnica de modulação mais utilizada era a de modulação direta do sinal emitido pela fonte óptica. Nesta modulação, a amplitude do sinal era controlada com a aplicação de uma corrente elétrica na fonte geradora (um laser ou um LED - Light Emitting Diode). Entretanto, apesar do baixo custo, observou-se que esta técnica de modulação não era eficiente quando trabalhada com fontes de luz de maior largura de banda, como o LED. Isso acontece porque o efeito de dispersão do sinal passa a ser significativo, limitando, por consequência, a taxa de transmissão máxima desse sistema de comunicação [1].

Para contornar este problema, técnicas de modulação externa foram desenvolvidas, utilizando-se fontes de luz contínuas [1], [2]. Com esta técnica, a luz é modulada ao passar por um dispositivo de guiamento de onda, externo à fonte óptica. Assim, a aplicação de um campo elétrico altera os parâmetros de fase, polarização e amplitude do sinal óptico por efeito da variação da parte imaginária (eletro-absorção) ou da parte real (eletro-refração) do índice de refração do material em que a onda se propaga. Os primeiros moduladores externos foram fabricados baseados em materiais ferro-elétricos como o niobato de lítio [3]. Entretanto, a necessidade de integração óptoeletrônica no mesmo dispositivo motivou a busca por moduladores baseados em materiais semicondutores. O silício ganhou grande atenção nesse sentido porque, além de ser o material mais comumente utilizado na indústria de componentes microeletrônicos [4], é também um material com elevado índice de refração na faixa de frequências ópticas, o que aumenta a eficiência do confinamento da luz em seu interior, uma vez que é possível obter um maior contraste entre o índice de refração do guia em relação ao substrato.

Apesar desta vantagem, o efeito eletro-óptico no silício puro não apresentou eficiência significativa na região espectral utilizada pelos sistemas de telecomunicações [5] e por este motivo, a busca por técnicas de modulação mais eficientes que utilizassem o silício como núcleo do guia de onda, tornou-se necessária. Dentre as muitas alternativas apresentadas, a mais eficiente explorava o efeito da dispersão devido ao plasma de portadores livres, que está associada à variação da concentração de cargas livres no silício por meio de sua dopagem, o que provoca variações mais significativas tanto em sua permissividade real quanto imaginária [6].

No contexto da busca por técnicas de modulação cada vez mais velozes, energeticamente eficientes e geometria de menor footprint, a utilização de ressoadores WGM (Whispering Galery Modes) representou um enorme avanço. Estes dispositivos, quando conectados a outras estruturas 
guiadoras por meio de acoplamento evanescente, produzem um perfil de transmissão característico na região espectral da ressonância.

Quando o silício é o material utilizado para o núcleo do guia, é possível obter dispositivos com diâmetros na ordem de alguns micrometros $(\mu \mathrm{m})$ com uma grande sensibilidade a pequenas perturbações nas propriedades de absorção e refração do dispositivo. Como resultado, obtêm-se moduladores de intensidade que, mesmo para uma aplicação de tensões elétricas relativamente baixas, resultam em um deslocamento bastante significativo do comprimento de onda de ressonância da cavidade [7], [8]. Com isso, são obtidas estruturas eficientes em termos de profundidade de modulação e consumo de potência na ordem de centenas de fJ/bit [9]. Trabalhos recentes de moduladores WGM obtiveram, para tensões de chaveamento entre 1 a $2 \mathrm{~V}$, ressoadores cujo consumo de potência foi inferior a $100 \mathrm{fJ} / \mathrm{bit}$ [10], [11].

Entretanto, muito embora sejam dispositivos excessivamente compactos em relação aos moduladores convencionais, há algumas limitações intrínsecas que impedem sua operação a altas taxas de modulação. A primeira delas está associada à dopagem do silício, que a despeito das evoluções recentes, ainda é um processo lento, que limita a velocidade em algumas dezenas de $\mathrm{Gb} / \mathrm{s}$ [5], [6]. A segunda limitação está na principal característica de uma cavidade ressoadora. A grande eficiência de cavidades ressoadoras em termos de variação do perfil de transmissão é devido à estreita largura de banda de ressonância e o efeito de melhoramento de campo que, por sua vez, é um fator limitador da velocidade máxima de modulação, pois são inversamente proporcionais ao tempo de vida do fóton no interior da cavidade [12], [13]. Portanto, para uma fabricação otimizada destes dispositivos, é necessário levar em consideração estes fatores, especialmente quando se deseja obter um modulador que não seja apenas eficiente na variação da intensidade do sinal, mas que também opere a altas taxas.

Neste contexto, o grafeno surgiu como possível candidato capaz de contornar esses dois entraves tecnológicos dos processos de modulação usando a dopagem de silício. Este material, composto de átomos de carbono em estrutura cristalina hexagonal com a espessura de um átomo, tem dentre muitas propriedades físicas incomuns, uma excepcional capacidade de transporte eletrônico, sendo o material com uma das mais elevadas mobilidades de carga e densidade de corrente em temperatura ambiente [14]. Adicionalmente, é um material que próximo ao nível de Fermi possui uma curva de dispersão eletrônica linear, o que permite uma fácil manipulação de sua condutividade com a alteração de seu potencial químico, que entre outras formas, pode ser alterado por aplicação de tensão elétrica e varia quase instantaneamente [15]. 
Estas características possibilitarão a superação da lenta resposta para o processo de variação de portadores no permitindo. Portanto, a utilização do grafeno como material eletro-óptico possibilitou um controle mais rápido e em maior magnitude de sua condutividade óptica viabilizando, desta forma, não apenas uma operação em taxas de operação maiores, como também dispositivos que com essas características, possuem um maior potencial de miniaturização e consumo de potência bastante reduzido para uma menor tensão de variação entre os estados ligado/desligado, qualidades estas indispensáveis às novas gerações de tecnologia de modulação óptica [16].

O segundo aspecto, relacionado às limitações do ressoador propriamente dito, deve-se novamente a eficiência na variação das características de perdas do grafeno na região de potencial químico próximo ao nível de Fermi. Uma vez que para certo intervalo de variação deste parâmetro são obtidas respostas bastante significativas na mudança de sua condutividade óptica, é factível a obtenção de resultados satisfatórios em profundidade modulação mesmo para ressoadores de maior largura de banda [20], [21].

A primeira proposta de moduladores baseados em grafeno, feita por Midrio et al. [20], uma parte do ressoador de silício de geometria anelar tem sua região superior coberta por 2 camadas de grafeno (entre elas, há uma camada fina camada de um material dielétrico alumina, formando uma estrutura capacitiva). Esta estrutura está acoplada a um guia de onda de silício que, com a alteração da sua condutividade via aplicação de um potencial elétrico, dessintoniza o ressoador da sua condição de acoplamento crítico, resultando em uma resposta mais eficiente em termos de mínimo de transmissão e, por consequência, a intensidade de transmissão da onda que é detectada pela porta de saída do guia é alterada de maneira bastante significativa.

Como resultado, obteve-se um modulador cuja intensidade na região de ressonância foi alterada de $-40 \mathrm{~dB}$ com o grafeno equivalente a um potencial químico de $0,3 \mathrm{eV}$, representando seu estado desligado, para uma transmissão de $-0,48 \mathrm{~dB}$ equivalendo a um potencial químico de $0,5 \mathrm{eV}$ e representado seu estado desligado. Mesmo com está significativa resposta em profundidade de modulação, foi necessária uma tensão de chaveamento que variou de $0,9 \mathrm{~V}$ no seu estado desligado para 2,6 V em seu estado ligado, com um consumo de potência de $60 \mathrm{fJ} / \mathrm{bit}$, sendo este um resultado bastante expressivo [9], [10]. Esta configuração, ilustrada na Figura 1, foi considerada um ressoador de raio médio de $5 \mu \mathrm{m}$, uma região angular do ressoador contendo grafeno equivalente a $116^{\circ}$ (condição de acoplamento crítico) e guias de onda (barramento e ressoador) de $400 \mathrm{~nm}$ de largura e $220 \mathrm{~nm}$ de espessura. Para a camada de alumina e o a do grafeno possuem, respectivamente, 7 e $0,34 \mathrm{~nm}$ de espessura e a mesma largura do barramento e o ressoador, permitindo um dispositivo de largura de banda superior a $100 \mathrm{GHz}$, o que já elimina possíveis 
limitações à taxa de modulação, considerando o corrente estágio de evolução de outras tecnologias de modulação e, adicionalmente, reduzindo os indesejados custos energéticos no controle da estabilidade da temperatura desses dispositivos ressoadores, que também dependem inversamente da sua largura de banda [15].

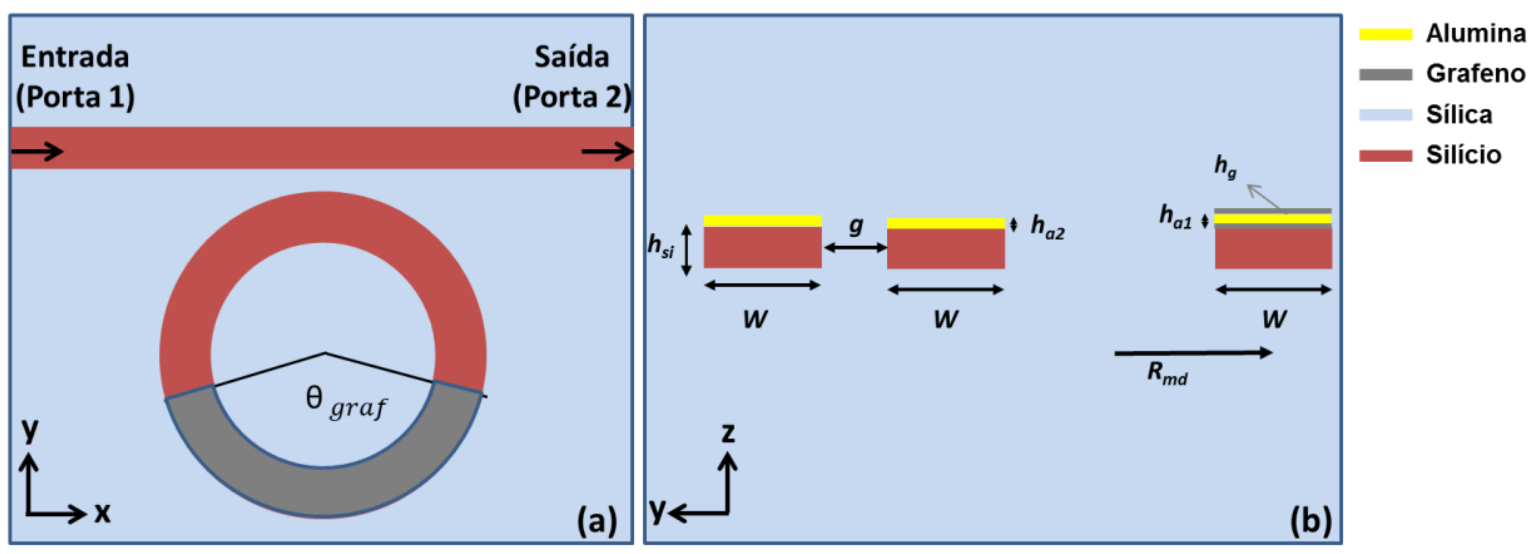

(c)

\begin{tabular}{ll}
\hline Parâmetros do Ressoador & Valores \\
\hline $\mathbf{W}(\mathrm{nm})$ & 400 \\
$\mathbf{g}(\mathrm{nm})$ & 100 \\
$\boldsymbol{h}_{s i}(\mathrm{~nm})$ & 220 \\
$\boldsymbol{h}_{\boldsymbol{g}}(\mathrm{nm})$ & 0,34 \\
$\boldsymbol{h}_{a 1}(\mathrm{~nm})$ & 7 \\
$\boldsymbol{h}_{a 2}(\mathrm{~nm})$ & 7,34 \\
$\boldsymbol{\theta}_{\text {graf }}$ (graus) & 116 \\
\hline
\end{tabular}

Figura 1 - (a) Vista superior e transversal (b) do modulador proposto por Midrio et al. [20]; (c) parâmetros geométricos e figuras de mérito do modulador.

\section{$1.1 \quad$ Justificativa}

A evolução da tecnologia de modulação óptica está associada ao projeto de dispositivos que permitam uma resposta de modulação a taxas cada vez maiores, a uma resposta de modulação eficiente e, adicionalmente, permita a máxima miniaturização e redução do seu consumo de potência. Nesta direção, a utilização de cavidades WGM e dispositivos que exploram o efeito da variação de condutividade do grafeno permitem atingir este objetivo [7], [11]. Em relação às cavidades, como mostrado em outros trabalhos, o efeito de confinamento de energia para uma dada ressonância permite gerar efeitos de modulação bastante significativos com pequenas perturbações nas propriedades refrativas ou de absorção da cavidade, que ocupa, comparado à outras geometrias 
de moduladores, uma área bem menor [12]. Em relação ao grafeno, a vantagem está em sua resposta rápida e bastante significativa de suas propriedades de condutividade óptica para a aplicação de um pequeno potencial químico próximo ao nível de Fermi [15-[20].

\subsection{Objetivo e Metodologia}

Por fim, o presente trabalho tem como objetivo geral a investigação teórica do domínio da frequência de estruturas ressoadoras baseadas em grafeno, utilizando o mesmo princípio de funcionamento proposto pelo trabalho anteriormente citado, realizando ajustes geométricos que aumentem seu potencial de miniaturização, permitindo dispositivos de menor footprint, consumo de potência e maior FSR (Free Sprectral Range), sem que esta redução geométrica implique em uma degradação de sua resposta em termos de profundidade de modulação, que tende a ocorrer quando as perdas por curvatura do ressoador passam a se aproximar da ordem de grandeza das provocadas pelo grafeno [20]. Para todas as simulações serão utilizados ressoadores de raios médios entre 2,3 e $2,4 \mu \mathrm{m}$ em que, na primeira estrutura, a condição de acoplamento crítico é obtida com a variação das perdas (grafeno) do ressoador até obter-se a configuração de transmissão mínima com o ajuste feito para o potencial químico próximo a $0,3 \mathrm{eV}$ e, no segundo modelo de modulador, para uma configuração de perdas fixas ajustadas a um potencial químico de $0,5 \mathrm{eV}$, variou-se a distância de separação até obter a mesma condição. A metodologia de análise empregada neste trabalho envolve o modelamento e simulação de estruturas a serem investigadas a viabilidade como moduladores ópticos de eletroabsorção. Todas simulações foram realizadas em estruturas em 3D, analisadas no domínio de frequência, utilizando o software de elementos finitos COMSOL Multiphysics.

\subsection{Organização da Dissertação}

Esta dissertação está organizada em cinco capítulos. No primeiro capítulo, tem-se a introdução do trabalho, a justificativa, os objetivos e a metodologia empregada para se alcançar os objetivos propostos.

No segundo capítulo serão abordados temas relevantes para o entendimento deste trabalho, especialmente relacionados à condutividade do grafeno e como ocorre sua manipulação a fim de se obter um modulador óptico.

No terceiro capítulo serão detalhados os conceitos fundamentais relativos aos ressoadores, explicando alguns dos parâmetros e figuras de mérito que os caracterizam e a teoria do acoplamento crítico. 
No capítulo 4 encontra-se a análise numérica, explicando a elaboração da estrutura otimizada e condições de contorno. Ao final deste capítulo são apresentados os resultados obtidos neste trabalho.

Por fim, no capítulo 5, constam as conclusões e as perspectivas para futuros trabalhos. 
Neste capítulo, será feita uma revisão bibliográfica do tema principal deste trabalho, que são os moduladores ópticos integrados. Serão abordados tópicos teóricos para o entendimento do conceito de modulação, em particular os moduladores de eletroabsorção baseados em grafeno. Assim, serão analisados os efeitos da variação da condutividade do grafeno com a aplicação de um potencial elétrico, que modifica suas características de absorção óptica. Em seguida, será abordada a teoria do acoplamento critico em estruturas ressoadoras, uma vez que foi optado por explorar as perdas destas estruturas de modo a controlar a transmissão/modulação da luz.

\subsection{O Grafeno}

O carbono é um dos elementos químicos mais abundantes em nosso planeta, sendo a matéria prima básica de muitas estruturas orgânicas e inorgânicas [22], [14]. Além de fazer parte da composição de inúmeros tipos de macromoléculas, existem também materiais e estruturas compostas exclusivamente de átomos de carbono, estes são chamados alótropos de carbono. Os mais conhecidos deles são o grafite e o diamante, materiais amplamente utilizados na indústria [22], [23].

Nas últimas três décadas, três novos alótropos de carbono foram descobertos. No ano de 1985, uma estrutura composta por sessenta átomos de carbono de arranjo hexagonal que geometricamente se assemelha a uma bola de futebol foi batizado de fulereno [23]. Posteriormente, no ano de 1991, foram descobertas pelo físico japonês Sumio Iijima estruturas de dimensão radial nanométrica e geometria cilíndrica, denominadas de nanotubos de carbono [24]. Por último, em 2004, os físicos da universidade de Manchester conseguiram sintetizar uma estrutura estável de uma única camada de grafite, sendo batizado como grafeno. Considerado a "matéria prima" dos outros alótropos anteriormente descobertos, este novo material passou a ser objeto de estudo massivo da comunidade científica.

Nos trabalhos experimentais e teóricos feitos com este material, descobriu-se inúmeras propriedades físicas incomuns. Dentre as mais relevantes, pode-se enumerá-las da seguinte forma:

\section{a) Propriedades mecânicas}

Possui coeficientes de elasticidade, dureza, resistência a tensão incomparáveis, sendo o grafeno considerado o material mais forte já observado na natureza [25], [26]. 


\section{b) Propriedade térmica}

Elevada condutividade térmica, da ordem de $(4.84 \pm 0.44) \times 103$ a $(5.30 \pm 0.48) \times$ $103 \mathrm{~W} \cdot \mathrm{m}-1 \cdot \mathrm{K}-1[27]$.

\section{c) Propriedade eletrônica}

$\mathrm{Na}$ estrutura de banda do grafeno, a curva da banda de valência toca-se com a curva da banda de condução, o que torna o material um semicondutor de gap nulo. Para baixas energias, a relação de dispersão da energia em função do vetor do espaço recíproco k é linear, logo, para a região próxima ao nível de Fermi, seus elétrons e buracos se comportam como férmions de massa efetiva nula, propagando-se pela estrutura com uma velocidade de grupo de $10^{6} \mathrm{~m} / \mathrm{s}$ [28], [29].

\section{d) Propriedades de transporte eletrônico}

Possui uma das mais altas densidades de corrente e mobilidade de carga em temperatura ambiente já observadas em um material, atingindo velocidades superiores a $200000 \mathrm{~cm}^{2} V^{-1} \mathrm{~s}^{-1}[15]$.

\section{e) Propriedades ópticas}

O grafeno exibe um forte acoplamento com ondas eletromagnéticas no domínio óptico, que representa uma variação da condutividade com a aplicação de uma tensão e apresentando uma detecção fotônica ultrarrápida [30].

Todas essas propriedades, somadas ao baixo custo de fabricação de estruturas de grafeno [14], fazem deste material um forte concorrente para substituir a matéria prima empregada nos dispositivos tecnológicos modernos de forma muito mais eficiente e barata. Algumas aplicações de estruturas baseadas em grafeno já foram propostas para aplicação em tecnologia de foto detecção, moduladores de alta velocidade, circuitos integrados, componentes de células fotovoltaicas entre muitas outras [28], [32].

\subsubsection{A Condutividade Óptica do Grafeno}

A condutividade óptica do grafeno é obtida com a resolução da integral da Fórmula de Kubo [35], que é dada por: 


$$
\begin{aligned}
& \sigma(\mu, \omega, T, \Gamma)_{\text {total }}=j e^{2} \frac{(\omega-j 2 \Gamma)}{\pi \hbar^{2}}\left[\frac{1}{(\omega-2 j \Gamma)^{2}} \int_{0}^{\infty} \varepsilon\left(\frac{\partial f_{d}(\varepsilon, \mu)}{\partial \varepsilon}-\frac{\partial f_{d}(-\varepsilon, \mu)}{\partial \varepsilon}\right) d \varepsilon-\right. \\
& \left.\int_{0}^{\infty} \frac{f_{d}(-\varepsilon, \mu)-f_{d}(\varepsilon, \mu)}{(\omega-2 j \Gamma)^{2}-4(\varepsilon / \hbar)^{2}} d \varepsilon\right]
\end{aligned}
$$

onde $f_{d}(\varepsilon)$ representa a distribuição de densidade eletrônica de Fermi-Dirac, $\mu$ é o potencial químico, $\omega$ é a frequência angular, T é a temperatura absoluta em Kelvin (K) e $\Gamma$ a fração de espalhamento das partículas carregadas. A resolução desta integral permite-nos obter as expressões da condutividade intrabanda e interbanda. Assim,

$$
\sigma(\mu, \omega, T, \Gamma)_{\text {intra }}=-j \frac{T e^{2 k_{B} T}}{\pi \hbar^{2}(\omega-j 2 \Gamma)}\left(\frac{\mu_{c}}{k_{B} T}+2 \ln \left(e^{-\frac{\mu_{c}}{k_{B} T}}+1\right)\right)
$$

refere-se à condutividade intrabanda. E, considerando a temperatura como sendo $\mathrm{T}=300 \mathrm{~K}$, é válida a aproximação $k_{B} T \ll\left|\mu_{c}\right|, \hbar \omega$. Portanto, temos a condutividade independente de $\mathrm{T}$, denominada interbanda, dada por [36], [37]

$$
\sigma(\mu, \omega, 0, \Gamma)_{\text {inter }} \cong \frac{-j e^{2}}{4 \pi \hbar} \ln \left(\frac{2\left|\mu_{c}\right|-(\omega-j 2 \Gamma) \hbar}{2\left|\mu_{c}\right|+(\omega-j 2 \Gamma) \hbar}\right)
$$

A condutividade total (2.1) é, portanto, a soma das condutividades em (2.2) e (2.3). Da mesma forma, a condutividade do grafeno também pode ser definida como a soma de sua parte real e complexa, ou seja:

$$
\sigma_{\text {total }}=\sigma_{\text {real }}+\sigma_{\text {im }}
$$

Em que a parte real, com as aproximações feitas acima, possui apenas contribuições dos termos interbanda e a imaginária, de termos inter e intrabanda. Pela definição da permissividade complexa de materiais, temos que:

$$
\varepsilon_{\text {complexa }}=\varepsilon_{\mathrm{r}}-\mathrm{i} \frac{\sigma}{\Delta \omega}
$$


Substituindo (2.4) em (2.5), temos que:

$$
\varepsilon_{\text {complexa }}=\varepsilon_{\mathrm{r}}+\frac{\sigma_{i m}}{\Delta \omega}-\mathrm{i} \frac{\sigma_{\text {real }}}{\Delta \omega}
$$

Na Figura 1 (a), (b), (c), (d), (e) e (f) são mostradas, respectivamente, as condutividades e constantes dielétricas efetivas em função do potencial químico $\mu$ para comprimentos de onda de 1530, 1550 e $1570 \mathrm{~nm}$, que representam o intervalo espectral referente à da banda $\mathrm{C}$, considerandose $\hbar \Gamma=5 \mathrm{meV}$ e $\mathrm{T}=300 \mathrm{~K}$. Considerou-se, no cálculo da constante dielétrica, uma espessura de $0,34 \mathrm{~nm}$ da camada de grafeno.

Na comparação gráfica entre a evolução da permissividade com a condutividade do grafeno, observa-se que a parte imaginária da permissividade acompanha o comportamento da variação do termo real da condutividade. Logo, sendo o objetivo desta dissertação trabalhar com moduladores que exploram o efeito de variações das perdas do material, é do interesse avaliar exclusivamente a componente real da curva de condutividade. Em relação a esta curva, foi observado que:

1) A curva tem um perfil de variação equivalente a uma tangente hiperbólica, com uma região de potencial químico em que a condutividade é máxima e aproximadamente constante, uma região de queda abrupta, e outra em que ela é próxima de zero e decai suavemente.

2) A melhor eficiência do efeito de variação das perdas é obtido para a região de máxima variação da condutividade, que ocorre para potencias químicos entre 0,3 a 0,5 eV. Portanto, dispositivos de modulação devem ser sintonizados neste intervalo, a fim de se obter um melhor desempenho, tanto em termos de profundidade de modulação como numa melhor eficiência energética e de tensão de chaveamento do dispositivo.

3) Para os 3 comprimentos de onda considerados, não há variações significativas tanto nas curvas de condutividade quanto na de permissividade. Logo, para a região equivalente a banda C, é possível considerar o efeito de dispersão como sendo pouco significativo, permitindo a operação de moduladores para este intervalo espectral, que representa uma importante janela em dispositivos de telecomunicações 
a)

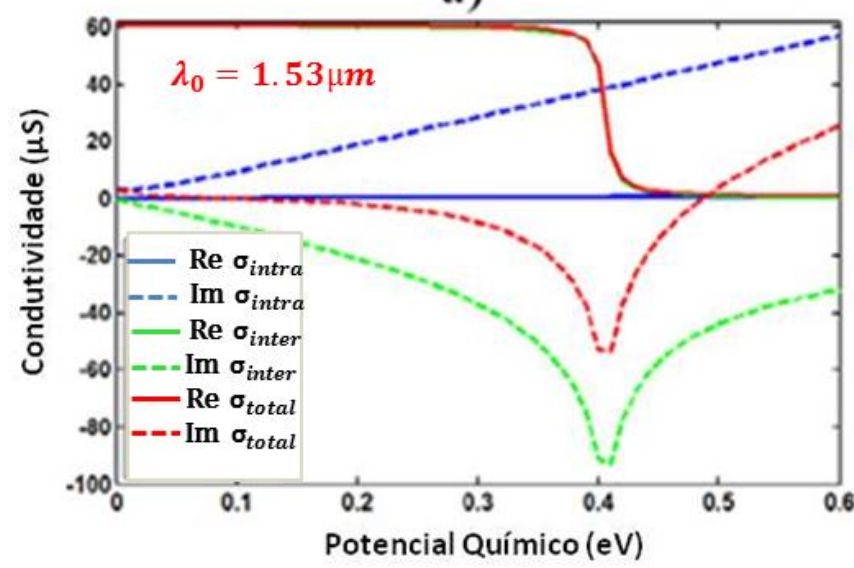

c)

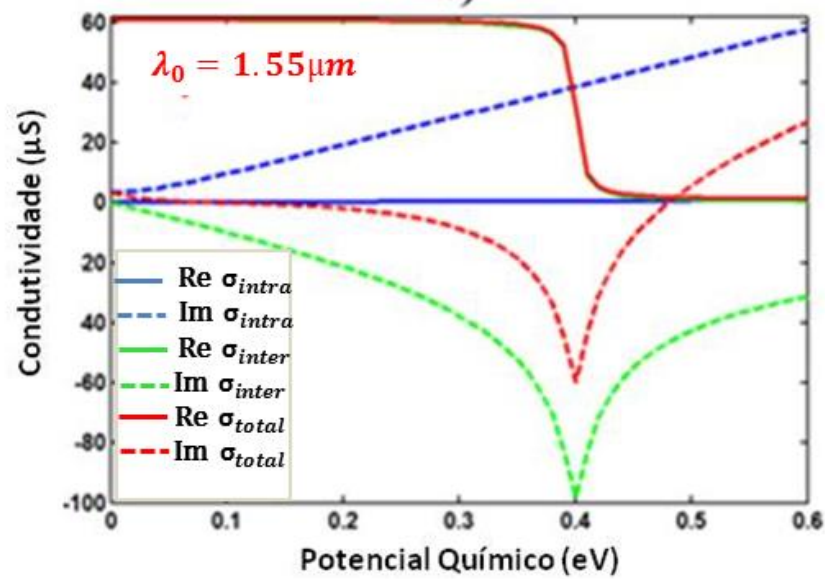

e)

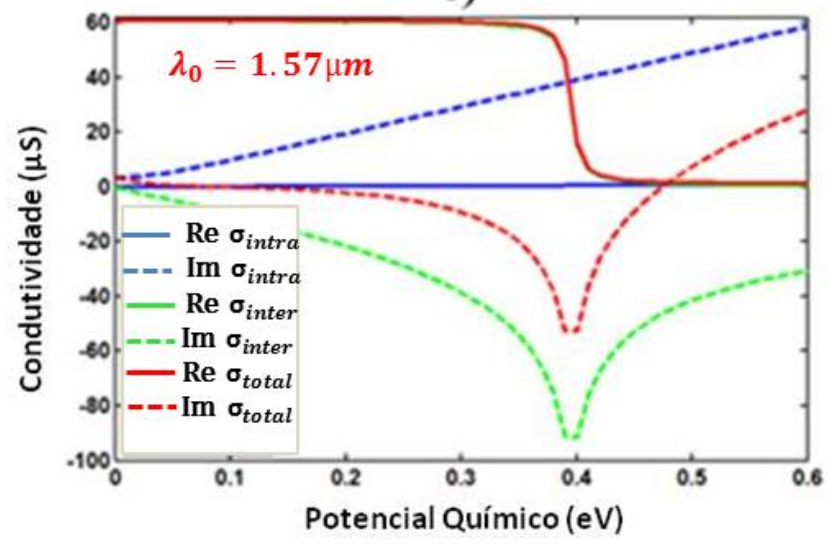

b)

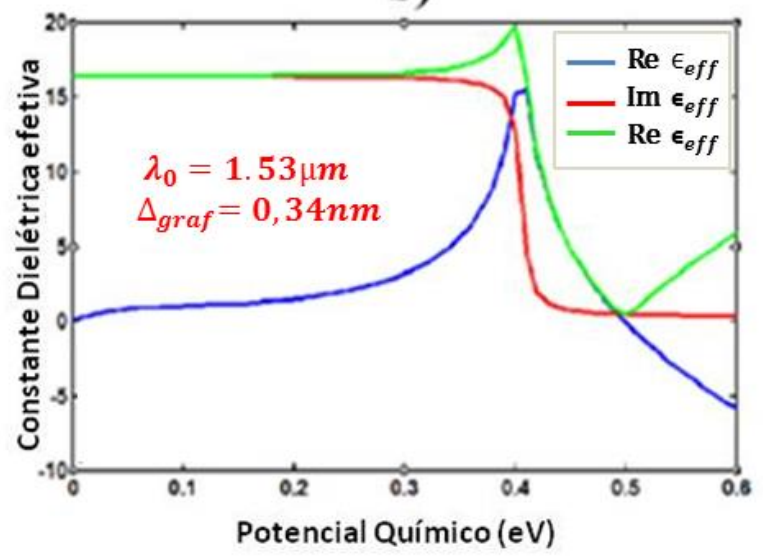

d)

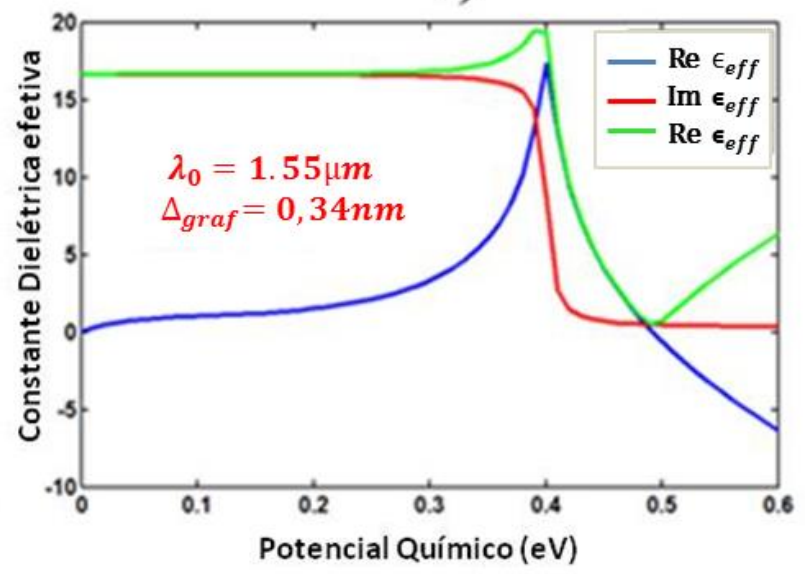

f)

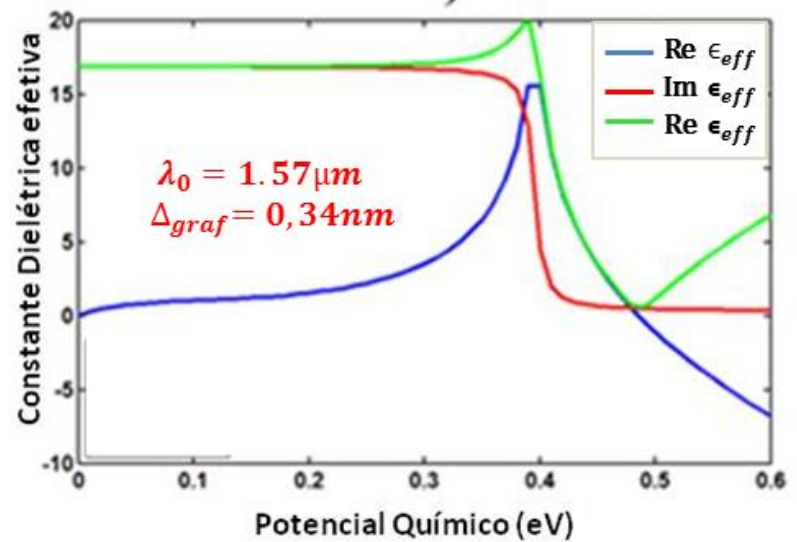

Figura 2 - Condutividade elétrica e constante dielétrica em função do potencial químico $\mu$ para comprimentos de onda de $1.53 \mu \mathrm{m}(\mathrm{a}, \mathrm{b}), 1.55 \mu \mathrm{m}(\mathrm{c}, \mathrm{d})$ e $1.57 \mu \mathrm{m}(\mathrm{e}, \mathrm{f})$.

Fonte: Autor. 


\subsection{Princípio de Funcionamento dos Moduladores de Eletro-Absorção Baseados em Grafeno}

Os moduladores de eletro-absorção convencionais utilizam o efeito da mudança do espectro de absorção de alguns materiais com a aplicação de um campo elétrico controlando, desta forma, a intensidade de luz que se propaga pelo dispositivo óptico. Para os semicondutores, como é o caso do silício, os efeitos Franz-Keldysh e Stark de confinamento quânticos, comumente usados em materiais ferro-elétricos e polímeros eletro-ópticos, apresentam uma eficiência muito pequena na variação de seu coeficiente de absorção [6]. Variações maiores nos índices de refração de semicondutores só são alcançadas por meio do efeito de dispersão em plasma, que está associado à variação da concentração de portadores de cargas livres que alteram tanto a parte real quanto a parte imaginária do índice de refração do material. O modelo de Drude-Lorentz descreve esta variação do índice de refração em função da concentração de elétrons $N_{e}$ e buracos $N_{h}$, e a equação que mostra a variação do coeficiente de absorção $\alpha$ do material é dada por [5], [6]:

$$
\Delta \alpha=\frac{\lambda_{0}^{2} e^{3}}{4 \pi^{2} \varepsilon_{0} c^{3} n}\left(\frac{\Delta N_{e}}{\mu_{e}\left(m^{*} c e\right)^{2}}+\frac{\Delta N_{h}}{\mu_{h}\left(m^{*} c h\right)^{2}}\right)
$$

Sendo $e, c, \varepsilon_{0}, n, \mu_{h}, \mu_{e}, m^{*}{ }_{c e}$ e $m^{*}{ }_{c h}$, respectivamente, a carga elementar do elétron, a velocidade da luz e permissividade no vácuo, o índice de refração do material, permeabilidades magnética e massas efetivas associadas aos elétrons e buracos.

Na Figura 3 é feita a representação esquemática deste modulador em sua visão superior (a) e transversal (b) considerando uma geometria de ressoador anelar. A região $+p$ é dopada positivamente (buracos) e $+n$ é onde ocorre a dopagem negativa. Contatos elétricos entre as duas regiões são responsáveis pela diferença de potencial que causa a movimentação dos portadores livres (alterando as propriedades do silício localmente).

Apesar de este método apresentar uma boa eficiência em termos de velocidade de chaveamento e não sofrer limitações quanto à largura de banda, o efeito eletro-óptico ainda não se comparava ao obtido por materiais eletro-ópticos tradicionais, o que resultava em dispositivos significativamente maiores para atingir a mesma resposta de modulação.

Neste contexto, algumas técnicas alternativas de modulação surgiram e, entre elas, mais recentemente passou-se a utilizar folhas de grafeno integradas a guias de onda de silício como moduladores de eletro-absorção. 
(a)

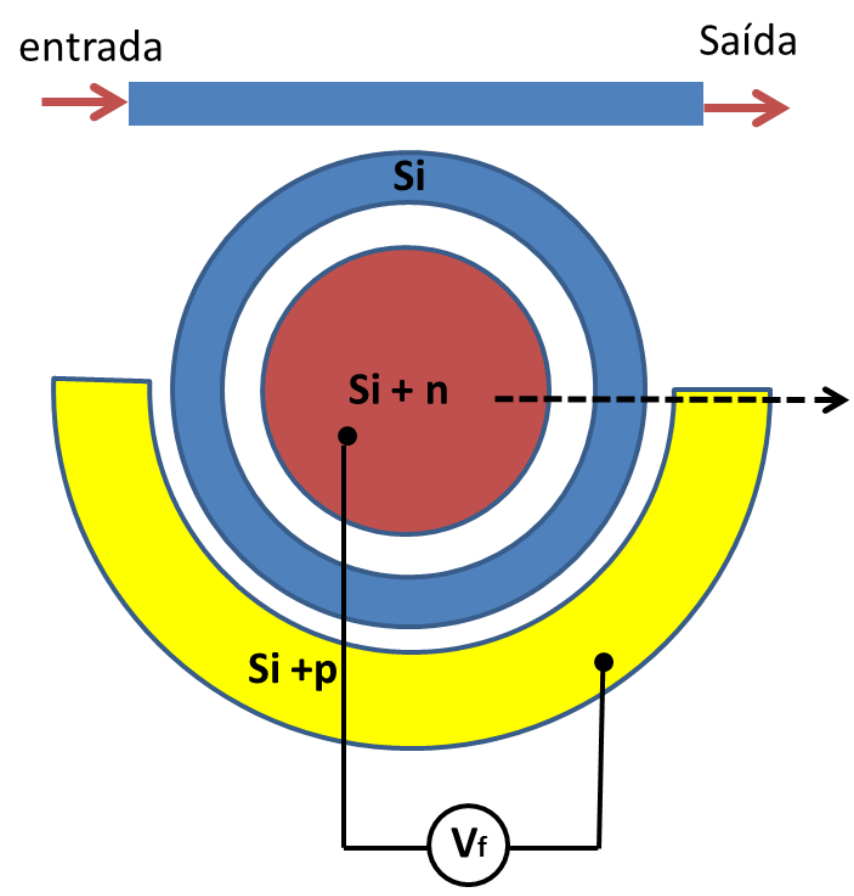

(b)

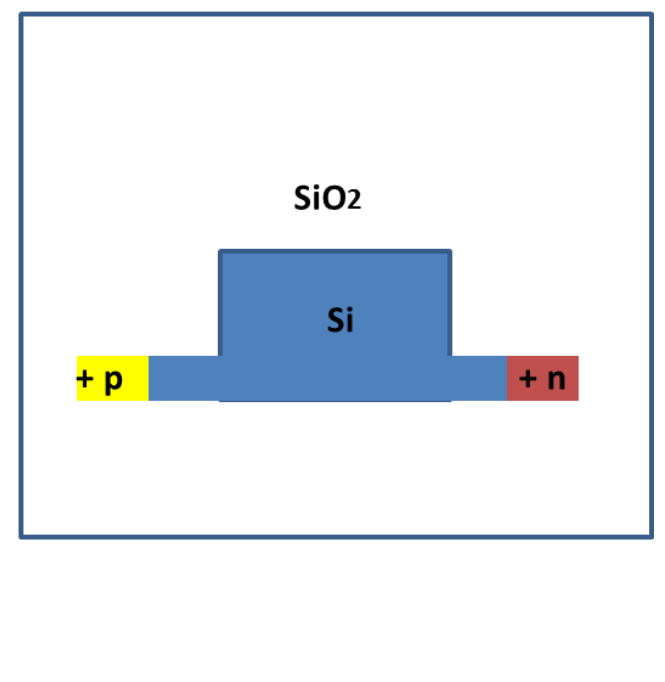

Figura 3 - Representação superior (a) e transversal (b) de um modulador de silício que utiliza o efeito de modulação por dispersão em plasma de portadores de cargas livres.

Como princípio de funcionamento, modificam-se as propriedades de condutividade do grafeno com a variação de seu potencial químico via aplicação de uma tensão elétrica que, por sua vez, afeta o coeficiente de absorção do grafeno. Como o processo de mobilidade de carga do grafeno é muito mais rápido e energeticamente eficiente do que em moduladores de silício dopado, [20] pode-se obter, portanto, moduladores mais rápidos, de pequeno footprint e cuja tensão necessária para atingir os níveis desejados de modulação são bem pequenos.

A aplicação de uma tensão no grafeno varia a densidade de portadores, cuja equação é dada por:

$$
n_{s}=\frac{2}{\pi \hbar^{2} v^{2} F} \int_{0}^{\infty} \varepsilon\left[f_{d}(\varepsilon)-f_{d}\left(\varepsilon+2 \mu_{c}\right)\right] d \varepsilon
$$

Sendo $\hbar, v_{F}$ e $\varepsilon$ respectivamente a constante de Planck reduzida $\left(\frac{h}{2 \pi}\right)$, velocidade de Fermi ( $\left.\cong 9.5 \times 10^{5} \mathrm{~m} / \mathrm{s}\right)$ e a energia dos portadores, mostrada na Figura 4 como função do potencial químico. 


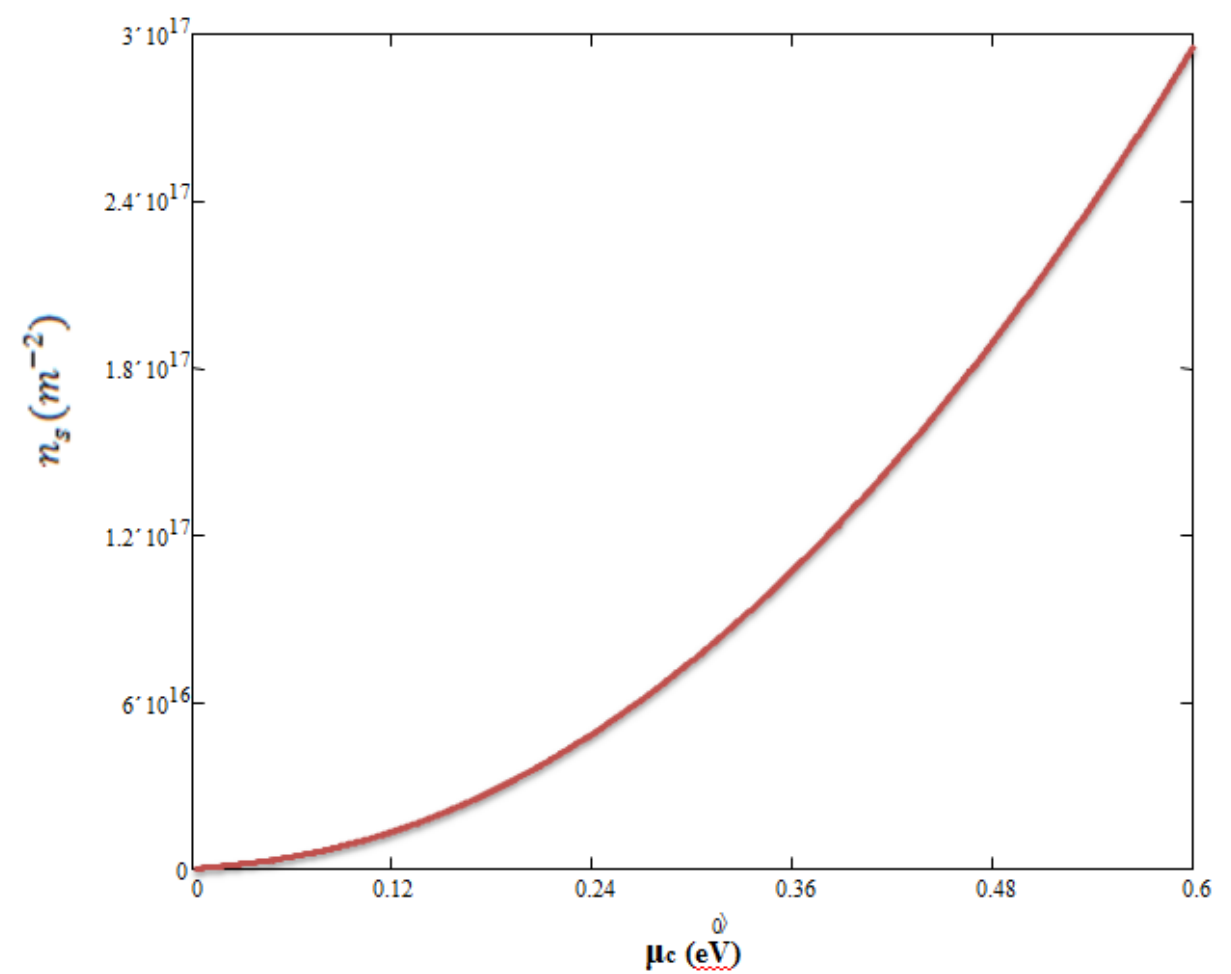

Figura 4 - Densidade de portadores em função do potencial químico.

Fonte: Autor.

Nos moduladores baseados em grafeno propostos, em sua maioria, adota-se uma estrutura capacitiva [16], com uma camada de óxido de alumínio entre duas camadas uma de grafeno. Logo, a equação que dá a tensão necessária para carregar o grafeno é da seguinte forma:

$$
V_{\mu_{c}}=\frac{Q_{\mu_{c}}}{C}
$$

onde $Q_{\mu_{c}}$ é a carga acumulada nas folhas de grafeno para um potencial químico $\mu_{c}$, que é dada por:

$$
Q_{\mu_{c}}=\rho_{\mu_{c}} e A,
$$

onde A é a área da placa do capacitor, $e$ é a carga de um elétron e $\rho_{\mu_{c}}$ é a densidade de carga para o potencial químico $\mu_{c}$. A capacitância $C$ é definida da forma:

$$
C=\frac{\varepsilon_{0} \varepsilon_{r, \text { dielétrico } A}}{h_{\text {dielétrico }}}
$$


Para $A, \varepsilon_{r, \text { delétrico }} h_{\text {dielétrico }}$ sendo, respectivamente, a área, constante dielétrica relativa e a espessura da camada dielétrica. Substituindo (2.8) e (2.7) em (2.6), tem-se a equação:

$$
V_{\mu_{c}}=\frac{\rho_{\mu_{c}} e h_{\text {dielétrico }}}{\varepsilon_{0} \varepsilon_{r, \text { dielétrico }}}
$$

E a energia necessária para se variar o potencial químico de $\mu_{1 c}$ a $\mu_{2 c}$ é dada por:

$$
E_{\mu_{1 c}, \mu_{2 c}}=\frac{1}{2} \frac{\left(Q^{2}{ }_{\mu_{1 c}}-Q^{2}{ }_{\mu_{2 c}}\right)}{2 C}=\frac{1}{4}\left(\rho_{\mu_{1 c}}^{2}-\rho_{\mu_{2 c}}^{2}\right) e^{2} \frac{h_{\text {dielétrico } A}}{\varepsilon_{0} \varepsilon_{r, \text { dielétrico }}}
$$

Nas Figura 5 (a), (b) e (c) são apresentadas, respectivamente, para diferentes valores de potencial químico, as curvas de energia em função da espessura do dielétrico para um capacitor de área fixada em $4.05 \mu \mathrm{m}^{2}$ a energia em função da área para uma espessura do material dielétrico fixa em $7 \mathrm{~nm}$, e a tensão elétrica em função da área do capacitor variando-se a espessura do dielétrico (a e c) e para o caso de espessura constante do dielétrico de $7 \mathrm{~nm}$ variando-se a área (b).

Das equações (2.12) e (2.13), pode-se inferir que:

1. Como é mostrado Figura 5 (a) e (b), energia necessária para variação do potencial químico de $\mu_{1 c}$ para $\mu_{2 c}$, obedece a mesma relação de proporcionalidade para

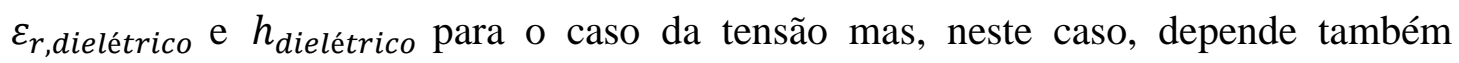
diretamente da área ocupada pelas placas do capacitor;

2. No gráfico da Figura 5 (c) mostra-se que a variação da tensão necessária para se obter um potencial químico $\mu_{c}$ (tomando como partida o nível de Fermi), é função apenas

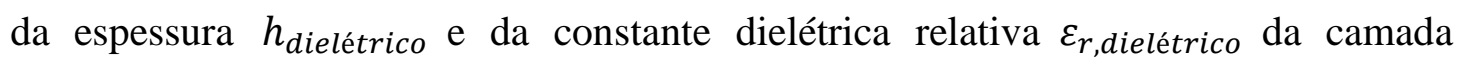
dielétrica, sendo a primeira uma relação de proporcionalidade direta e a segunda, inversa;

3. Considerando diferentes potenciais químicos para valores fixos de espessura ou camada dielétrica, os gráficos da Figura 5 de energia e tensão de chaveamento crescem de maneira não linear, pois é uma função dependente da densidade de portadores. Então, quanto maior for o distanciamento do nível de Fermi, maior será a tensão e energia necessária para uma variação de $0,05 \mathrm{eV}$ do potencial químico. 
(a)

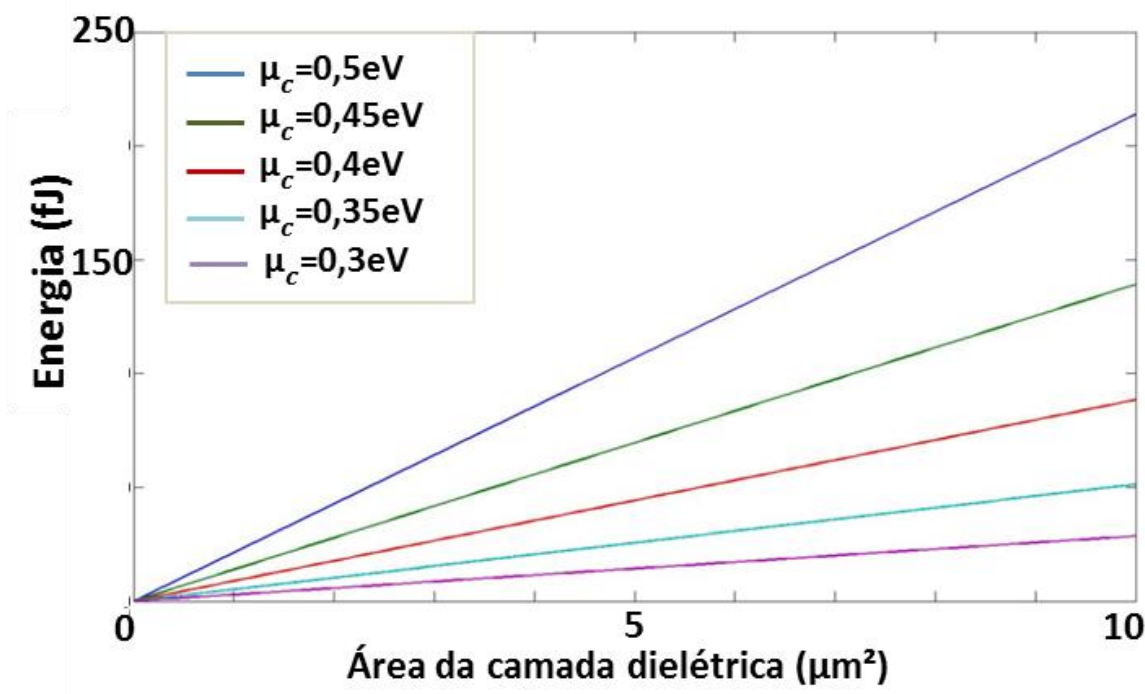

(b)

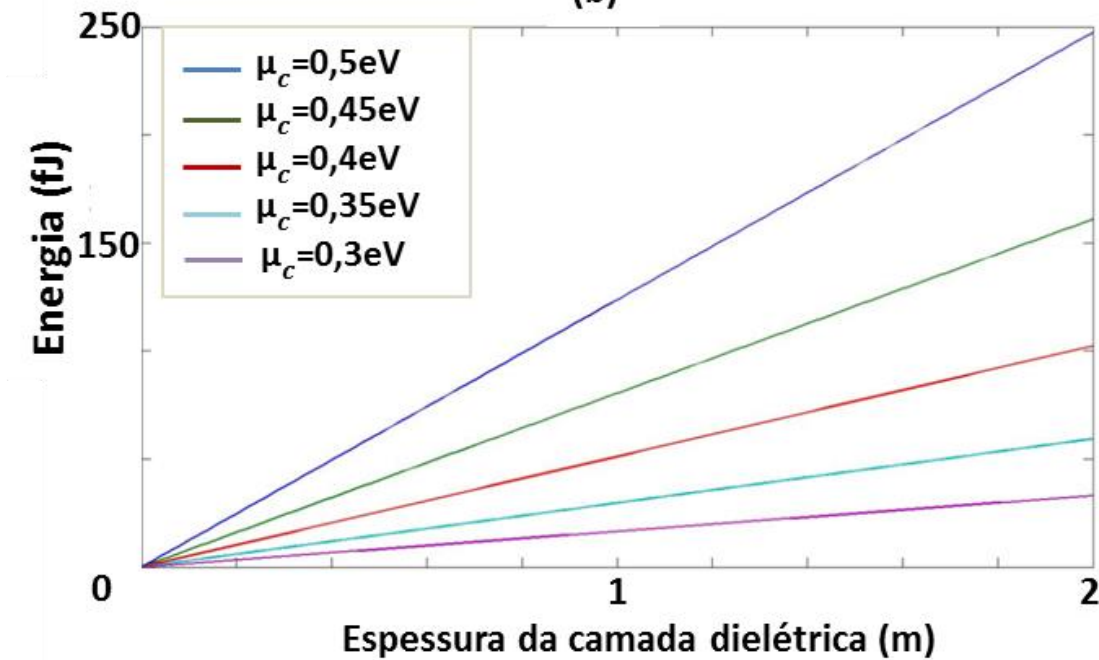

(c)

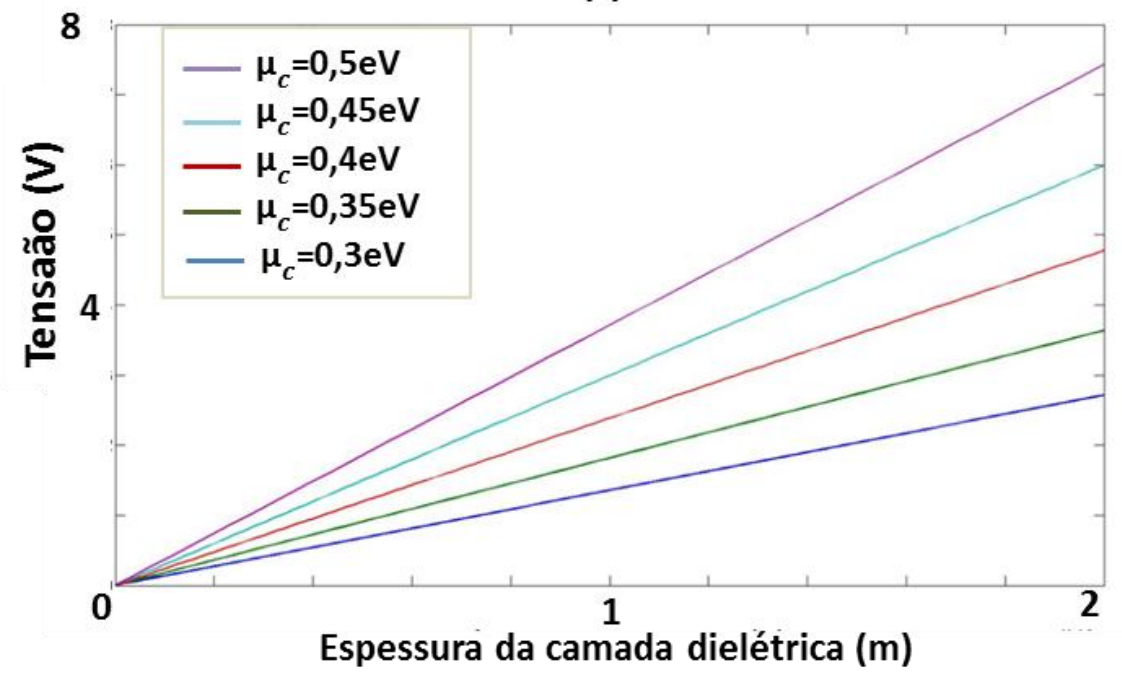

Figura 5 - Variação da energia (fJ) em função da espessura (a) e área (b) camada dielétrica e variação da tensão de chaveamento em função da espessura da camada dielétrica (c) para valores de potenciais químicos variáveis entre 0,3 à $0,5 \mathrm{eV}$.

Fonte: Autor. 
Isso significa que, para obter um modulador com baixo consumo de potência e que demande uma tensão para atingir a resposta desejada em profundidade de modulação, deve-se buscar os seguintes procedimentos, que são:

1. Reduzir a área ativa do dispositivo;

2. Reduzir ao máximo permitido pelas condições de fabricação a espessura da camada dielétrica do capacitor;

3. Minimizar o intervalo de potencial químico considerado para o chaveamento do modulador, utilizando, preferencialmente, intervalos na região de maior variação da condutividade óptica, que no caso de dispositivos cujo comprimento de onda de operação localizam-se na região espectral da banda $\mathrm{C}$, representam o intervalo de 0,3 a $0,5 \mathrm{eV}$. 
Neste capítulo serão abordados alguns conceitos básicos relacionados ressoadores WGM em formato de anel ou microdiscos, que serão utilizados como dispositivos de modulação neste trabalho, tendo foco prioritário em suas figuras de mérito. Finalmente, será abordada a teoria de acoplamento crítico, fundamental para a compreensão do mecanismo de modulação óptica será utilizada nestas estruturas.

\subsection{Introdução}

O termo Whispering Gallery Modes (WGM) foi inicialmente utilizado por Lord Rayleigh, no início do século XX, para descrever o fenômeno da propagação de ondas sonoras na região próxima a superfície de uma galeria, observado na catedral de St. Paul, em Londres [38]. Já no início do século XX, foram obtidas as equações de auto frequência para este padrão de reflexão em ondas eletromagnéticas propagando em cavidades esféricas de superfície metálica e dielétrica [39]. Somente no ano de 1961, foi possível observar experimentalmente um padrão WGM no domínio óptico. No estudo, investigou-se a propagação de um laser em um ressoador cristalino composto de Sm: $\mathrm{CaF}_{2}$, cuja dimensão era da ordem de alguns milímetros [40]. Apesar disso, apenas no inicio de 1990 esses dispositivos passaram a ser estudados extensivamente e com isso, surgiram muitas aplicações tecnológicas no domínio óptico [41]. Entre suas principais características estão capacidade de confinar energia com baixas perdas (alto fator de qualidade) e modos de propagação de pequeno volume, permitindo a fabricação de estruturas de dimensões bastante reduzidas e que operam para comprimentos de onda na região da banda $\mathrm{C}$, possibilitando, desta forma, uma fácil integração em componentes de chip, para aplicações como dispositivos de sensoriamento, moduladores ou filtros ópticos, dentre muitos outros [42], [43]. Estes ressoadores, além de apresentarem geometria esférica, podem assumir formatos cilíndricos, discos, anéis, toróides, entre os mais comuns.

Neste trabalho, optou-se por geometrias de discos e anéis, que são mais utilizadas em dispositivo de modulação [8], [43]. Logo, para as equações que definem os principais parâmetros característicos destes dispositivos (comprimento de onda de ressonância, largura de banda de meia altura, fator de qualidade, Free Spectral Range, finesse), assim como o mecanismo de transferência de energia por acoplamento evanescente entre um barramento e um ressoador (teoria do acoplamento crítico), serão considerados, a priori, para estas configurações geométricas. 


\subsection{Parâmetros Caracterizadores dos Ressoadores}

Por serem dispositivos de alta seletividade e bom potencial para miniaturização, os ressoadores em formato anelar, disco ou toróide têm sido utilizados como componentes de sistemas de multiplexação de comprimento de onda (WDM), especialmente para moduladores e filtros ópticos [7], [8]. O dispositivo funciona como um armazenador de energia para um comprimento de onda de ressonância, que ocorre quando a seguinte condição é satisfeita:

$$
n_{e f f} L=m \lambda_{\text {ress }}
$$

Sendo $n_{\text {eff }}$ o índice efetivo do guia, $L$ o perímetro médio do ressoador, $\lambda_{\text {ress }} \mathrm{o}$ comprimento de onda de ressonância e $m$ um múltiplo inteiro deste comprimento de onda, que representa o número azimutal do modo.

Além da condição de ressonância, outros parâmetros que caracterizam um ressoador serão apresentados a seguir.

\section{a) Faixa Espectral Livre (ou Free Spectral Range, FSR)}

O FSR do ressoador dá a distância espectral entre duas regiões de ressonância do dispositivo, definida da seguinte forma:

$$
F S R=\frac{\lambda^{2} \text { ress }}{n_{g} L}
$$

Em que $\lambda_{\text {ress }}$ e $L$ foram definidos anteriormente e $n_{g}$ representa o índice de refração de grupo que se propaga na cavidade, definido matematicamente da forma:

$$
n_{g}=n_{e f f}-\lambda_{0} \frac{d n_{e f f}}{d \lambda}
$$

O FSR é uma importante figura em se tratando de moduladores, pois define a região do espectro permitida para alocação de canais de modulação sem que ocorra uma interferência com outras ressonâncias daquele dispositivo. Essa interferência, por sua vez, é a causa distorções na transmissão daquele sinal, impedindo uma leitura correta da informação enviada pelo modulador. 
Portanto, para um ressoador que se comporte como um dispositivo de modulação, é vantajoso que seu FSR seja o maior possível, pois isso permite uma maior quantidade de canais de modulação em que se pode compactar na região espectral de operação.

\section{b) Fator de Qualidade}

O fator de qualidade (Q) de um ressoador permite avaliar o quão seletivo é este dispositivo para um determinado comprimento de onda. Como definição geral, tem-se a seguinte equação:

$$
Q=\omega_{\text {ress }} \frac{\text { Pot }_{\text {total }}}{\text { Pot }_{\text {dissipada }}}
$$

Ou seja, o fator de qualidade quantifica o grau de confinamento de energia no interior da cavidade ressoadora. Portanto, quanto menor forem as perdas da cavidade, maior será o seu Q. Em dispositivos de modulação utilizando cavidades ressoadoras acopladas a um outro guia de onda, a equação 3.3, em termos de seus de seus parâmetros de transmissão, é definida da seguinte forma:

$$
Q=\frac{\lambda_{\text {ress }}}{\Delta \lambda_{F W H M}}
$$

onde $\Delta \lambda_{F W H M}$ é definido como a região espectral do centro da ressonância em que a transmissão máxima cai pela metade. Em dispositivos ressoadores acoplados a barramentos, esta definição pode ser feita em termos de coeficientes de transmissão, acoplamento e perda do ressoador denominados, respectivamente, pelas variáveis $k, t$ e $\alpha$ (definidos com mais detalhes na próxima se secção, que aborda a teoria do acoplamento crítico). Para a estrutura de modulador desta cavidade, tendo um ressoador acoplado a um único guia de onda, temos a definição dada por [43]:

$$
\Delta \lambda_{F W H M}=\frac{(1-t \alpha) \lambda^{2} r e s s}{\pi n_{g} 2 \pi R \sqrt{(t \alpha)}}
$$

E substituindo a equação (3.6) em (3.5), o fator de qualidade é agora definido da forma:

$$
Q=\frac{(1-t \alpha)}{\lambda_{r e s s} \pi n_{g} 2 \pi R \sqrt{(t \alpha)}}
$$


Ao se estudar os sistemas com ressoadores WGM (para os quais se tem uma transferência de energia por acoplamento de onda evanescente) esta definição de fator de qualidade é muito importante. Estabelecendo alguns desses coeficientes, é possível obter informações de suas características de transferência e armazenamento de energia com a determinação de apenas um desses coeficientes.

\section{c) Finesse}

A finesse de um ressoador é definida por:

$$
F=\frac{F S R}{\Delta \lambda_{F W H M}}
$$

Isto quer dizer que uma maior finesse de um dispositivo o tornará mais eficiente em termos de compactação de canais, pois estes ressoadores terão alta seletividade e uma grande distância entre as regiões ressonância.

\subsection{Acoplamento Crítico}

A manipulação da transferência de energia entre um guia de onda e uma estrutura ressonante, como micro anéis, toróides e microdiscos é muito importante em termos de aplicações tecnológicas, especialmente em estruturas moduladoras ou sensores.

No caso dos moduladores, que é o foco deste trabalho, a modificação da condição de acoplamento crítico entre um guia de onda e um ressoador, seja por deslocamento espectral da ressonância ou variação das perdas ópticas do ressoador com a aplicação de uma tensão elétrica, gera mudanças no padrão da intensidade da onda transmitida para a porta de saída (representada na Figura 6 pela porta 2) obtendo, assim, uma modulação de intensidade da onda.

Neste capítulo, será estudada a teoria do acoplamento crítico [44], [45] analisando as condições necessárias para que esta condição seja estabelecida. Na Figura 6, está ilustrado o esquema de transferência de energia entre um ressoador e um barramento, bem como seus coeficientes de transmissão, acoplamento e perdas da cavidade. 


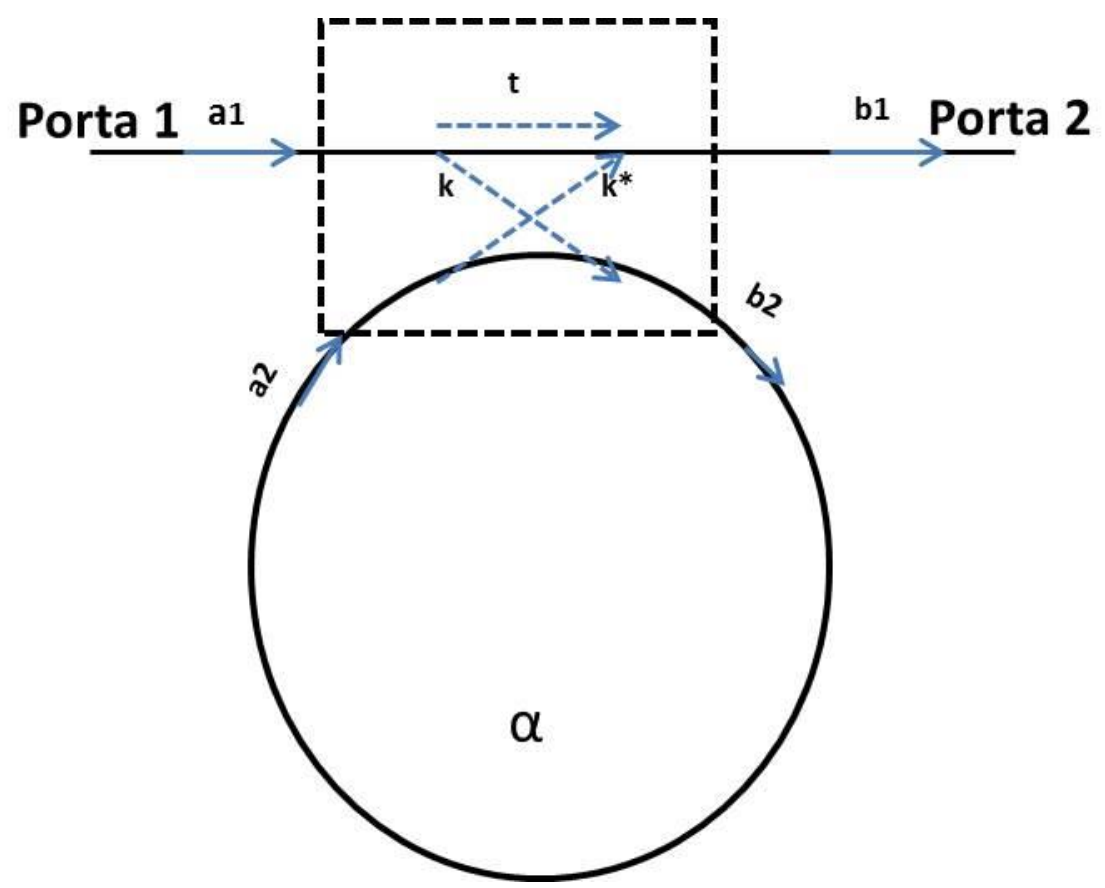

Figura 6 - Representação esquemática do acoplamento entre um guia de onda e um ressoador.

Fonte: Autor

É considerada uma representação genérica de um barramento acoplado a um ressoador curvo. Para a condição ideal de transferência de energia (em que as ondas se propagam em apenas uma direção do guia e a potência óptica total da região de acoplamento que entra é igual à potência de saída), temos o sistema representado pela matriz:

$$
\left(\begin{array}{l}
b_{1} \\
b_{2}
\end{array}\right)=\left(\begin{array}{cc}
t & k \\
-k^{*} & t^{*}
\end{array}\right)\left(\begin{array}{l}
a_{1} \\
a_{2}
\end{array}\right)
$$

onde $t$ e $k$ representam, respectivamente, as constates de transmissão e de acoplamento entre os guias, sendo que:

$$
|t|^{2}+|k|^{2}=1
$$

E como condição de circulação no interior do anel, tem-se a expressão dada por:

$$
a_{2}=b_{2} \alpha e^{i \theta}
$$


onde $\alpha$ e $\theta$ representam, respectivamente, o fator de perda (ou ganho) e a diferença de fase da onda por circulação no interior do anel. Substituindo (3.3) e (3.2) em (3.1), considerando-se a relação de substituição

$$
|t|^{2}=1-|k|^{2}
$$

pode-se obter as seguintes expressões para as amplitudes $b 1$ e $a 2$ :

$$
\begin{aligned}
& b_{2}=\frac{-\alpha+t e^{-i \theta}}{-\alpha t^{*}+t e^{-i \theta}} \\
& a_{2}=\frac{-\alpha k^{*}}{-\alpha t^{*}+t e^{-i \theta}}
\end{aligned}
$$

E uma vez que, sem perda de generalidade, pode-se considerar o valor da onda de entrada al como unitário, temos que a transmissão da porta 1 para a porta 2 é dada por:

$$
\mathrm{T}=\left|\frac{b_{1}}{a_{1}}\right|^{2}=\left|b_{1}\right|^{2}=\frac{\alpha^{2}+|\mathrm{t}|^{2}-2 \alpha|\mathrm{t}| \cos (\theta)}{1+\alpha^{2}|\mathrm{t}|^{2}-2 \alpha|\mathrm{t}| \cos (\theta)}
$$

E na condição de ressonância, onde $\theta=m \pi$ para $m$ inteiro, tem-se que:

$$
\mathrm{T}=\frac{\alpha^{2}+|\mathrm{t}|^{2}-2 \alpha|\mathrm{t}|}{1+\alpha^{2}|\mathrm{t}|^{2}-2 \alpha|\mathrm{t}|}=\frac{(\alpha-|\mathrm{t}|)^{2}}{(1-\alpha|\mathrm{t}|)^{2}}
$$

Com isso, obtém-se a equação da transmissão em função apenas de $\alpha$ e t. Pela equação em (3.7), pode-se ver que:

$$
\mathrm{T}=0 \text { quando } \alpha=\mathrm{t},
$$

sendo esta a condição para o acoplamento crítico.

Na Figura 7 é mostrada graficamente a transmissão T em função do $\alpha$ do ressoador para os valores de $\mathrm{t}=0.8,0.85,0.9,0.95$ e 0.99 . É possível observar uma variação rápida do perfil

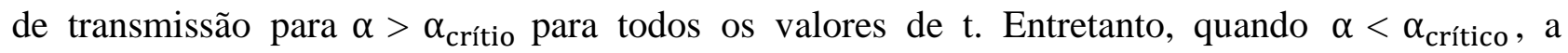
variação do perfil de $\mathrm{T}$ é mais suave quanto menor for o valor de $t$. Logo, para valores de $t$ 
próximos de um, a transmissão do dispositivo será bastante sensível às variações do coeficiente $\alpha$ em relação a seu valor crítico, tanto em termos de redução como aumento. Mas, à medida que o valor de $t$ se distância de 1 , o perfil de transmissão do gráfico para a região próxima ao acoplamento crítico irá variar sensivelmente apenas com o afastamento à direita, ou seja, com a redução das perdas do ressoador. Ao se projetar um ressoador, saber as características da curva de transmissão possibilita um controle mais eficiente deste dispositivo, uma vez que, conhecendo o perfil de variação desta curva, é possível definir o controle mais efetivo das perdas do ressoador, tendo como objetivo obter melhores variações curva de transmissão, seja por meio do aumento ou diminuição do coeficiente de perdas.

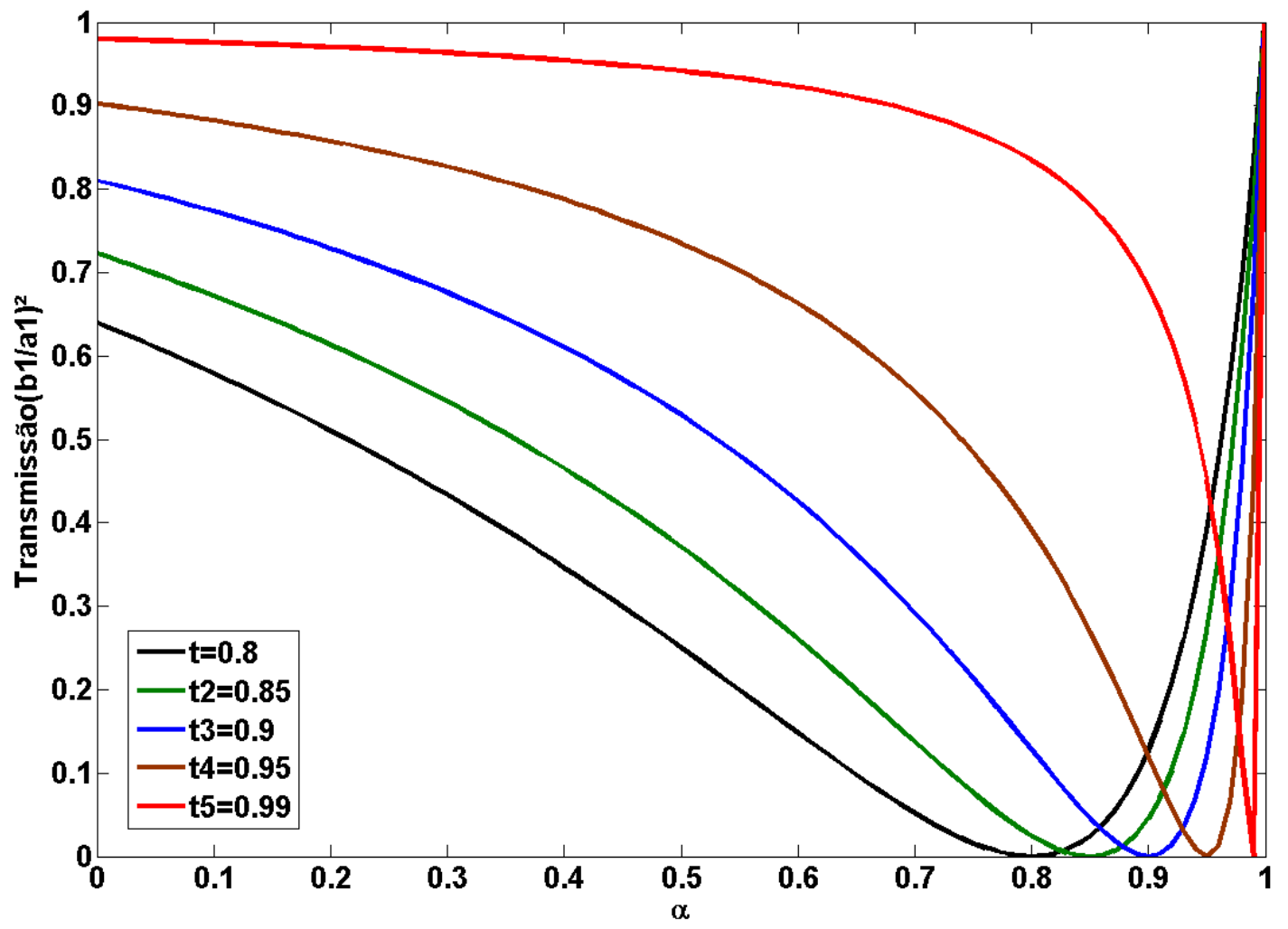

Figura 7 - Variação da transmissão T em função de $\alpha$.

Fonte: Autor. 
Neste capítulo serão apresentados e discutidos os resultados das simulações realizadas. Também será descrito o procedimento de otimização das estruturas, assim como as condições de contorno.

\subsection{Software Utilizado}

As simulações foram feitas utilizando o software comercial COMSOL Multiphysics versão 3.5a, que se baseia no método dos elementos finitos para a discretização espacial. No caso específico deste trabalho, foi utilizado o módulo RF para análise de problemas envolvendo soluções estacionárias no domínio da frequência, para o cálculo dos índices efetivos, e na análise tridimensional da propagação do campo na estrutura investigada. A escolha por se fazer a análise em 3D em detrimento de sua simplificação bidimensional ocorreu devido a imprecisões da aproximação feita via método do índice efetivo para o caso estudado. Então, trabalhou-se com um contraste de índice de refração bastante elevado, o que, por sua vez, não permitiu uma representação fidedigna do confinamento modal do ressoador, e isso forneceu resultados imprecisos para as figuras características do dispositivo.

\subsection{Estruturas de Moduladores Investigadas}

Neste trabalho, foram propostas duas estruturas de moduladores baseados em grafeno utilizando o mesmo efeito de controle de sua condutividade óptica (via aplicação de uma tensão elétrica).

Para primeiro modulador, foi proposto um dispositivo cuja condição de acoplamento crítico foi ajustada a um potencial químico do grafeno equivalente a $0,3 \mathrm{eV}$ e, para o modulador ligado, sintonizado a $0,5 \mathrm{eV}$ Este intervalo entre os potenciais químicos para os estados desligado/ligado representa a região variação abrupta na condutividade real do grafeno, permitindo a obtenção de uma relação otimizada em termos de tensão de chaveamento e consumo de potência por bit.

O objetivo desta primeira estrutura investigada é mostrar, baseado no modulador proposto por Midrio et al. [20], ser possível obter um dispositivo de modulação óptica de igual sintonia para o acoplamento crítico (potencial químico de $0,3 \mathrm{eV}$ ) para um raio médio reduzido à metade, e ainda conseguir preservar satisfatoriamente a principal figura de mérito deste dispositivo de modulação 
(excepcional desempenho em profundidade de modulação), adicionando as vantagens de se trabalhar com dispositivos de menor footprint, que são seu menor consumo de potência e FSR mais largo.

Para a maior parte das simulações, foi adotado um ressoador com raio externo de $2,58 \mu \mathrm{m}$. Foi considerada, baseado nos cálculos de ressoador cuja largura do guia corresponde a $400 \mathrm{~nm}$ [20], que as perdas por curvatura de um ressoador de raio médio entre 2,3 $\mu \mathrm{m}$ a $2,5 \mu \mathrm{m}$ são uma ordem de grandeza inferior às causadas pela absorção óptica do grafeno correspondente a um potencial químico de 0,3 eV. Portanto, considerando esta configuração de guia, a contribuição das perdas representa uma redução no controle total das perdas do dispositivo e por isso, interfere no seu desempenho em profundidade de modulação. Nesta investigação, pretende-se mostrar que com ajustes adequados na geometria do modulador é possível minimizar esta degradação, aumentando, por consequência, o potencial de miniaturização deste dispositivo.

Na segunda estrutura, é investigado o mecanismo de modulação inverso, ou seja, sintonizando o acoplamento crítico do ressoador para o grafeno em uma região de potencial químico próxima de $0.5 \mathrm{eV}$ (estado desligado) e de $0,3 \mathrm{eV}$ correspondente ao estado ligado.

O raio externo para os ressoadores desta estrutura foi o mesmo da primeira, possibilitando uma melhor avaliação comparativa entre ambas. A escolha de um ressoador para um o grafeno com $0,5 \mathrm{eV}$ de potencial químico (representando uma configuração com perdas internas reduzidas) é feita no sentido de se avaliar a variação do desempenho da profundidade de modulação e outras figuras de mérito do dispositivo discutindo, as possíveis vantagens em relação à primeira estrutura. Foram realizadas simulações para diferentes parâmetros geométricos de largura do barramento $\left(\mathrm{w}_{1}\right)$ e região angular de grafeno no ressoador $\left(\theta_{\text {graf }}\right)$, e largura do ressoador (W) com a finalidade de maximizar a eficiência do dispositivo.

Para ambos os dispositivos investigados, foi desconsiderado o fator de perda associadas ao espalhamento devido a rugosidade de guias de onda fabricados, por conta das imperfeições nos processos de fabricação. De fato, para os raios considerados neste trabalho, este fator representa uma parcela pouco significativa das perdas totais e pode ser desconsiderado nos cálculos, mesmo para um dispositivo real [46], [47]. 


\subsection{Condições de Contorno}

Como condições de contorno, com exceção da região das portas de entrada e saída, toda a região de fronteira externa foi definida como Scattering Waves para o caso do campo incidente evitando-se, assim, a reflexão de radiação. As regiões de fronteira da caixa computacional que representam as portas 1 e 2 foram excitadas com um modo quasi-TE com propagação na direção x e componentes Ey e Ez, calculado por meio do módulo RF Perpendicular Waves do COMSOL Multiphysics.

\subsection{Obtenção da Condição de Acoplamento Crítico}

Como abordado no capítulo 3 a respeito das cavidades ressoadoras, ajustar o modulador para a condição de acoplamento crítico é essencial para maximizar a performance do dispositivo, já que, por definição, atinge-se esta condição quando a transmissão de energia na porta de saída é nula. Isto permite uma maior razão de transmissão do modulador em seus estados ligado/desligado [44]. Esta condição, assim como definida anteriormente, quando $\alpha$ (que representa o fator de perdas do ressoador em uma volta de propagação da onda ressonante) iguala-se ao coeficiente de transmissão t. Para os casos estudados neste trabalho, a sintonização para esta condição foi realizada das seguintes formas (envolvendo o coeficiente de transmissão $t$ e as perdas do ressoador $\alpha$ ):

\section{I) Fixando t e variando $\alpha$}

Mantendo-se fixo o coeficiente de transmissão, varia-se o $\alpha$ aumentando/diminuindo as perdas até a obtenção do valor mínimo na transmissão do parâmetro de espalhamento $\mathrm{S}_{21}$ (definido pela razão entre a potência da onda detectada na porta de saída em relação à potência total, que incide pela porta de entrada). Definindo-se o gap do dispositivo e a geometria do ressoador, variaram-se as perdas do ressoador com o acréscimo gradativo da secção angular de grafeno, (com passos de $5^{\circ}$ para cada simulação) até obtenção da transmissão mínima na porta de saída. Neste caso, a condutividade do grafeno é ajustada para o equivalente a potencial químico de $0,3 \mathrm{eV}$, calculado segundo a parte real da condutividade, obtida pela fórmula de Kubo; 


\section{II) Fixando $\alpha$ e variando $t$}

Estabelecendo um valor fixo para as perdas do ressoador, variou-se o valor de $\mathrm{t}$ por meio da alteração da distância de separação entre o ressoador e o barramento, até a obtenção do valor mínimo da transmissão do parâmetro de espalhamento $S_{21}$. Neste caso, inicialmente definiuse a geometria do ressoador e a secção angular contendo grafeno como um valor fixo, ajustado para um equivalente de potencial químico de $0,5 \mathrm{eV}$ e, para igualar o valor de $\alpha$ ao de t, variou-se o gap entre o ressoador e o barramento, em passos de $10 \mathrm{~nm}$ para cada simulação, partindo-se de um valor inicial de $150 \mathrm{~nm}$ até a obtenção do valor mínimo na transmissão, que configura a condição mais próxima possível ao acoplamento crítico.

\subsection{Secção Transversal e Aproximação de Homogeneização}

A estrutura adotada para os ressoadores baseados em grafeno nas diferentes simulações feitas neste trabalho tem uma configuração transversal similar à adotada por Midrio et al. [20] e Liu et al. [15] e, genericamente, é definida da seguinte forma: um guia de onda de silício, cuja altura é fixa e igual a $220 \mathrm{~nm}$, e largura $\mathrm{w}_{1}$, a ser definida nas simulações. Acima do guia de silício, há uma camada de grafeno, com espessura de 0,34 nm, uma camada dielétrica de alumina com $7 \mathrm{~nm}$ de espessura e outra camada de grafeno com a mesma espessura que a primeira. Foi adotado, para os índices de refração do silício, sílica e a alumina, os valores experimentais obtidos respectivamente em Salzberg and Villa [48], Malitson [49] e Malitson and Dodge [50].

Uma vez que as simulações foram feitas em três dimensões, demandam-se elevados custos computacionais de memória e processamento e a reprodução geométrica destas camadas na simulação seria inviável com os recursos disponíveis. Para contornar este problema, essas estruturas, inicialmente de quatro camadas, foram substituídas por guias de onda de uma única camada realizando a seguinte aproximação: inicialmente, calcula-se o modo fundamental quasi-TE do guia reproduzindo a estrutura com todas as quatro camadas e escolhendo adequadamente a condutividade do grafeno equivalente ao potencial químico que se queira sintonizar. Depois, obtido o índice efetivo deste modo, substitui-se a estrutura integral por um guia homogêneo de uma única camada, cuja parte real do índice de refração é a mesma do silício, acrescido de uma parte imaginária, que representa o fator de perdas da estrutura com as camadas de grafeno. Este valor complexo deve ser tal que, calculando-se o modo quasi-TE da estrutura homogênea, esteja o mais próximo possível da estrutura sem aproximações. Com isso, uma vez que as camadas de grafeno e alumina são extremamente finas comparadas ao guia de silício e estão fora do núcleo de 
guiamento, sua contribuição na alteração da parte real do modo é desprezível, sendo, portanto, dominante a contribuição ao fator de perdas da estrutura.

A ilustração esquemática do processo de homogeneização é representada na Figura 8, para uma estrutura de guia com as camadas de grafeno e alumina sem aproximações (a) e homogeneizado (b). Na Figura 9 (a), (b) e (c), são apresentadas as curvas de dispersão para a região espectral correspondente à banda C (1530 a $1570 \mathrm{~nm})$ para os índices de refração real e imaginário de um guia de largura $\mathrm{W}=600 \mathrm{~nm}$ de silício puro e para a estrutura inteira com grafeno e alumina, ajustado a potenciais químicos de 0,3 e 0,5 eV e, na Figura 9 (d), é apresentada a curva de variação da parte imaginária do índice de refração em função do potencial químico, para valores entre 0 a $0,65 \mathrm{eV}$ em um guia de onda de largura $\mathrm{W}=600 \mathrm{~nm}$ e comprimento de onda de ressonância $\lambda_{\text {ress }}=1544,6 \mathrm{~nm}$, que representa aproximadamente a faixa de ressonância dos ressoadores simulados para estas dimensões de guia de onda. As aproximações para os guias homogêneos foram realizadas considerando os valores correspondentes aos mais próximos obtidos nos guias de onda com todas as camadas. Foi considerada, prioritariamente, a convergência da parte imaginária do índice efetivo (que fornece as características de perdas do guia devido à interação do modo com o grafeno).

Como segunda aproximação, foi considerando que, uma vez que os modos radiais que se propagam no interior do ressoador diferem em seu perfil modal em um ligeiro deslocamento na direção radial em comparação a guias de onda retos de mesma largura, a interação com o grafeno, que ocorre na direção vertical do guia, é aproximadamente a mesma, e por isso, foi possível considerar o mesmo coeficiente de perdas. Na Figura 10 é apresentado o módulo do campo elétrico normalizado na direção radial para um guia reto, e um guia do ressoador para uma largura de $\mathrm{W}=600 \mathrm{~nm}$ e $\lambda_{\text {ress }}=1545 \mathrm{~nm}$. Observa-se um perfil de distribuição radial de campo ligeiramente deslocado à direita no ressoador em relação ao modo de um guia de onda reto que, em termos de índice de refração efetivo, representa uma variação de 2,56 para 2,57. Isso mostra que é razoável considerar, no caso do ressoador com este raio, os dois perfis modais como sendo aproximadamente os mesmos e, portanto, o coeficiente de perdas dos guias com grafeno como sendo os mesmo para os dois guias. 
(a)

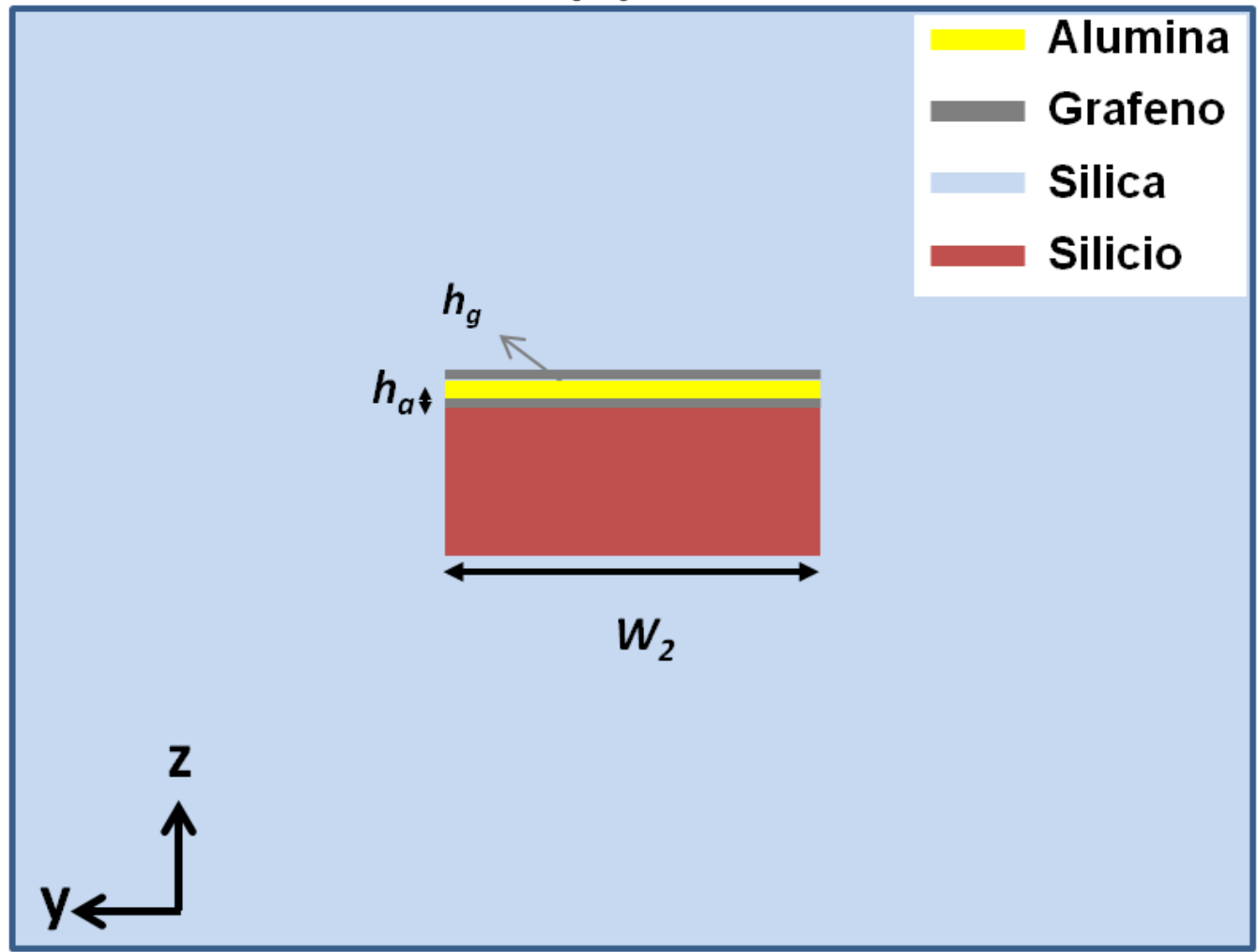

(b)

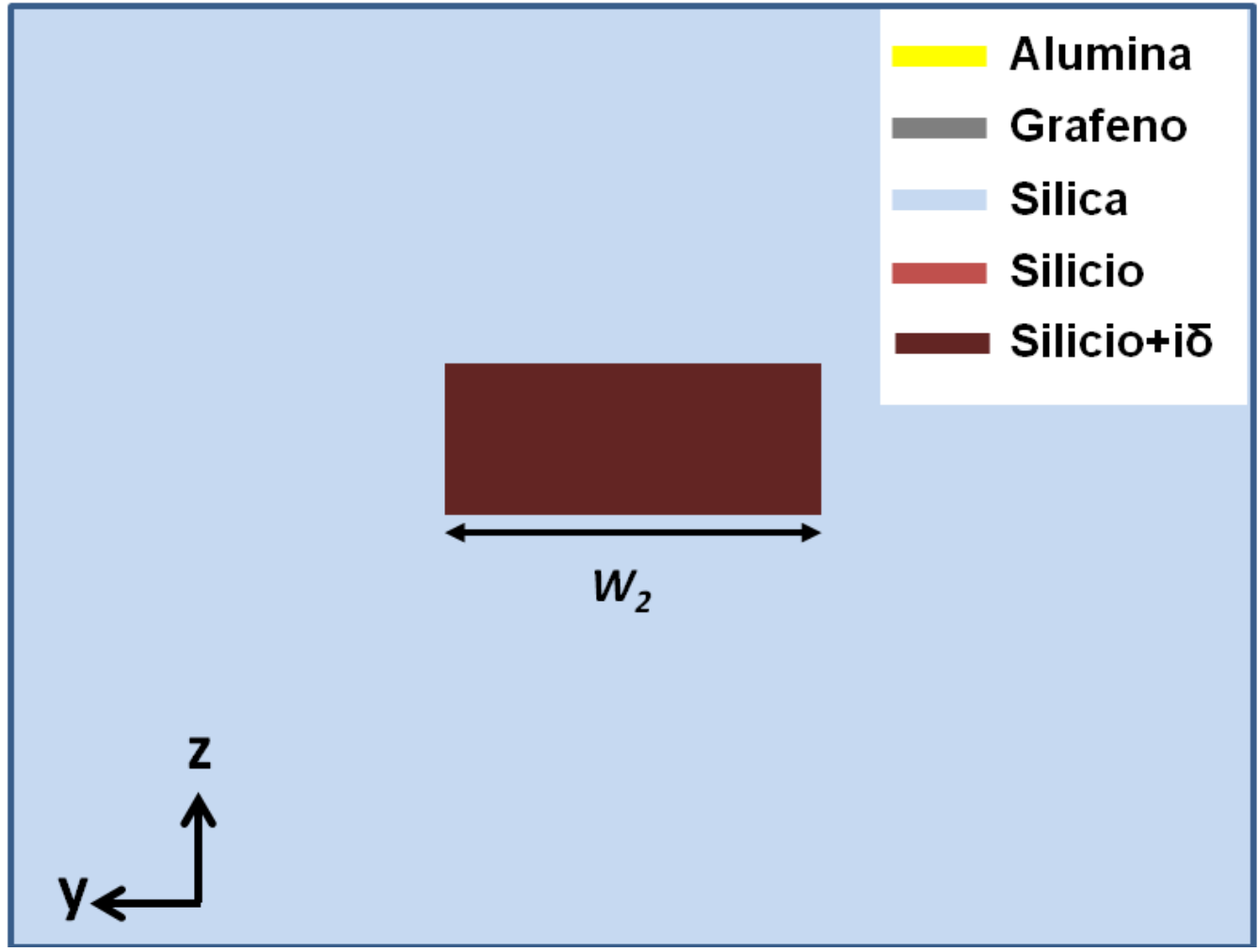

Figura 8 - (a) Guia de onda de silício com duas camadas de grafeno, de espessura hg =0,34 nm e uma camada de alumina de espessura ha $=7 \mathrm{~nm}$; (b) Aproximação de homogeneização da estrutura proposta na figura (a). Fonte: Autor. 
(a)

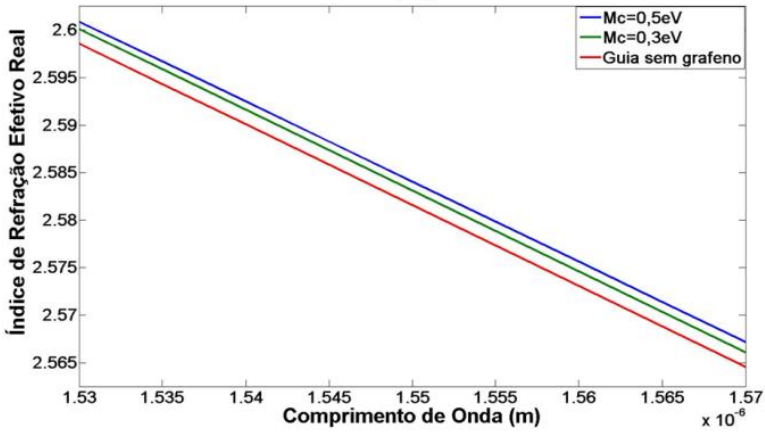

(c)

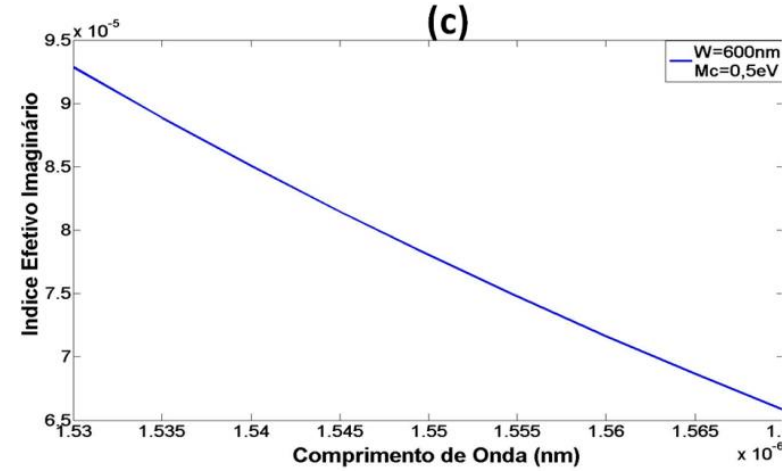

(b)

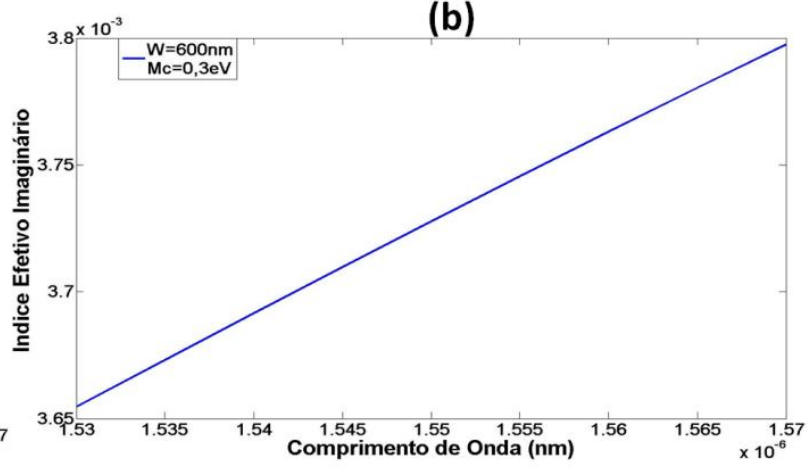

(d)

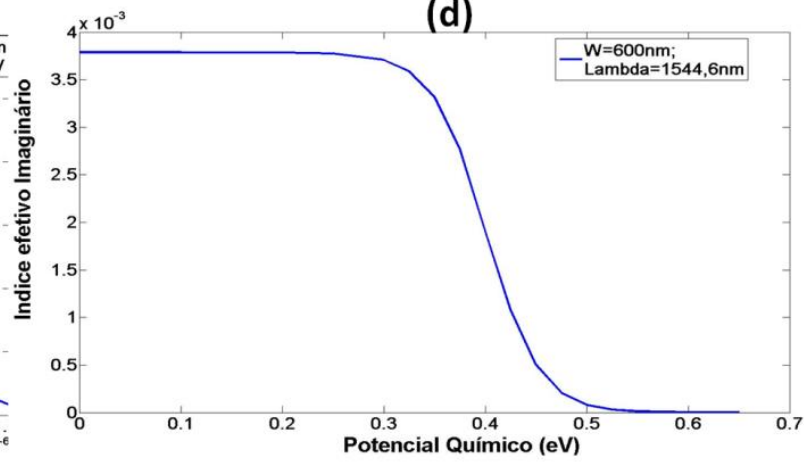

Figura 9 - (a) Curvas de dispersão dos índices de refração real para um guia sem grafeno (vermelha) e com grafeno em potenciais químicos ajustados a 0,3 (verde) e 0,5 (azul) eV para uma largura de $\mathrm{W}=600 \mathrm{~nm}$; (b) Curva de dispersão da parte imaginária do índice de refração para um potencial químico de $0,5 \mathrm{eV}$; (d) Curva de variação do índice de refração imaginário em função do potencial químico para um guia de largura $\mathrm{W}=600 \mathrm{~nm}$ e $\lambda_{\text {ress }}=1544,6 \mathrm{~nm}$.

Fonte: Autor.

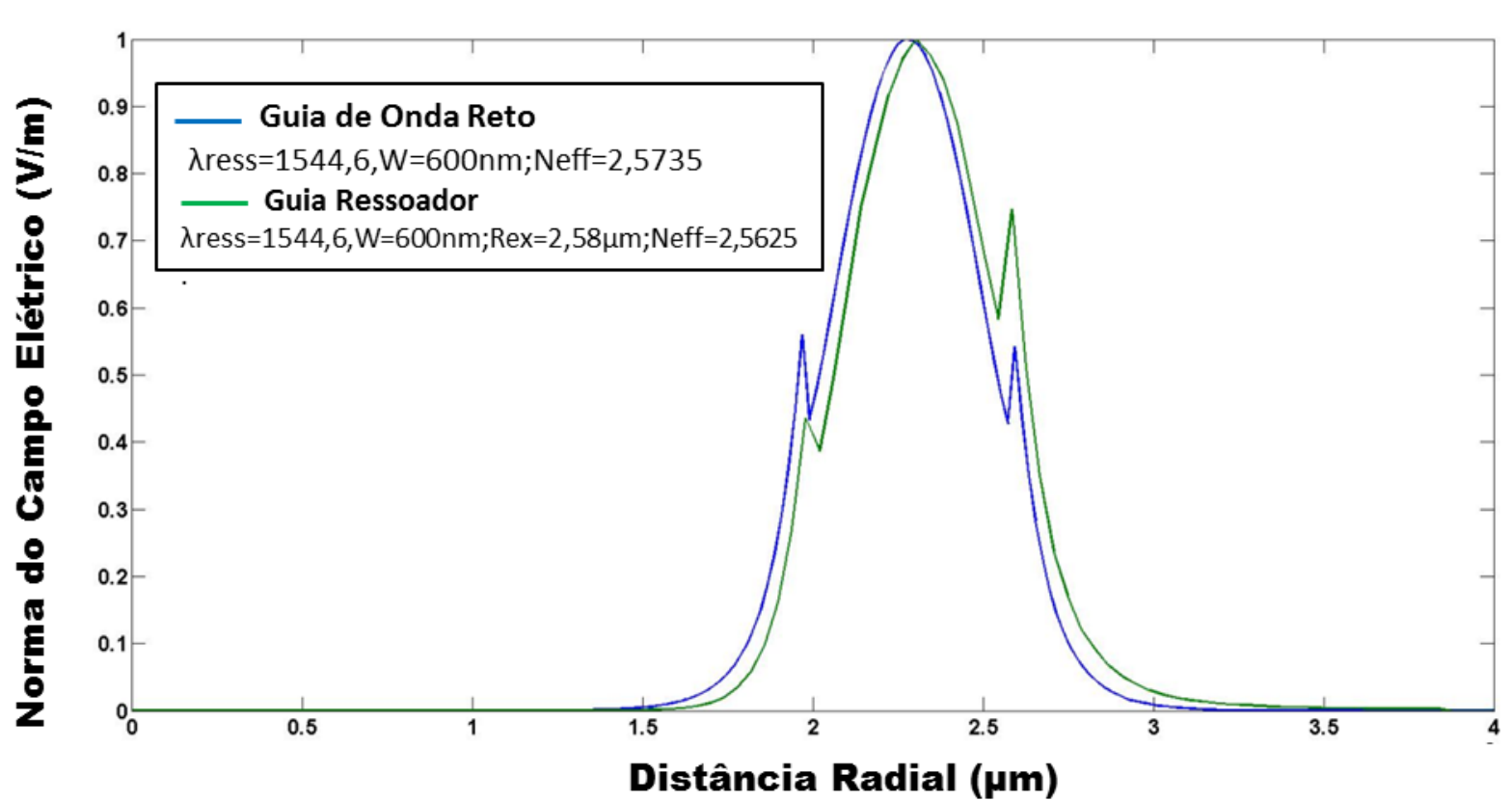

Figura 10 - Distribuição do módulo do campo elétrico normalizado para um guia de onda (azul) e ressoador (verde) para $\mathrm{W}=600 \mathrm{~nm}$ e $\lambda_{\text {ress }}=1544,6 \mathrm{~nm}$.

Fonte: Autor. 


\subsection{Acoplamento Crítico Ajustado para um Potencial Químico de 0,3 eV}

Esta configuração, inicialmente proposta por Midrio et al. [20] para um raio médio de $5 \mu \mathrm{m}$, consiste em um barramento de espessura $\mathrm{h}=220 \mathrm{~nm}$ e largura $\mathrm{w}_{1}$, acoplado a um ressoador, de mesma espessura h e largura W (separado do barramento por uma distância g) que é preenchido por uma secção angular de grafeno considerando-se um potencial químico de $0,3 \mathrm{eV}$. Esse potencial corresponde à condutividade óptica ainda próxima ao do nível de Fermi.

A região angular do ressoador contendo grafeno é definida para sintonia mais próxima possível ao acoplamento crítico. Neste caso, se trabalha para a condição de acoplamento crítico de um ressoador com mais perdas intrínsecas. Isso permite, por sua vez, uma estrutura de modulação com maior largura de banda o que, dentre inúmeras vantagens ao dispositivo, elimina-se a limitação em se trabalhar a taxas de modulações mais altas devido a diminuição do tempo de meia vida do fóton no interior da cavidade (fator que limita a máxima velocidade de modulação do dispositivo) [13] e, adicionalmente, permite-se obter um ressoador menos sensível a variações de ressonância causadas pela sensibilidade térmica do silício que, em moduladores de largura de banda estreita, aumenta consideravelmente o consumo de potência global do dispositivo [15], [9].

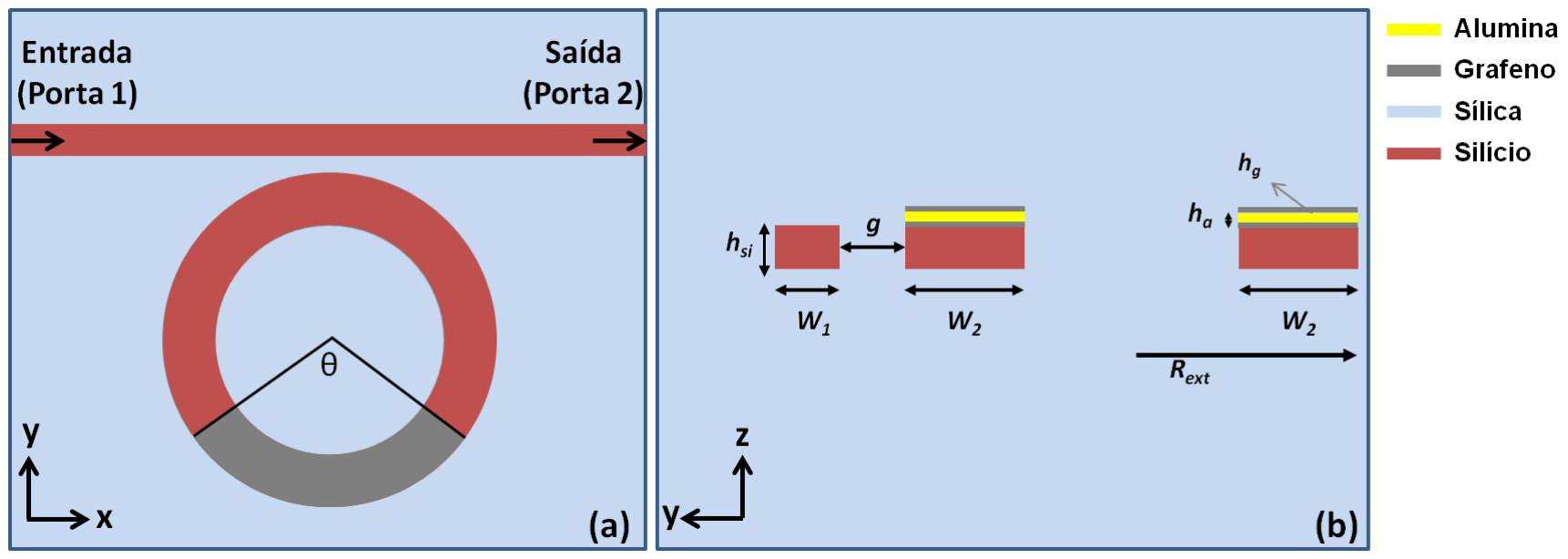

Figura 11 - Vista superior (a) e secção transversal (b) do modulador.

Fonte: Autor. 


\subsection{Otimização Geométrica do Ressoador}

No processo de otimização deste modulador, buscou-se obter um dispositivo com uma geometria mais adequada à preservação de sua profundidade de modulação para ressoadores com raios menores que $3 \mu \mathrm{m}$ uma vez que, para esta configuração de modulador, a fração de perdas associadas à curvatura do guia e a redução do acoplamento de energia entre o barramento e o ressoador são responsáveis pela redução da razão de entre a transmissão de energia do modulador desligado para o seu estado ligado. A escolha de um ressoador com raio externo de 2,58 $\mu \mathrm{m}$ foi feita considerando o cálculo para um guia de silício (imerso em substrato e superstrato de sílica) de $400 \mathrm{~nm}$ de largura a 220 de altura [20], as perdas por curvatura de um ressoador com raio médio de aproximadamente 2,4 $\mu \mathrm{m}$ são uma ordem de grandeza menor às associadas ao grafeno para um potencial químico de $0,3 \mathrm{eV}$. Portanto, para obter-se a estrutura otimizada, seguiram-se, passo a passo, os seguintes procedimentos:

\section{a) Minimização das perdas intrínsecas provocadas pela curvatura do ressoador}

Como é bem conhecido na literatura, ressoadores WGM em formato de disco, em comparação com os de geometria em anel, tem maior fator de qualidade uma vez que estas cavidades não possuem fronteiras associadas ao seu raio interno (inexistentes), que apresentam menores perdas globais de curvatura e espalhamento dos modos radiais [51], [52]. Portanto, o procedimento de minimizar as perdas intrínsecas do dispositivo deve ser dividido em partes, que são:

\section{a.1) Estabelecer a maior largura do ressoador que permita apenas a propagação de modos radiais de primeira ordem}

Esses ressoadores em formato de disco, apesar de eliminarem o fator de perda provocado pela interação do modo com uma das paredes guia, permitem a propagação de modos radiais de ordens mais altas. Tendo em vista que cada modo possui distribuição campo distinta, os índices efetivos são diferentes e, portanto, suas ressonâncias ocupam o espectro de frequência de forma desordenada. Isto, por sua vez é responsável pela redução do FSR do dispositivo, sendo indesejado que ocorra para um dispositivo de modulação, uma vez que esta é uma das mais importantes figuras de mérito. 
A resolução deste problema está em se adotar um ressoador em anel de maior largura, que permita a propagação do modo radial de primeira ordem com o mínimo de interação possível com as paredes de seu raio interno e que seja capaz de atenuar fortemente os modos de mais altas ordens, no limite de sua total supressão.

Para delimitar esta largura W máxima para o dispositivo, na Figura 12 (a) são traçadas as curvas de dispersão do comprimento de onda de ressonância em função do raio interno do ressoador (considerando o raio externo como sendo de 2,58 $\mu \mathrm{m}$ para todos os ressoadores simulados) para o modo radial de primeira ordem e número azimutal $\mathrm{m}=24$ e o modo radial de segunda ordem de número azimutal $\mathrm{m}=20$. Nas Figura 12 (b), (c), (d) e (e), são mostradas as distribuições da norma do campo elétrico para estes dois modos para larguras de $1000 \mathrm{~nm}$ e $600 \mathrm{~nm}$.

Pelo gráfico da Figura 12 (a), observa-se que à medida que se reduz a largura do ressoador, há um deslocamento decrescente do comprimento de onda de ressonância deste modo, que de acordo com a equação (3.1) (que relaciona o seu índice efetivo com o comprimento de onda de ressonância, modo azimutal e perímetro médio do ressoador), mostra-se que esta variação significa uma diminuição do índice efetivo, que ocorre devido ao aumento da interação do modo com as paredes do seu raio interno, diminuindo o confinamento modal.

Para o modo de primeira ordem, esta curva é praticamente constante até uma largura de $700 \mathrm{~nm}$ (raio interno de $1,88 \mu \mathrm{m}$ ), ponto no qual o índice efetivo passa a decrescer, ainda que de forma lenta, até uma largura de $500 \mathrm{~nm}$ (raio interno de 2,08 $\mu \mathrm{m}$ ), onde seu decrescimento passa a ser mais acentuado. Para o modo de segunda ordem, a partir de $1000 \mathrm{~nm}$ (raio interno de 1,58 $\mu \mathrm{m}$ ) observa-se uma variação bastante acentuada.

$\mathrm{Na}$ análise do perfil da norma do campo elétrico, é possível observar que para uma largura de $600 \mathrm{~nm}$ (raio interno de 1,98 $\mu \mathrm{m}$ ), o campo do modo de segunda ordem interage fortemente com as paredes internas e praticamente se extingue para larguras menores, enquanto o modo de primeira ordem ainda interage fracamente com as paredes do raio interno por isso, neste ponto, foi estabelecido o valor de corte para a largura máxima desta geometria para um dispositivo que funcione como modulador óptico. 
(a)

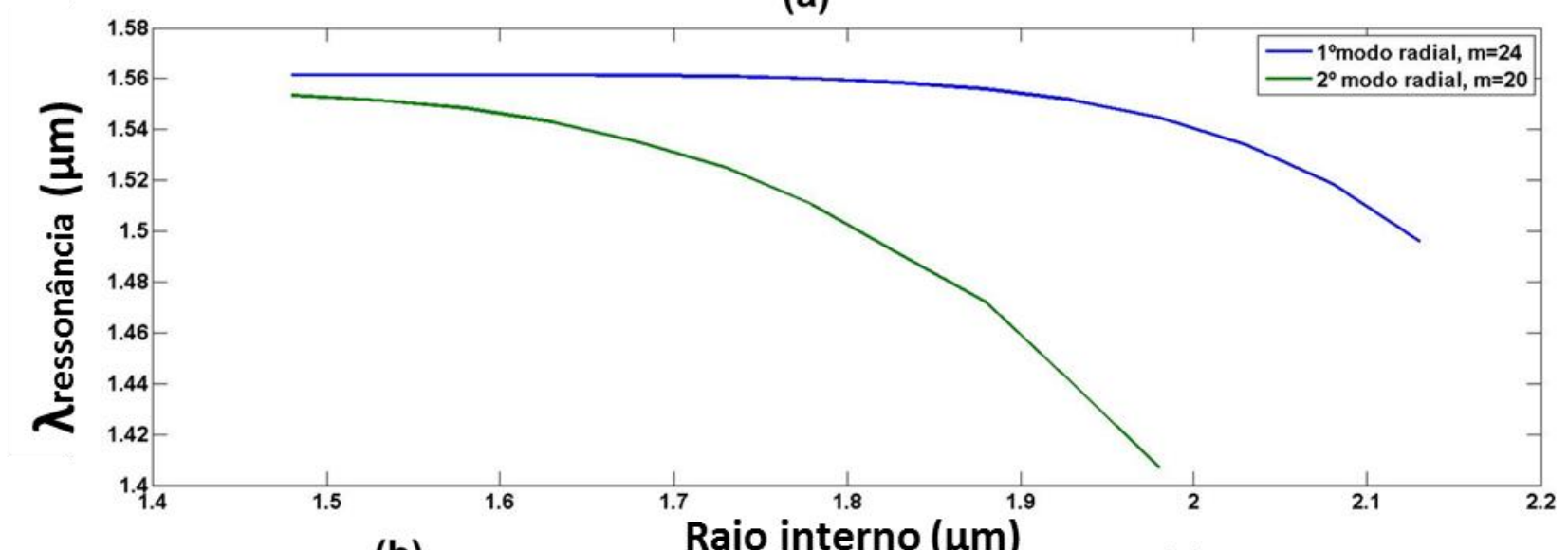

(b)

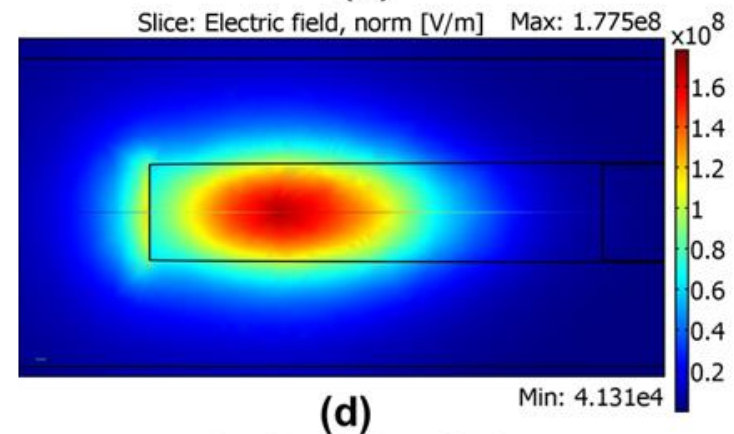

Slice: Electric field, norm [V/m] Max: $6.144 \mathrm{e} 8$

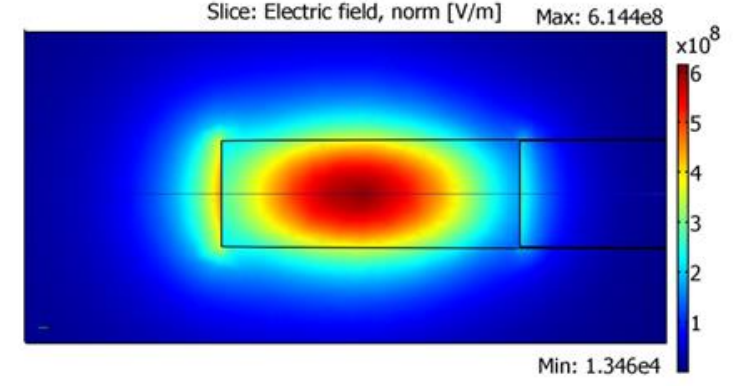

(c)

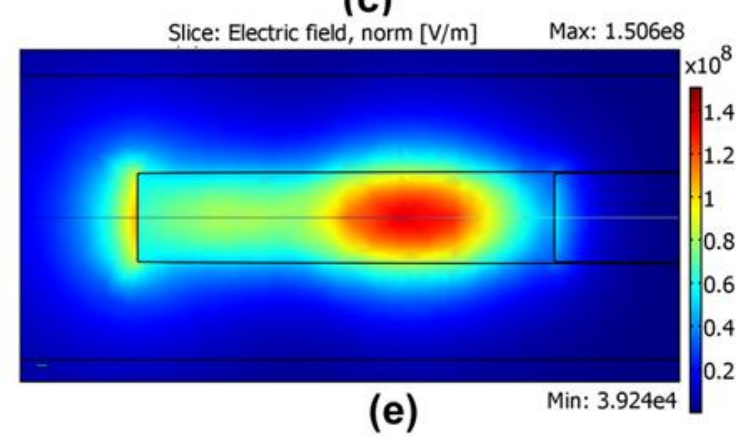

Slice: Electric field, norm [V/m] Max: $1.031 \mathrm{e} 8$

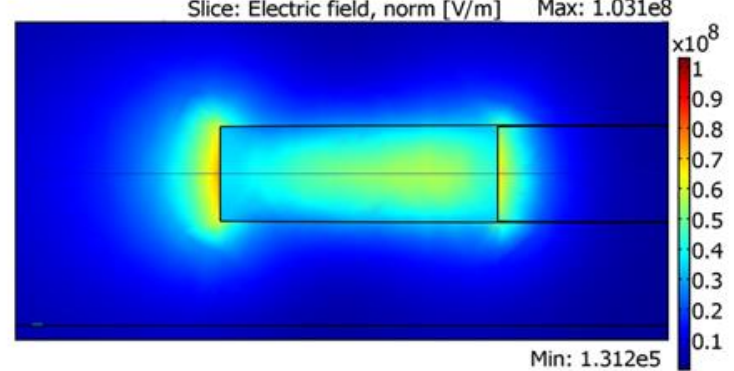

Figura 12 - (a) Curva de dispersão do modo radial de primeira (verde) e segunda (azul) ordem em função da largura W do ressoador; Norma do campo elétrico (V/m) para (b) $\mathrm{W}=1 \mu \mathrm{m}, \lambda=1,5617 \mu \mathrm{m}$, (c) $\mathrm{W}=1 \mu \mathrm{m}, \lambda=1,548 \mu \mathrm{m}$, (d) $\mathrm{W}=0,6 \mu \mathrm{m}, \lambda=1,5446 \mu \mathrm{m}$ e (e) $\mathrm{W}=0,6 \mu \mathrm{m}, \lambda=1,407 \mu \mathrm{m}$.

Fonte: Autor.

\section{a.2) Verificar quantitativamente a redução das perdas do dispositivo em relação aos de raios menores}

Uma vez estabelecida a largura mínima para um ressoador com propagação apenas de modos radiais de $1^{a}$ ordem, é importante verificar se o ganho em termos de redução das perdas intrínsecas do dispositivo ainda é relevante se comparado a ressoadores de menor largura. Por esta razão, foram analisadas as variações das perdas, via cálculo de suas larguras de banda de $-3 \mathrm{~dB}$ $\left(\Delta \lambda_{F W H M}\right)$, para ressoadores de diferentes larguras $\mathrm{W}=600 \mathrm{~nm}, \mathrm{~W}=500 \mathrm{~nm} \mathrm{e} \mathrm{W}=400 \mathrm{~nm}$, considerando, respectivamente, $\lambda_{\text {ress }}=1544,6 \mathrm{~nm}, \lambda_{\text {ress }}=1556,9 \mathrm{~nm}$ e $\lambda_{\text {ress }}=1532 \mathrm{~nm}$, que foram 
escolhidos com valores próximos propositalmente, a fim de minimizar a dependência espectral na resposta do dispositivo em relação a esta variável.

$\mathrm{Na}$ Figura 13, podemos observar a evolução da largura de banda, que aumenta em quase cinco vezes, passando de 0,089 nm considerando um W de $600 \mathrm{~nm}$ até 0,422 nm para $\mathrm{W}=400 \mathrm{~nm}$, nos permite inferir, segundo os cálculos que relacionam as perdas do dispositivo com a largura de banda [43], [44], que houve um aumento proporcionalmente equivalente nas perdas do ressoador, indicando uma redução bastante significativa, o que justifica, assim, a escolha desta geometria em detrimento de um anel com a mesma largura do barramento, que comumente é adotada para ressoadores WGM.

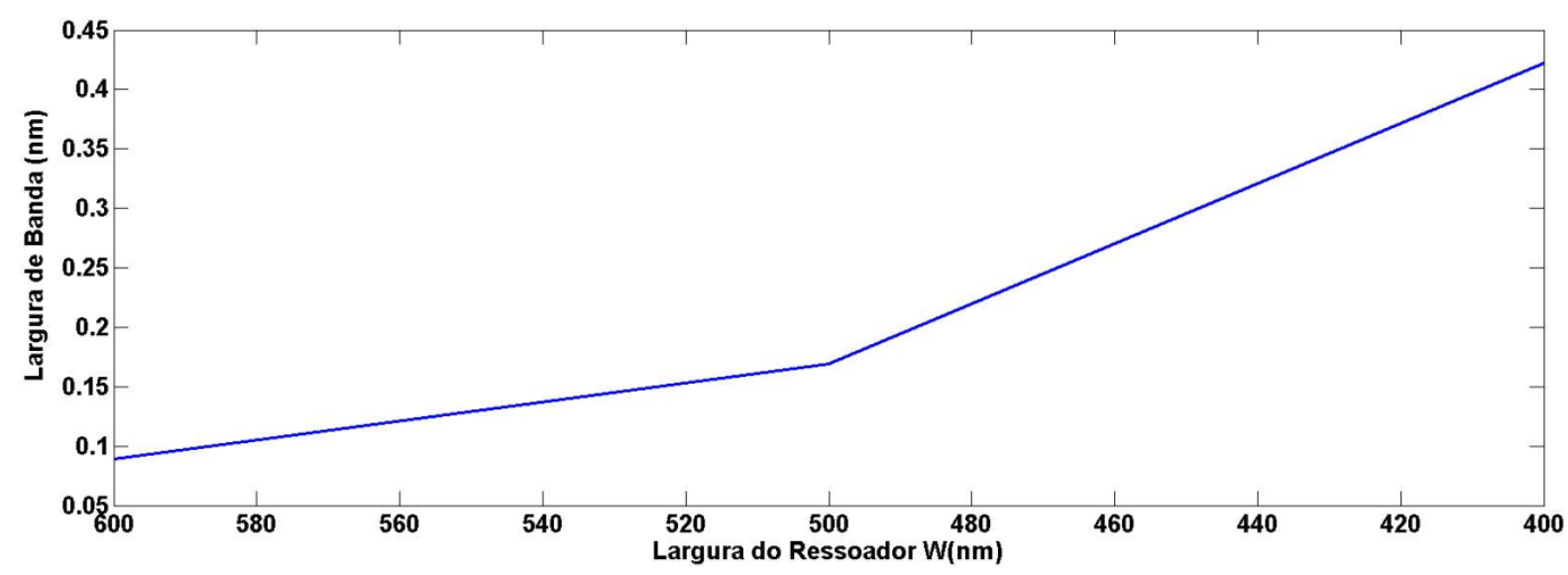

Figura 13 - Largura de banda em função da largura W do ressoador.

Fonte: Autor.

\section{b) Melhorar o acoplamento entre o barramento e o ressoador em função da largura w1 do barramento e distância de separação}

Como pontuado inicialmente, ao se adotar um ressoador de raio reduzido, diminui-se, por consequência, o acoplamento de energia, considerando uma mesma separação e diminui, por fim, a quantidade de grafeno para a condição de acoplamento crítico, comprometendo seu desempenho em termos de profundidade de modulação. Logo, com objetivo de investigar a evolução desta variável para a condição de acoplamento crítico em função de variações geométricas, foram feitas simulações para um ressoador de altura igual a $\mathrm{h}=220 \mathrm{~nm}$, largura $\mathrm{W}=600 \mathrm{~nm}$ e comprimento de ressonância na faixa de $1544,5(+-0,2) \mathrm{nm}$, para larguras $\mathrm{W}_{1}$ dos barramentos entre 400 a $320 \mathrm{~nm}$ em variações de $20 \mathrm{~nm}$ cada, e considerando três parâmetros g de separação entre ressoador e barramento, de 80, 100 e $120 \mathrm{~nm}$. 
Como observado na Figura 14 e na Figura 15, há uma relação inversamente proporcional entre separação do dispositivo e constante de acoplamento, onde para cada valor de gap considerado, há um deslocamento positivo constante desta curva à medida que se diminui a distância de separação sendo, portanto, vantajoso reduzir ao máximo esta separação, dentro dos limites possíveis de fabricação atual.

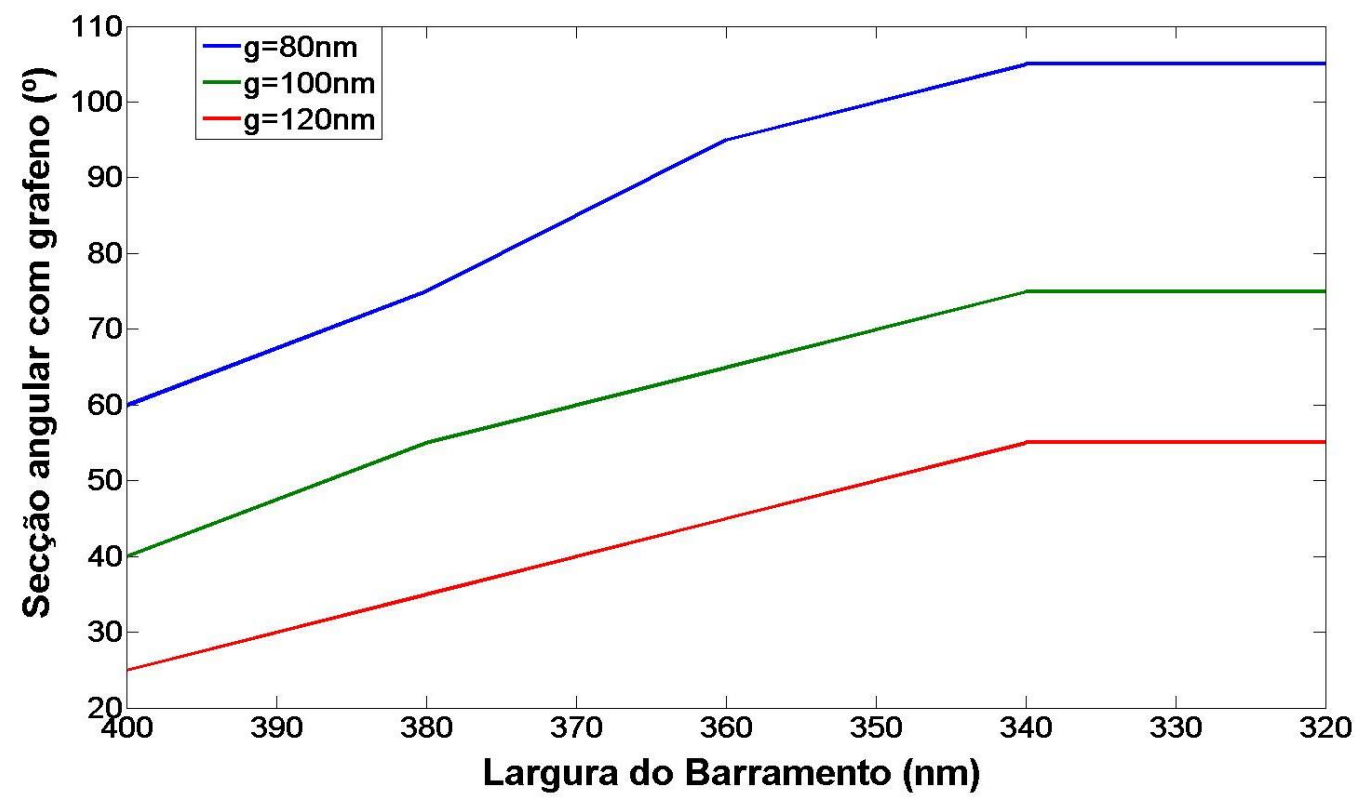

Figura 14 - Secção angular de grafeno em função da largura w1 do barramento, parametrizado para as distâncias de separação entre barramento e ressoador $\mathrm{g}=80,100$ e $120 \mathrm{~nm}$.

Fonte: Autor.

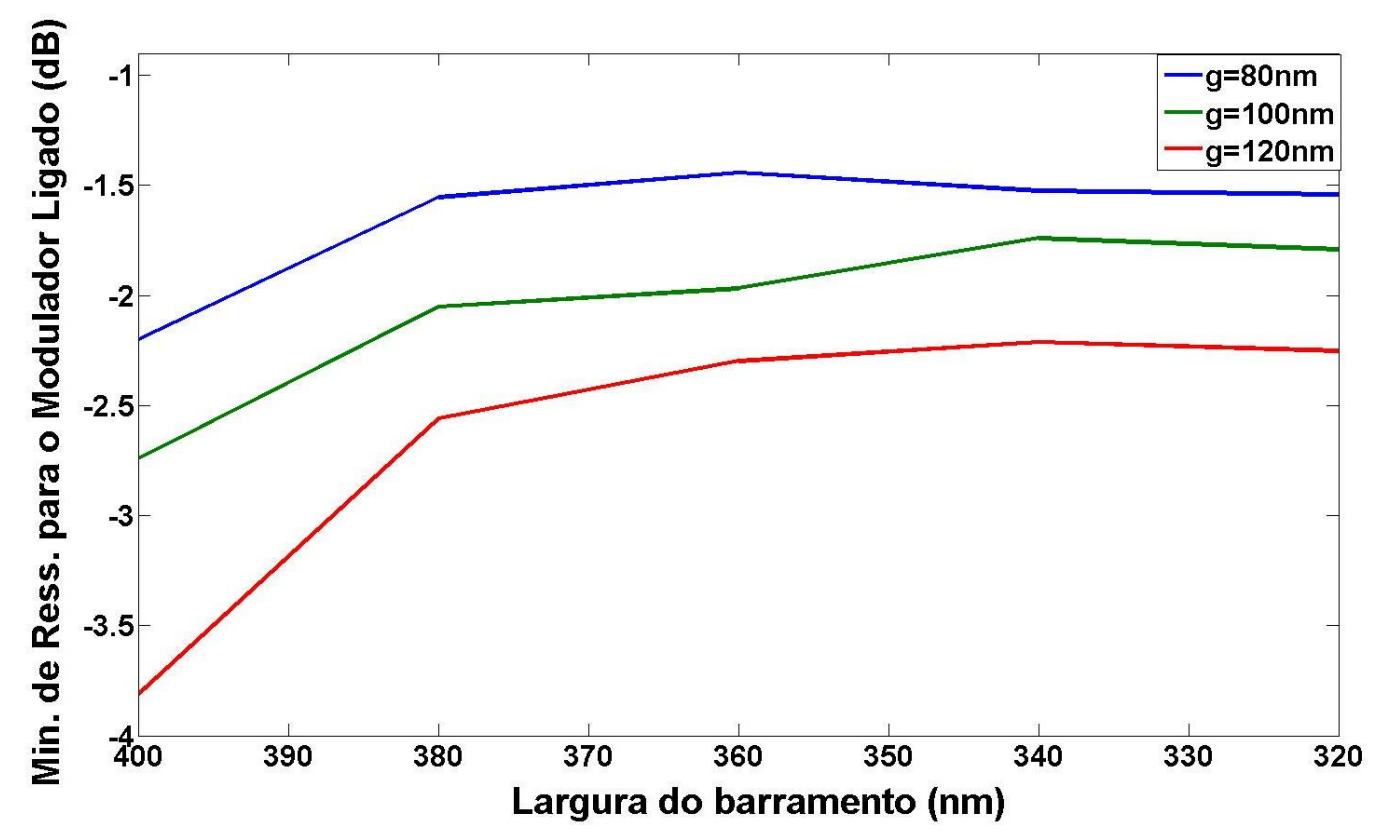

Figura 15 - Mínimo de ressonância do modulador ligado em função da largura w1 do barramento, parametrizado para as distâncias de separação entre barramento e ressoador $\mathrm{g}=80,100$ e $120 \mathrm{~nm}$.

Fonte: Autor. 
Já em relação à largura do barramento, observa-se a mesma evolução inversamente proporcional com sua diminuição, entretanto, este ganho em termos de melhor acoplamento tende a uma saturação quando o barramento atinge $u m w_{1}=340 \mathrm{~nm}$. Isso acontece porque, ao mesmo tempo em que se aumenta a fração de energia evanescente do barramento, aumentando o comprimento de interação com o ressoador, ocorre, com a diminuição dessa largura, um pior casamento de fase entre os guias, o que contribui para o efeito inverso.

Em relação à curva do mínimo de transmissão para o modulador em seu estado ligado, que nos fornece a profundidade de modulação do dispositivo, é possível ver que, especificamente para a curva de menor distância de separação, há um ponto de saturação para um w $w_{1}$ menor do que a evolução da quantidade de grafeno, que ocorre porque à medida que o aumento da quantidade de grafeno no ressoador passa a representar um aumento significativo das perdas intrínsecas do dispositivo, isto diminui a transmissão máxima do modulador em seu estado ligado. Por fim, as investigações feitas por meio da evolução destas curvas nos permitem concluir que:

1. A redução da distância é vantajosa para o aumento do acoplamento do dispositivo, pois obedece a uma razão de inversa de proporcionalidade que mesmo para distâncias muito pequenas, não chega a seu ponto de saturação. Entretanto, ao se projetar um modulador, deve-se levar em consideração a dificuldade na fabricação de dispositivos com separação inferior a 100 nm, uma vez que seu controle passa a ser cada vez mais difícil [53];

2. Reduzir a largura $\mathrm{w}_{1}$ do barramento pode gerar ganhos na resposta do dispositivo, entretanto, há uma limitação neste procedimento, uma vez que a redução desta largura para um ressoador cujas dimensões de raio externo e interno são fixas diminui o casamento de fase entre os guias, que contribui para o efeito inverso. Para um ressoador de largura $\mathrm{W}=600 \mathrm{~nm}$, o acoplamento máximo para um barramento $\mathrm{w}_{1}=340 \mathrm{~nm}$;

3. Observa-se, por fim, que o aumento da quantidade de grafeno para o acoplamento crítico (devido ao aumento da energia acoplada ao ressoador) não se reflete obrigatoriamente em uma resposta mais eficiente em profundidade de modulação. Tendo em vista que, aumentando a fração de energia acoplada, diminui-se o coeficiente t, o que suaviza a variação da curva de transmissão em função de $\alpha$. Esta curva, mudança gera uma degradação ou saturação sua performance em profundidade de modulação. Para a geometria estudada neste trabalho, a saturação ocorre para uma secção angular de grafeno de entre 75 a 100 graus. 


\section{c) Análise e Comparação das Figuras de Mérito do Modulador Otimizado}

Ao final, obteve-se como geometria otimizada para este dispositivo um modulador de $\mathrm{w}_{1}=340 \mathrm{~nm}, \mathrm{~g}=100 \mathrm{~nm}$ e $\mathrm{W}=600 \mathrm{~nm}$ e a região de grafeno, para o ressoador em seu acoplamento crítico, equivalente a uma região angular de $75^{\circ}$, e foi plotada na Figura 16 (a) as curvas de transmissão do dispositivo em seu estado desligado $\left(\mu_{\mathrm{c}}=0,3 \mathrm{eV}\right)$ e ligado $\left(\mu_{\mathrm{c}}=0,5 \mathrm{eV}\right) \mathrm{o}$ como ilustração gráfica da profundidade de modulação deste dispositivo.

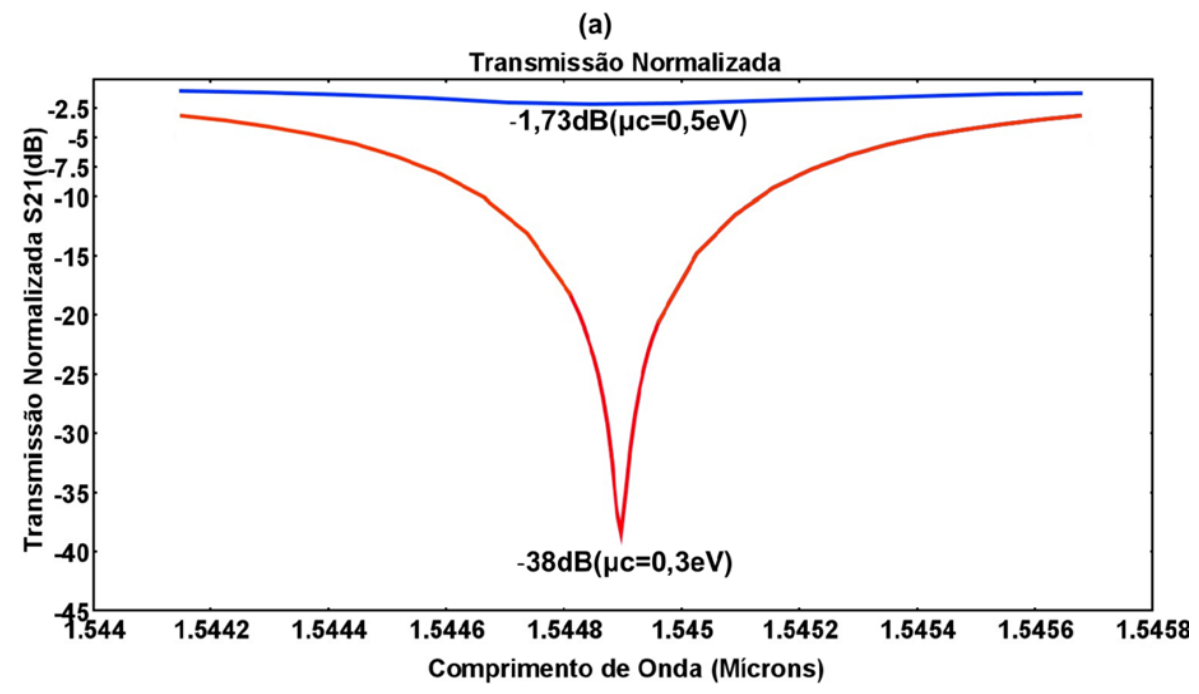

(b)

\begin{tabular}{|c|c|}
\hline Figuras de Mérito & Resultados \\
\hline Largura de Banda -3dB (nm) & 1,41 \\
\hline $\begin{array}{c}\text { Consumo de Potência } \\
\text { (fJ/bit) }\end{array}$ & 26 \\
\hline $\begin{array}{c}\text { Tensão de Variação } \\
\text { Ligado/Desligado (V) }\end{array}$ & 0,9(Desligado) e 2,6(Ligado) \\
\hline Footprint ( $\mathbf{m m}^{\mathbf{2}}$ ) & 25 \\
\hline FSR (nm) & 40 \\
\hline
\end{tabular}

Figura 16 - (a) Curvas de Transmissão para o modulador em seu estado ligado $(\mu=0,5 \mathrm{eV})$ e desligado $(\mu=0,3 \mathrm{eV}) \mathrm{em}$ função do comprimento de onda; (b) Figuras de mérito do modulador.

Fonte: Autor.

A partir destes parâmetros, é possível obter outras figuras de mérito importantes deste modulador, mostradas na tabela da Figura 16 (b), como seu consumo de potência (obtida por meio 
da equação 2.13, considerando a área do capacitor como a região do ressoador contendo grafeno), tensão de variação entre os estados ligado/desligado (equação 2.12), largura de banda (segundo a definição de $\Delta \lambda_{F W H M}$ ) e seu FSR (calculado pela diferença espectral entre o modo azimutal $\mathrm{m}=25$ e $\mathrm{m}=24)$, características que permitem inferir as qualidades do dispositivo como uma tecnologia de modulação eficiente.

Avaliando os valores obtidos para este dispositivo é possível observar que, com os ajustes de otimização feitos, obteve-se um modulador com grande eficiência em termos de consumo de potência e tensão de chaveamento, preservando em patamares razoáveis sua profundidade de modulação e largura de banda, permitindo uma operação eficiente como modulador de alta velocidade. Adicionalmente, sua dimensão reduzida garante FSR bastante largo ao modulador, que também é importante para a maior alocação de canais de modulação, aumentando a taxa agregada de transmissão.

\section{d) A Influência da Largura do Ressoador na Resposta do Dispositivo}

Uma vez definida a configuração padrão deste dispositivo, é importante que se faça uma avaliação quantitativa de como varia o seu desempenho à medida que se aumenta o raio interno do anel até o ponto em que o barramento e o ressoador passam a ter larguras similares, obtendo-se, portanto, o melhor casamento de fase. Como explicado anteriormente, a escolha de um ressoador de maior largura foi feita no sentido de minimizar as perdas e, com isso, ter um dispositivo mais eficiente em profundidade de modulação.

Para os ressoadores simulados, buscou-se manter a mínima variação espectral entre as ressonâncias, a fim de obter resultados que sofressem influências pouco significativas em relação a esta variável. Para isso, buscou-se ajustar as ressonâncias para valores próximos ao do ressoador de maior largura $(600 \mathrm{~nm})$, sem alterar, inicialmente, o raio externo do dispositivo $(2,58 \mu \mathrm{m})$. Entretanto, para o caso de um ressoador de largura $\mathrm{W}=500 \mathrm{~nm}$ com essa dimensão de raio externo, os dois modos azimutais mais próximos estão localizados para comprimentos de onda de $1518,3 \mathrm{~nm}(\mathrm{~m}=24)$ e $1556,7(\mathrm{~m}=25)$.

Uma vez que, para este raio externo, a variação da resposta espectral da largura de banda para um ressoador considerando a banda $\mathrm{C}$ é significativamente maior que pequenas variações em seu raio (variações de $0,1 \mu \mathrm{m}$ ) [20], [47], [53], optou-se por reduzir o raio externo deste ressoador, reajustando a ressonância do modo $\mathrm{m}=25$ para 1533,7 nm, considerando agora 
um raio externo de 2,52 $\mu \mathrm{m}$. Para os demais moduladores, manteve-se o mesmo raio externo da simulação para largura $\mathrm{W}=600 \mathrm{~nm}$, ou seja, $2,58 \mu \mathrm{m}$.

Na Tabela 1 estão especificados, para cada largura de ressoador considerada, os comprimentos de onda de ressonância, os potenciais químicos para os moduladores no modo ligado e desligado, e o mínimo de transmissão, em dB, para o modulador na condição mais próxima ao acoplamento crítico obtidas pelas simulações, cujos passos foram definidos na secção anterior. Como pode ser observado também neste caso, foram escolhidos potenciais químicos ligeiramente diferentes, para que representassem o mesmo coeficiente de perdas associado ao grafeno, tomando como base as perdas equivalentes aos potenciais químicos do modulador de maior largura.

Tabela 1 - Parâmetros dos ressoadores simulados em função da largura.

\begin{tabular}{|cccccc|}
\multicolumn{7}{c|}{ Parâmetros dos Ressoadores } \\
\\
\hline Largura W (nm) & 600 & 550 & 550 & 450 & 400 \\
\hline Ressonância (nm) & 1544,85 & 1534,2 & 1533,7 & 1533,2 & 1534,25 \\
\hline $\boldsymbol{\mu c}$ desligado (eV) & 0,3 & 0,3 & 0,3 & 0,3 & 0,3 \\
\hline $\boldsymbol{\mu c}$ ligado (eV) & 0,5 & 0,5024 & 0,503 & 0,5034 & 0,5034 \\
\hline $\begin{array}{c}\text { Min. Transmissão } \\
\text { Desligado (dB) }\end{array}$ & -40 & -40 & -45 & -65 & -36 \\
\hline Raio Externo $(\boldsymbol{\mu m})$ & 2,58 & 2,58 & 2,52 & 2,58 & 2,58 \\
\hline
\end{tabular}

Por fim, foram analisadas as evoluções dos parâmetros de distância de separação do barramento ao ressoador ( $\mathrm{gap}$ ), seção angular contendo grafeno, o mínimo de ressonância para o modulador ligado, e a largura a banda, FSR e o consumo de potência do modulador com a variação de seu raio externo, como apresentado na Figura 17, Figura 18, Figura 19, Figura 20, Figura 21. A largura do barramento $\mathrm{w}$ utilizada nestas simulações foi de $340 \mathrm{~nm}$, a mesma obtida para o modulador otimizado nos procedimentos 1 e 2 . A evolução das curvas nos mostra que:

1. A região angular de grafeno no ressoador para o acoplamento crítico aumenta à medida que se reduz a largura do guia. Isto ocorre devido ao melhor casamento de fase entre o ressoador e o barramento e pelo o aumento das perdas por curvatura, que para estes valores de separação não são da mesma ordem de grandeza do grafeno para um potencial químico ajustado a $0,3 \mathrm{eV}$. A evolução da largura de banda do ressoador, por ser uma figura dependente das perdas totais do dispositivo, 
acompanha a variação da curva anteriormente citada;

2. Apesar do aumento da região angular de grafeno, não se observou ganhos significativos em termos de profundidade de modulação, que permaneceram nos mesmos patamares entre larguras entre 600 a $450 \mathrm{~nm}$, sofrendo degradações significativamente maiores quando $\mathrm{W}=400 \mathrm{~nm}$. Isto sugere que os ganhos em melhor acoplamento não foram capazes de compensar os efeitos negativos provocados pelo aumento das perdas por curvatura com a redução da largura do ressoador;

3. Com o aumento da quantidade de grafeno para o acoplamento crítico (melhor casamento de fase entre o barramento e o ressoador), aumenta-se também o consumo de potência de modulação para ressoadores de menor largura, uma vez que este cálculo depende da área ativa do modulador (região contendo grafeno). Logo, além de degradar a resposta em profundidade de modulação, reduzir a largura do ressoador é energeticamente desfavorável ao dispositivo;

4. A redução da largura do ressoador é responsável pela diminuição do confinamento modal, que resulta na redução do seu índice efetivo (e, neste caso, também no índice de grupo). Portanto, como esperado (baseado na equação 3.2), observa-se uma redução do FSR, representando mais uma desvantagem para estes dispositivos em se adotar ressoadores de menor largura.

Pode-se concluir, para esta configuração de modulador, que utilizar ressoadores de maior largura foi vantajosa, pois muito embora eles representem uma redução acoplamento de energia entre o guia e o ressoador (reduzindo a região angular de grafeno sintonizada ao acoplamento crítico), este efeito é compensado pela redução das perdas por curvatura em relação aos ressoadores de menor largura, permitindo um dispositivo mais eficiente em termos de resposta em profundidade de modulação, para um menor consumo de potência e FSR mais largo. 


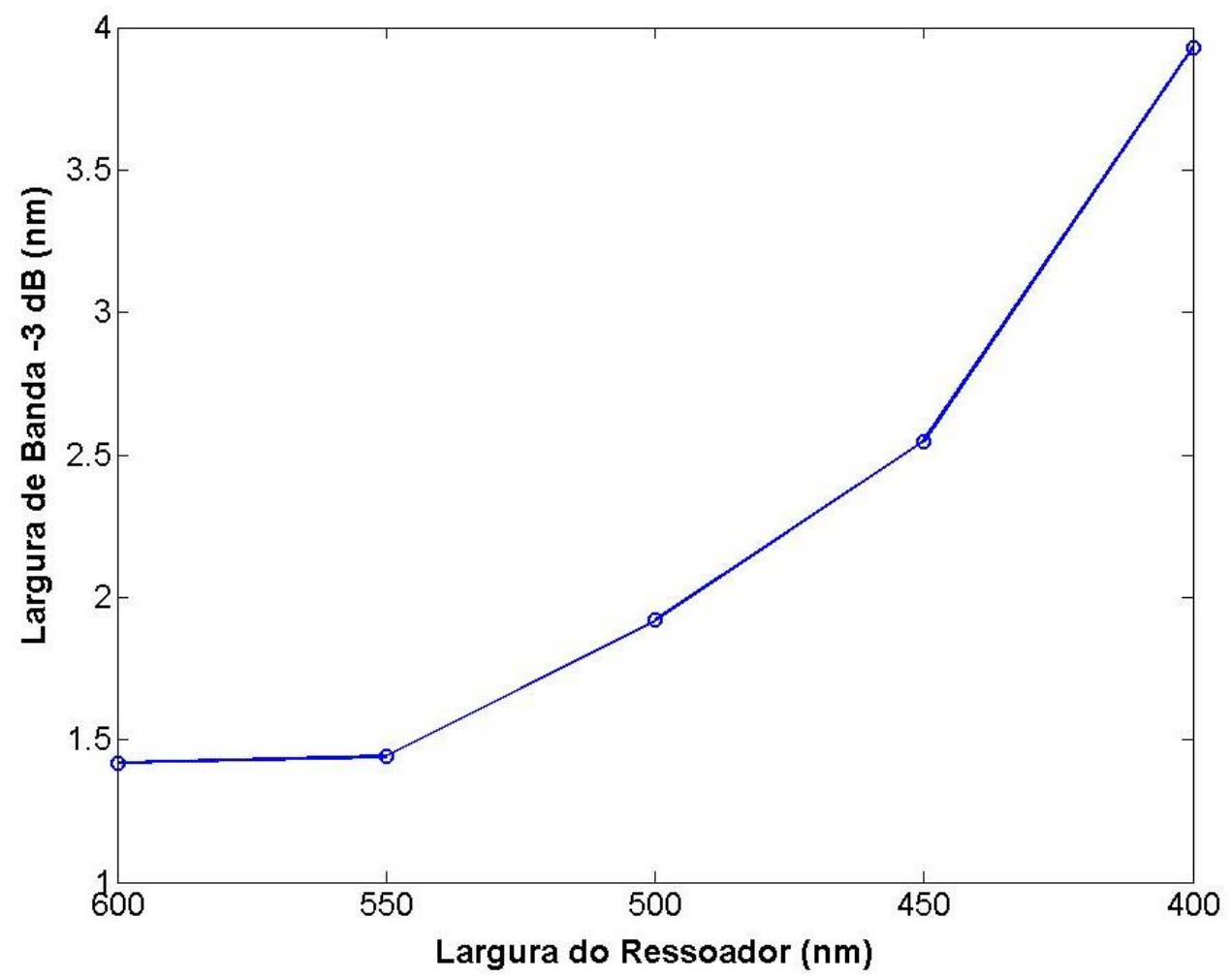

Figura 17 - Largura de banda do modulador para o desligado $(\mu=0,3 \mathrm{eV})$ em função de W. Fonte: Autor.

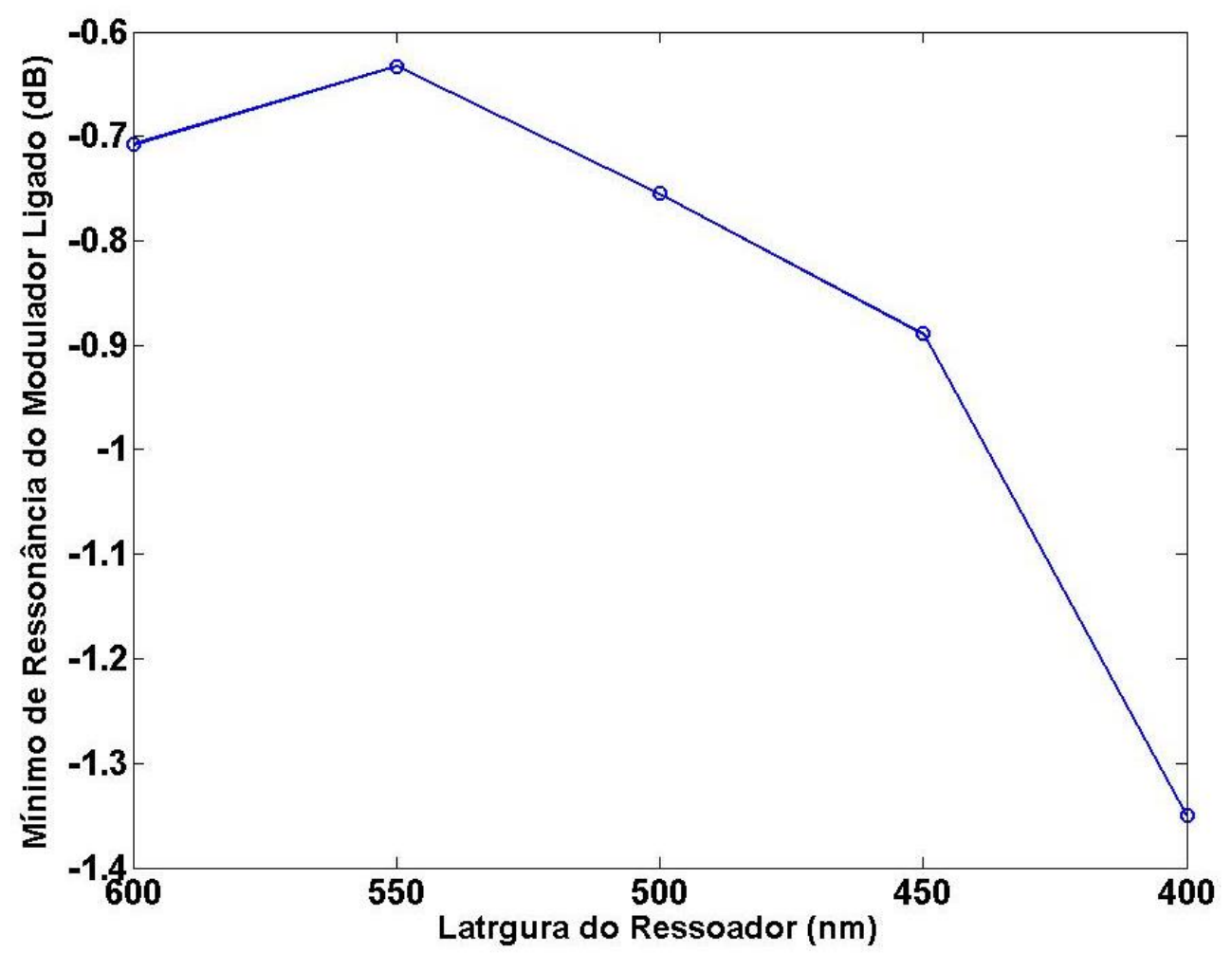

Figura 18 - Mínimo de transmissão S21 para o modulador ligado $(\mu=0,5 \mathrm{eV})$ em função de W. Fonte: Autor. 


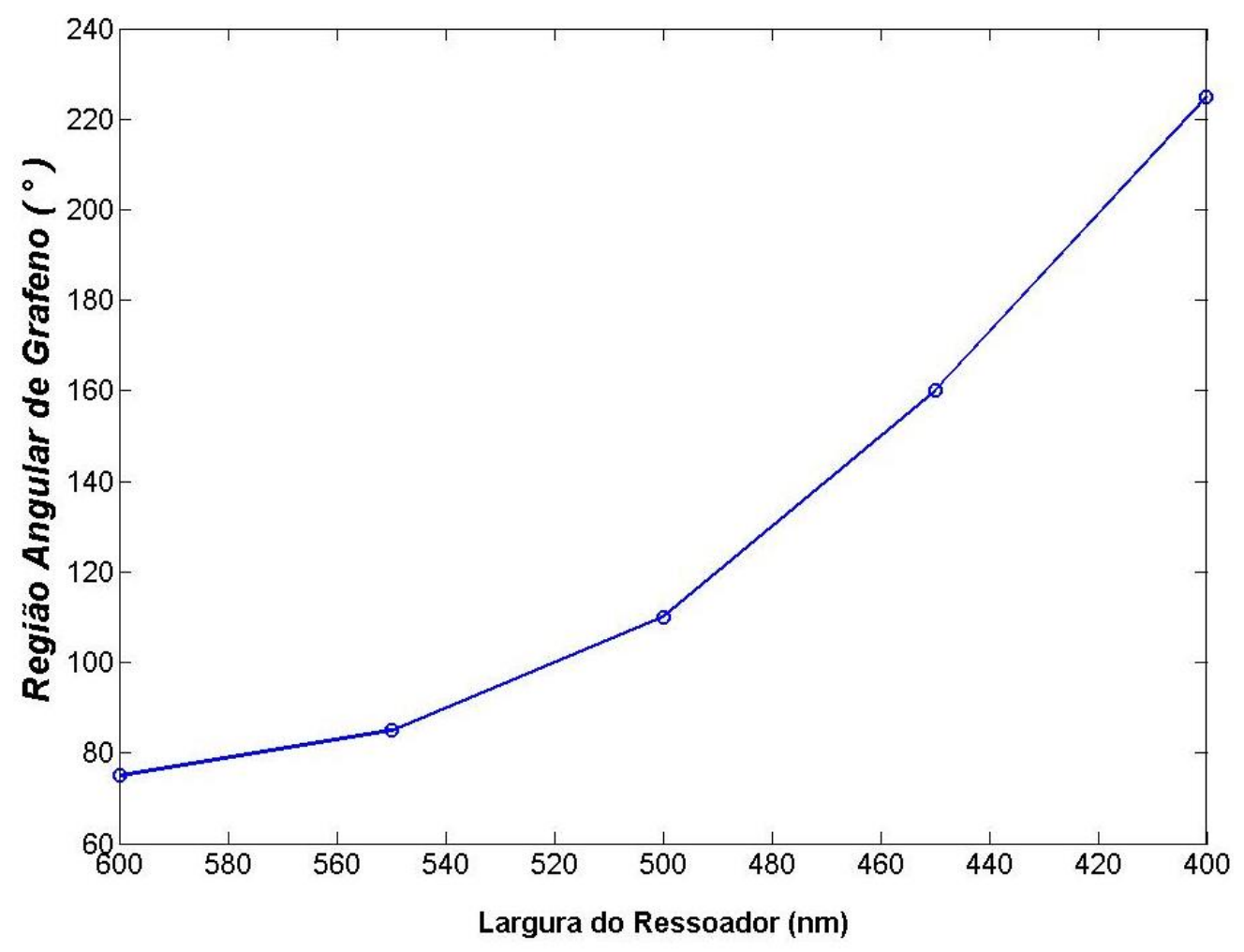

Figura 19 - Secção angular contendo grafeno em função de W.

Fonte: Autor.

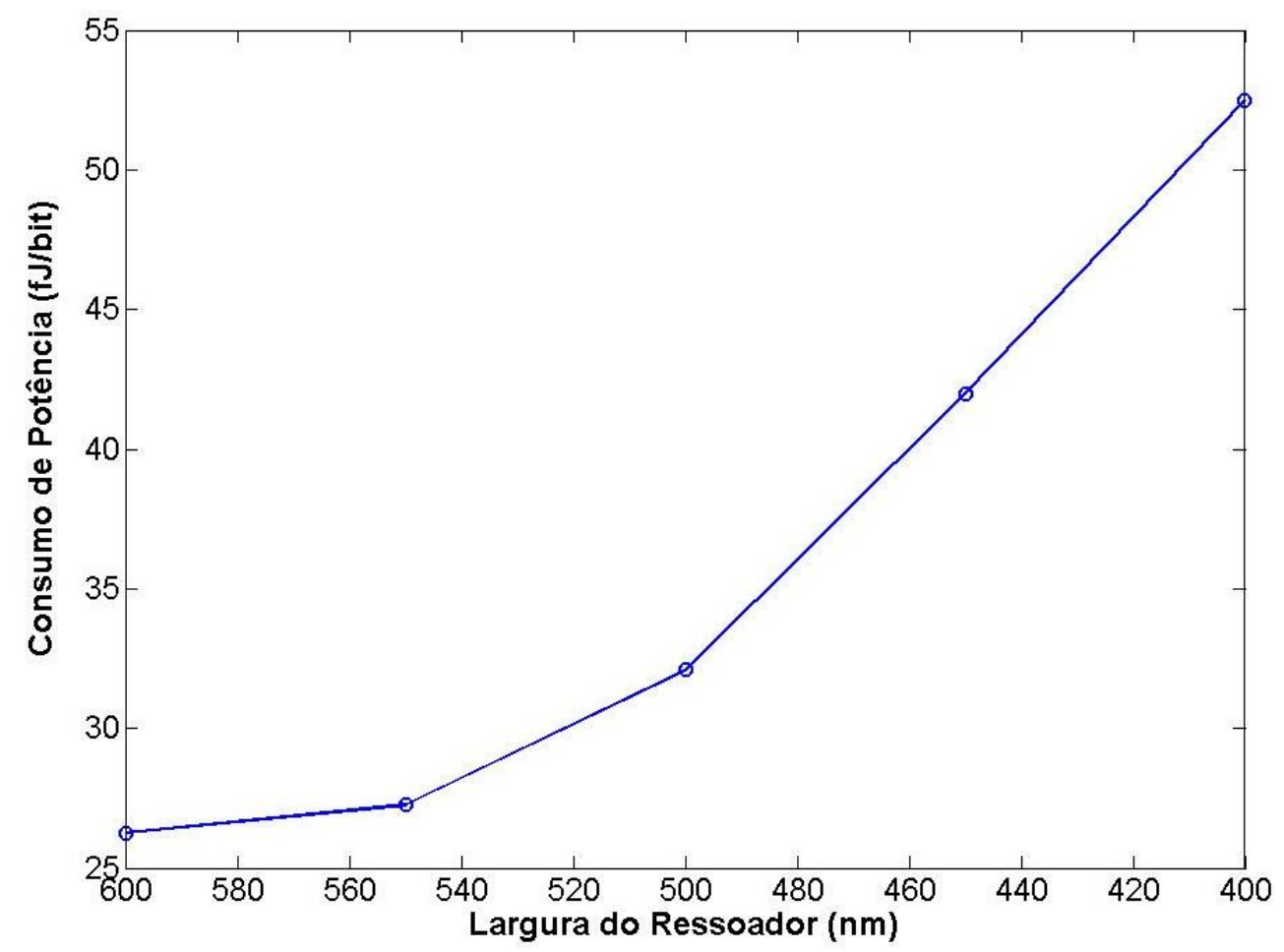

Figura 20 - Consumo de potência por bit em função da largura W do ressoador.

Fonte: Autor. 


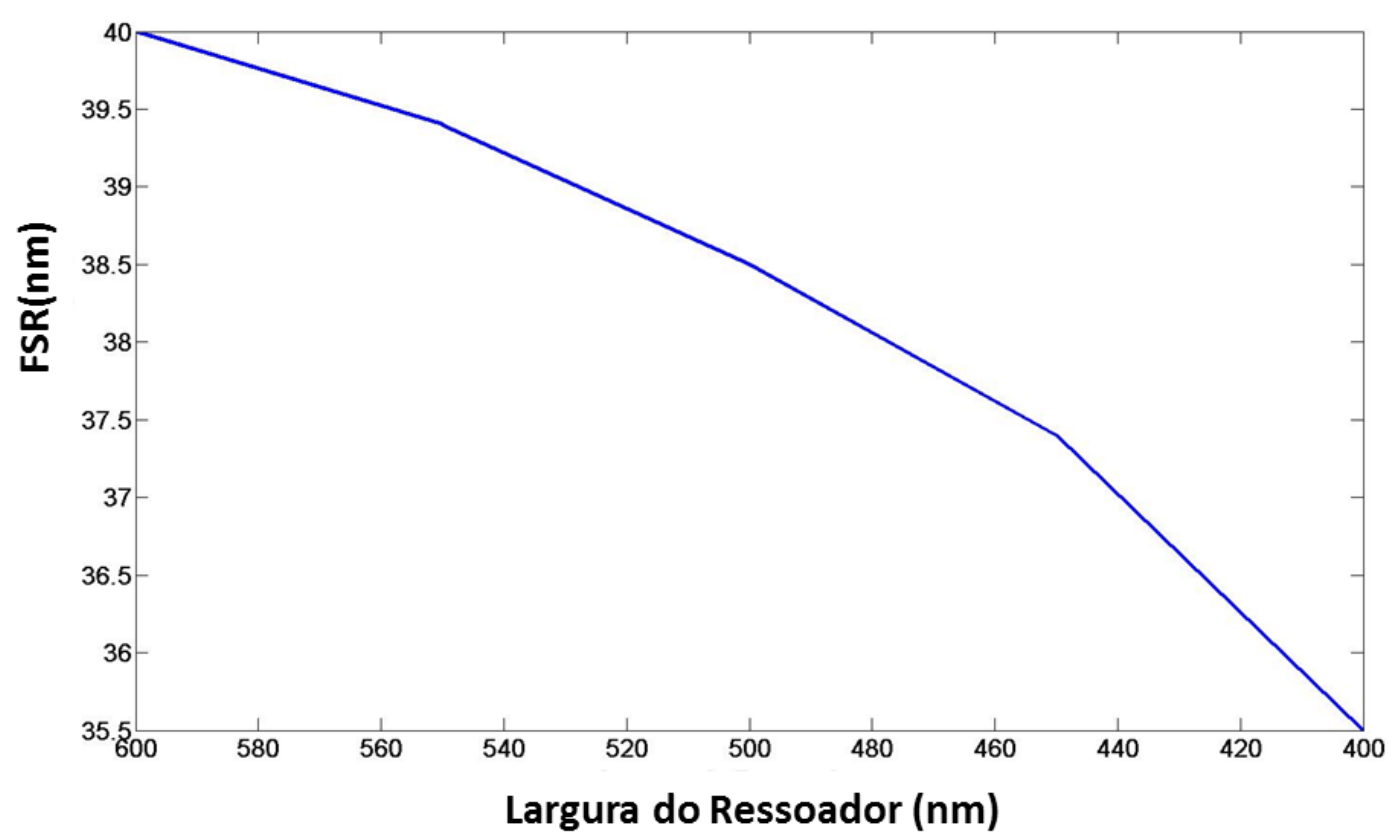

Figura 21 - FSR em função da largura W do ressoador.

Fonte: Autor

\subsection{Acoplamento Crítico Ajustado para um Potencial Químico de 0,5 eV}

Para esta configuração de modulador, foi proposta uma adaptação ao trabalho anterior, modificando a condição de acoplamento crítico para um potencial químico de $0,5 \mathrm{eV}$, correspondendo ao valor de menor condutividade ótica do grafeno na região de transição desta curva, enquanto o modulador ligado agora corresponde à um potencial químico de $0,3 \mathrm{eV}$.

Com esta mudança, busca-se alterar o perfil da curva de transmissão do modulador investigando-se, no processo de sintonização inversa (ao diminuir as perdas intrínsecas de grafeno associadas para a condição de acoplamento crítico), quais os ganhos de performance que este dispositivo apresenta, especialmente quanto a profundidade de modulação. Portanto, para maximizar a eficiência deste modulador, deve-se buscar, na otimização da estrutura, dois importantes caminhos: 


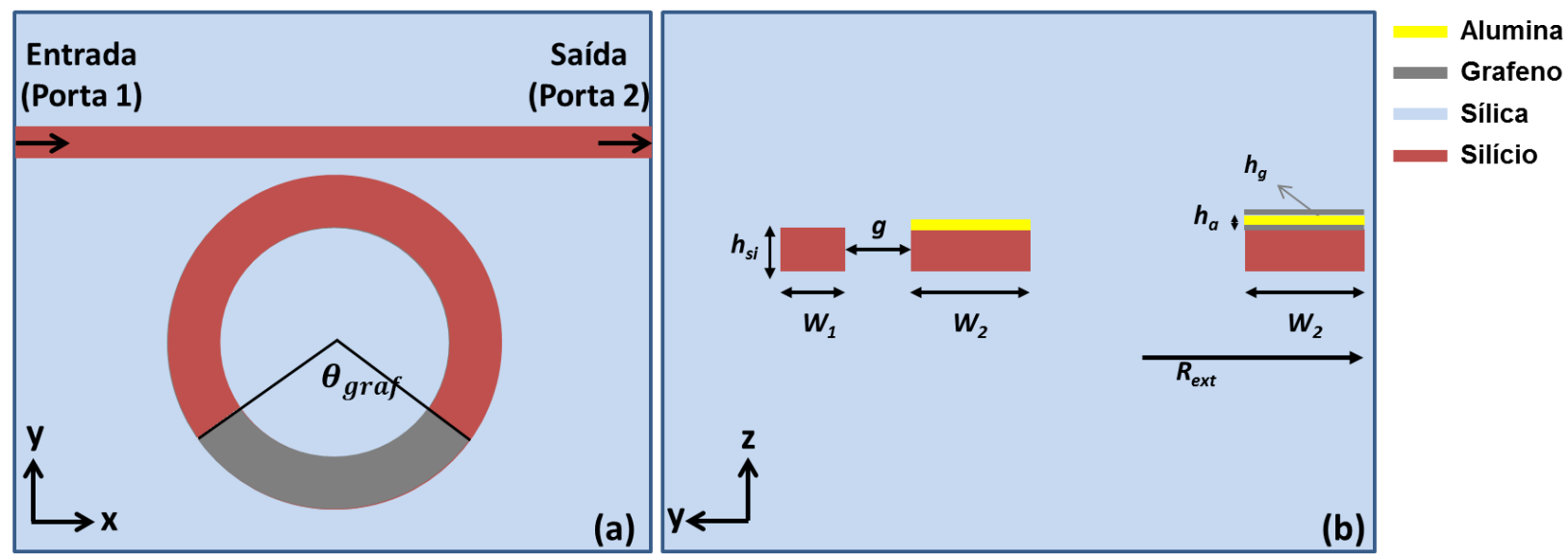

Figura 22 - Vista frontal (a) e lateral (b) do modulador.

Fonte: Autor.

\section{a) Redução das perdas por curvatura do ressoador}

A estrutura estudada possui dois fatores que contribuem de forma significativa para as perdas globais, que são a absorção óptica do grafeno e a curvatura do ressoador. Ao ajustar o grafeno na condição de acoplamento crítico para uma condutividade óptica equivalente a um potencial químico de $0,5 \mathrm{eV}$, a contribuição deste material nas perdas totais passa a ser menos significativa, aumentando-se, proporcionalmente, a contribuição causada pela curvatura do ressoador, considerando o raio externo adotado neste trabalho. Por isso, a redução das perdas por curvatura do ressoador tem um papel bastante preponderante, e assim como no primeiro caso, ela são obtidas considerando ressoador de larguras maiores, definindo-se também como largura máxima $\mathrm{W}=600 \mathrm{~nm}$ usando-se os mesmos critérios adotados no primeiro dispositivo.

\section{b) Definição da largura ótima do barramento $\left(w_{1}\right)$ e secção angular de grafeno no ressoador}

Nesta etapa de otimização, investigou-se, por meio de variações da secção angular do ressoador contendo grafeno, a evolução da profundidade de modulação, da distância de separação entre o barramento e ressoador e o fator de qualidade, considerando como parâmetro a largura do barramento para $\mathrm{w}_{1}=340,370$ e $400 \mathrm{~nm}$. Os resultados, ilustrados nos gráficos da Figura 23, Figura 24 e Figura 25, mostram que:

1. Para todos os valores de w1 considerados, há uma melhora na resposta do dispositivo em termos de profundidade de modulação quanto maior for a região angular de grafeno 
cobrindo o ressoador. Logo, além das vantagens do ponto de vista de fabricação (pois o controle da quantidade é mais fácil, diminuindo as imprecisões na fabricação), nesta configuração é a mais eficiente em termos de profundidade de modulação. Pelo mesmo gráfico, é bastante evidente que barramentos de diferentes larguras w1 não alteram a resposta do modulador para esta figura de mérito;

2. Observa-se uma evolução linear da largura de banda do ressoador à medida que se aumenta a quantidade de grafeno, sendo de $0,9 \mathrm{~m}$ para um ressoador de silício puro, para 0,22nm quando todo o dispositivo está coberto com grafeno. Mais uma vez, este resultado não é significativamente alterado quando consideradas diferentes larguras de barramento.

3. A evolução gráfica mostra que há um decrescimento aproximadamente linear do gap (para o modulador em seu acoplamento crítico) quanto maior a quantidade de grafeno. $\mathrm{O}$ resultado era esperado pois, ao adicionarmos perdas ao grafeno (diminuindo o $\alpha$ ), a nova configuração de acoplamento critico será obtida para um acoplamento maior (diminuindo o coeficiente t), que neste caso é obtido para um gap menor (quando os outros parâmetros geométricos do dispositivos forem fixos). Para o caso das curvas considerando diferentes larguras de barramento, observa-se um maior gap para valores iguais de grafeno, à medida que se reduz sua largura. Este efeito é explicado pelo aumento da fração de energia acoplada para larguras menores, como já havia sido observado no estudo do primeiro dispositivo de modulação.

Com isso, é possível concluir, que:

1. A largura $\mathrm{w}_{1}$ do barramento não causa variações significativas na largura de banda do modulador e, por isso, não altera a resposta da profundidade de modulação. Isso ocorre porque para o dispositivo ajustado ao acoplamento crítico, esta figura está relacionada às perdas intrínsecas do ressoador, que permanecem as mesmas com esta variação. Entretanto, como a largura do barramento altera a constante de acoplamento, a distância de separação para o acoplamento crítico para este intervalo de variações de $\mathrm{w}_{1}$. Considerando, portanto, que separações maiores são mais fáceis de fabricar, define-se $\mathrm{w}_{1}=340 \mathrm{~nm}$ como sendo a largura otimizada para o barramento; 
2. O dispositivo é mais eficiente em termos de profundidade de modulação quanto maior for a região angular de grafeno no ressoador. Além disso, uma vez que a taxa de modulação máxima é dependente da largura de banda do ressoador que, por sua vez, é diretamente proporcional às perdas do dispositivo, este aumento da região de grafeno é duplamente benéfico. Além disso, este dispositivo é mais fácil de fabricar e controlar, pois ao se delimitar uma secção angular da região ativa, pequenas imprecisões na fabricação podem deslocar a condição de acoplamento crítico, o que, por sua vez, é um fator que compromete negativamente o desempenho do dispositivo;

3. Dentre as desvantagens em se trabalhar com um modulador de maior área ativa (representada pela região de grafeno no ressoador) é seu maior consumo de potência. Entretanto, é possível compensar esse aumento com a redução na camada do material dielétrico, já que, segundo a equação 2.13, ela é diretamente proporcional a esta variável.

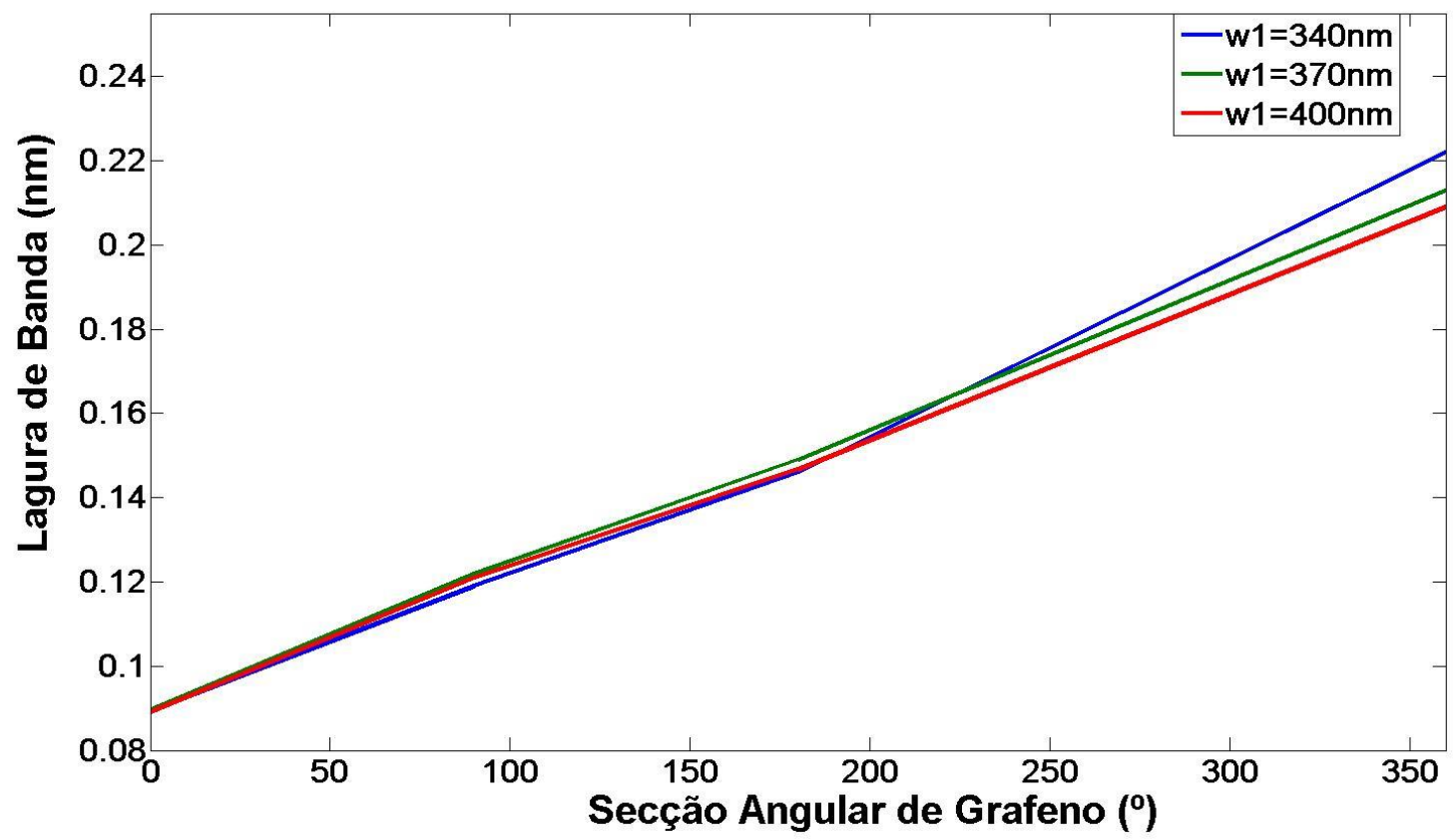

Figura 23 - Largura de banda do modulador ligado em função da secção angular de grafeno no ressoador, parametrizado para barramentos de larguras $\mathrm{w} 1=340,370$ e $400 \mathrm{~nm}$.

Fonte: Autor. 


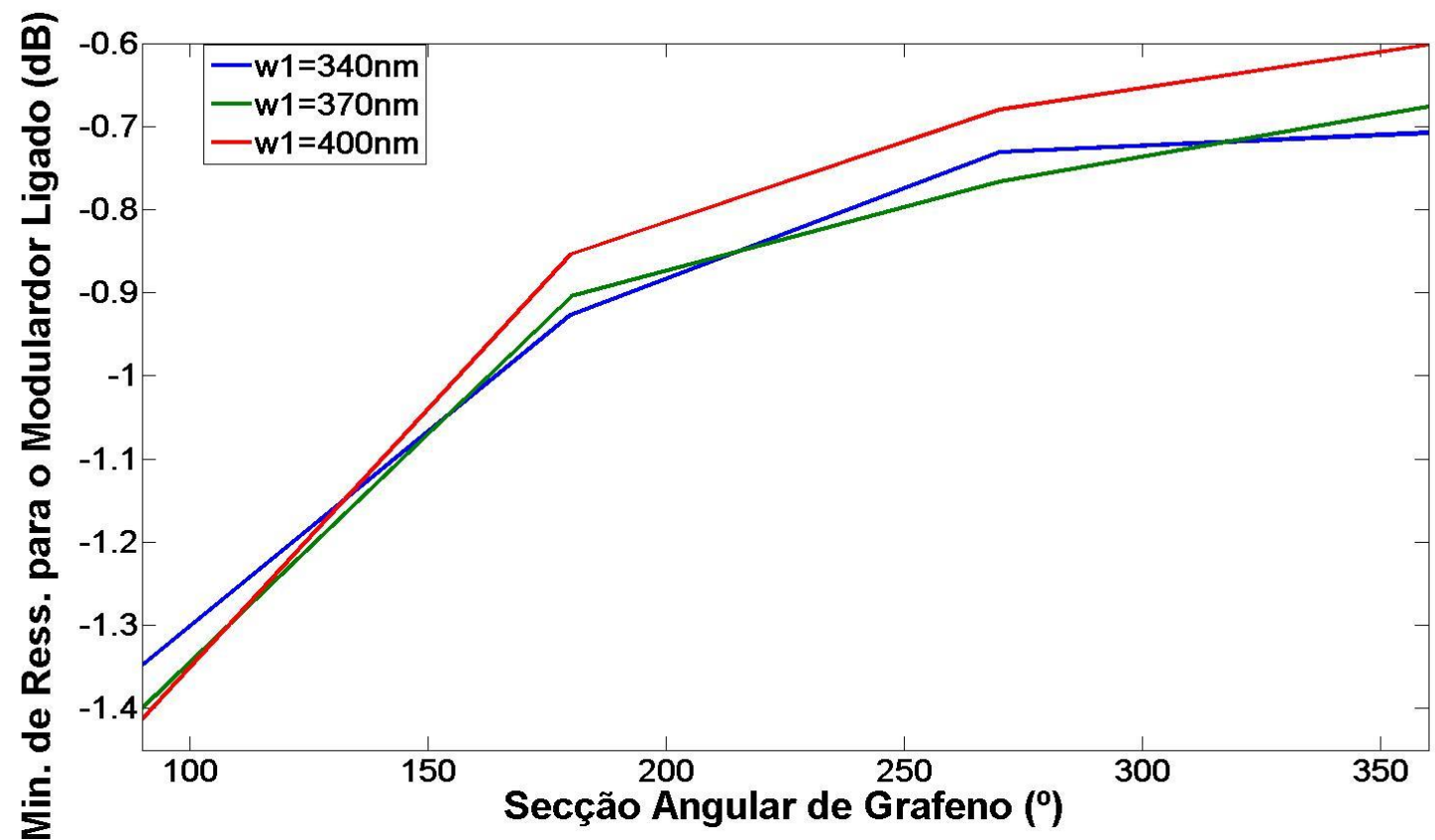

Figura 24 - Mínimo de ressonância do modulador ligado em função da secção angular de grafeno no ressoador, parametrizado para barramentos de larguras w1 $=340,370$ e $400 \mathrm{~nm}$.

Fonte: Autor.

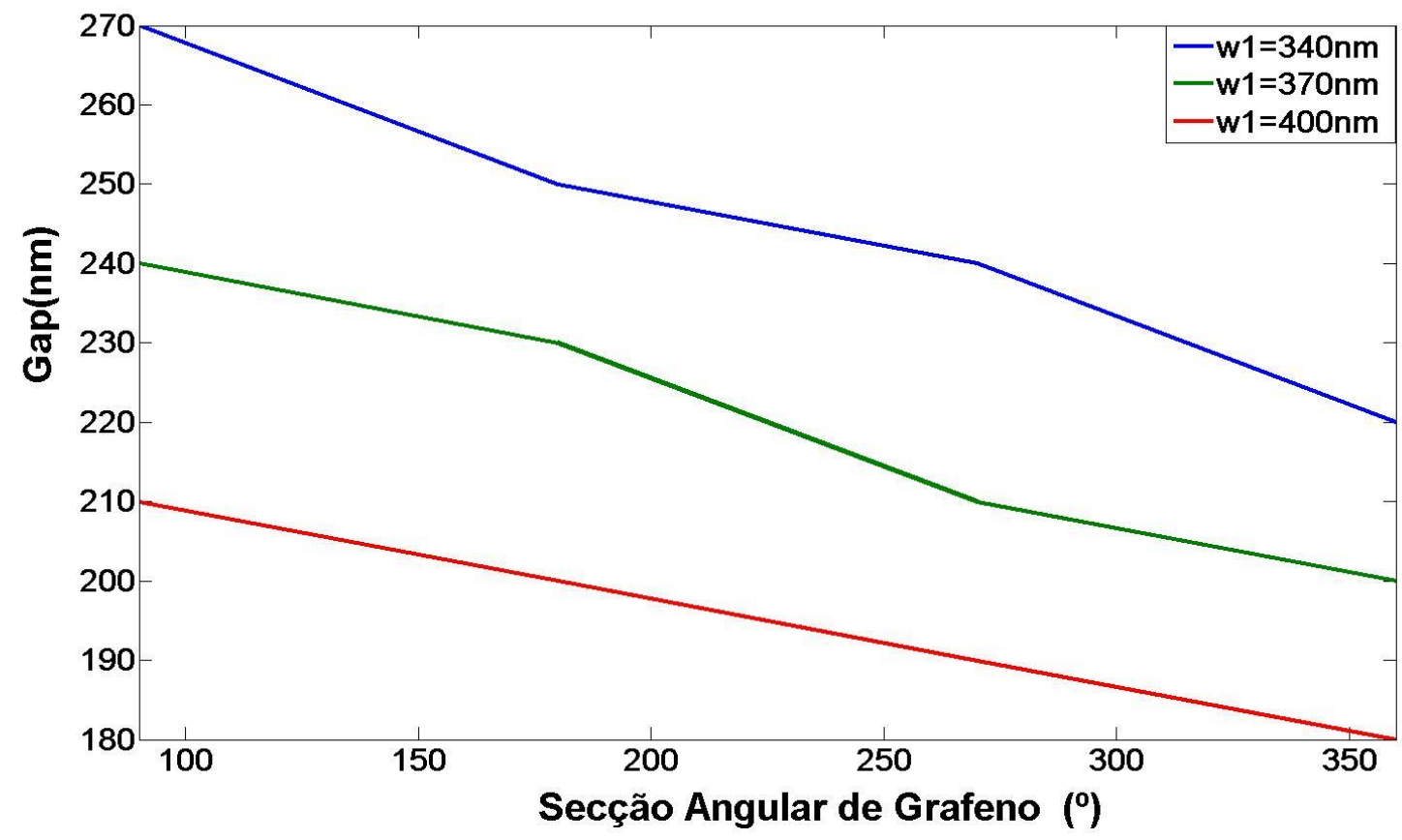

Figura 25 - Distância de separação entre o barramento e ressoador em função secção angular de grafeno no ressoador, parametrizado para barramentos para larguras de $\mathrm{w} 1=340,370$ e $400 \mathrm{~nm}$.

Fonte: Autor. 


\section{c) Análise das Figuras de Mérito do Modulador Otimizado}

Por fim, sendo o objetivo obter um modulador de melhor resposta em termos de profundidade de modulação, maior largura de banda, e que para estas características pudesse ser fabricado com a maior distância de separação possível, obteve-se como figuras otimizadas, um ressoador de largura $\mathrm{W}=600 \mathrm{~nm}$, com toda sua parte superior coberta por grafeno e um barramento de largura $\mathrm{w}_{1}=340 \mathrm{~nm}$.

A partir das figuras de mérito deste modulador (profundidade de modulação, largura de banda, consumo de potência e tensão de chaveamento), é possível observar um modulador com excepcional resposta em profundidade de modulação, como mostrado na Figura 26 (a), sendo bastante superior a obtida pela primeira estrutura investigada. Isso permite a obtenção de um dispositivo capaz de sofrer maiores reduções em seu raio e ainda manter um patamar adequado desta figura de mérito sendo, portanto, uma configuração mais adequada para ressoadores com maior potencial de miniaturização.

Por outro lado, tendo em vista que este dispositivo é ajustado para menores perdas intrínsecas, e sua maior eficiência em profundidade de modulação depende de uma maximização da área de grafeno do ressoador. Portanto, tem-se uma configuração que é responsável por uma configuração de modulador com maior consumo de potência e uma largura de banda mais estreita, como mostrado na tabela da Figura 26 (b), que é um fator que limita a máxima taxa de modulação do dispositivo (muito embora uma largura de banda de 0,22 $\mathrm{nm}$ seja capaz de suportar taxas de modulação relativamente altas para os atuais padrões tecnológicos [11]).

Por fim, é importante ressaltar que esta configuração, do ponto de vista de fabricação, é vantajosa em relação à primeira por dois importantes motivos. Em primeiro lugar, uma vez que o ajuste do acoplamento crítico é feito para um potencial químico com menores perdas ópticas do grafeno, é possível estabelecer distâncias de separação maiores, que são fáceis de fabricar e controlar. Isto, por sua vez, não ocorre no caso do primeiro modulador, uma vez que para um desempenho satisfatório, é necessária uma separação muito pequena, que do ponto de vista prático torna-se bastante difícil sua fabricação. Como segundo motivo, está a adoção de um modulador de configuração para a qual toda região superior do ressoador é coberta por grafeno. Isto garante um dispositivo de estrutura padrão mais simples e menos afetado pela possibilidade de erro na fabricação quanto a região de grafeno do guia, obtendo-se, por consequência, um modulador de fabricação mais precisa. 
(a)

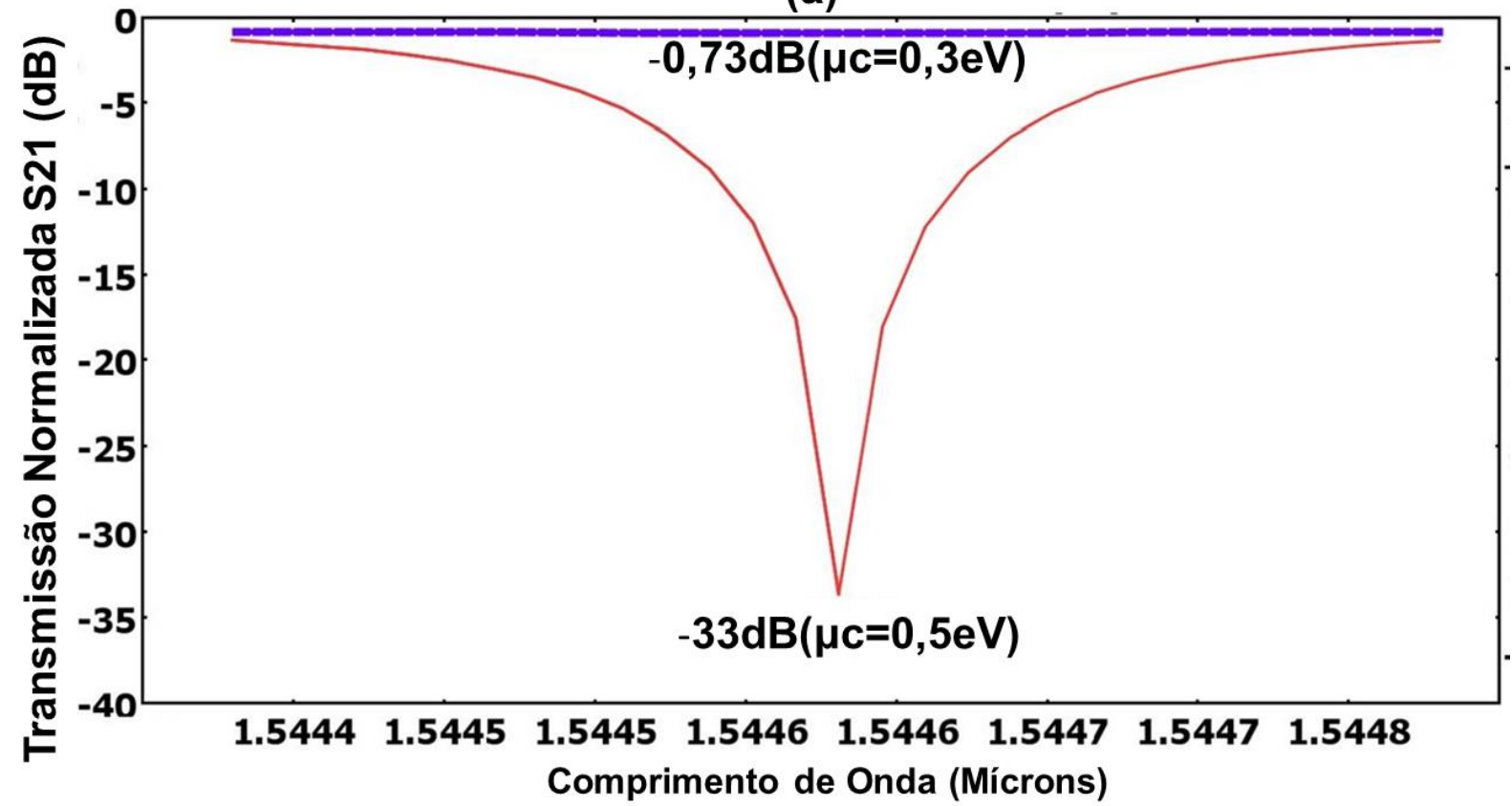

(b)

\begin{tabular}{|c|c|}
\hline Figuras de mérito & Resultados \\
\hline Largura de banda $(\mathrm{nm})$ & 0,22 \\
\hline Consumo de Potência (fJ/bit) & 126 \\
\hline Tensão de Chaveamento(V) & 0,9 (desligado) e 2,6(ligado) \\
\hline Footprint $\left(\mu \mathrm{m}^{2}\right)$ & 25 \\
\hline FSR $(\mathrm{nm})$ & 40 \\
\hline
\end{tabular}

Figura 26 - (a) Perfil de transmissão S21 do modulador ligado $(\mu=0,3 \mathrm{eV})$ e desligado $(\mu=0,5 \mathrm{eV})$; (b) Figuras de mérito do modulador em termos de footprint, largura de banda, tensão de chaveamento e consumo de potência por bit. Fonte: Autor.

d) Análise da Influência da Largura do Ressoador no Desempenho do Dispositivo

A análise da evolução qualitativa das figuras de mérito do modulador em função da variação da largura seguiu os mesmos procedimentos adotados para a primeira estrutura, em se tratando de ajustes no comprimento de onda de ressonância, largura $\mathrm{w}_{1}$ do barramento, dos potencias químicos dos moduladores no estados ligado e desligado e raios externos adotados para cada ressoador, mostrados na Tabela 2. 
Tabela 2 - Parâmetros dos ressoadores simulados em função da largura.

\begin{tabular}{|lccccc|}
\hline \multicolumn{7}{c}{ Parâmetros do Ressoadores } & & \\
Largura W(nm) & 600 & 550 & 550 & 450 & 400 \\
\hline Ressonância (nm) & 1544,6 & 1534 & 1533,45 & 1533 & 1534 \\
\hline $\boldsymbol{\mu c}$ desligado (eV) & 0,5 & 0,5024 & 0,503 & 0,5034 & 0,5034 \\
\hline $\boldsymbol{\mu c}$ ligado (eV) & 0,3 & 0,3 & 0,3 & 0,3 & 0,3 \\
\hline $\begin{array}{l}\text { Min. Transmissão } \\
\text { desligado (dB) }\end{array}$ & -36 & -32 & -35 & -39 & -35 \\
\hline Raio Externo ( $\boldsymbol{\mu m})$ & 2,58 & 2,58 & 2,52 & 2,58 & 2,58 \\
\hline
\end{tabular}

Fonte: Autor.

Feitas as considerações mencionadas, foram plotadas curvas de evolução do gap e largura de banda para o acoplamento crítico, o mínimo de ressonância para o modulador em seu estado ligado e o consumo de potência por bit do dispositivo. A curva do FSR, foi omitida nesta análise uma vez que os ressoadores dos dois moduladores possuem mesmas dimensões, apresentando, portanto, resultados aproximadamente iguais. Os resultados apresentados na Figura 27, Figura 28, Figura 29 e Figura 30 apontam que:

1. Em termos de mínimo de transmissão do modulador ligado, ilustrado na Figura 27, em que é possível avaliar a evolução da profundidade de modulação com a redução da largura do ressoador, observa-se uma alteração desprezível entre as larguras de $600 \mathrm{~nm}$ a $550 \mathrm{~nm}$. Para $\mathrm{W}=500 \mathrm{~nm}$, esta curva sofre uma inflexão e passa a crescer rapidamente, passando de $0,76 \mathrm{~dB}$ para um valor máximo de $-1,56 \mathrm{~dB}$, quando $\mathrm{W}=400 \mathrm{~nm}$. A degradação da resposta de profundidade de modulação é acompanhada pela curva da largura de banda do modulador, ilustrada na Figura 28, em que se observa o mesmo perfil de evolução, variando de 0,22 nm para 0,53 nm. Isto indica, como esperado, que o aumento das perdas intrínsecas por curvatura tem papel significativo na degradação da resposta deste dispositivo, especialmente para larguras inferiores a $550 \mathrm{~nm}$, para qual a taxa de variação das duas curvas passa a ser maior;

2. Na Figura 29, é ilustrada a evolução da distância de separação entre o barramento e o ressoador para a condição de acoplamento crítico. Pela evolução da curva, é possível avaliar a relação de preponderância dos ganhos em termos de aumento da fração de energia 
acoplada ao ressoador, devido ao melhor casamento de fase entre os guias, e as contribuições do aumento das perdas por curvatura. Observa-se um aumento crescente entre larguras de 600 a $500 \mathrm{~nm}$, até uma estabilização em $450 \mathrm{~nm}$ e um de crescimento a partir de $400 \mathrm{~nm}$. Portanto, se a construção de um dispositivo de modulação necessitar distâncias de separação maiores, este efeito deve ser considerado;

3. Por fim, na Figura 30 está ilustrada a evolução consumo de potência para variação de larguras do ressoador. Observa-se que, uma vez mantidas fixas a espessura do material dielétrico e aproximadamente constante os intervalos de variação dos potenciais químicos, esta variável torna-se exclusivamente dependente da região contendo grafeno que, neste caso, coincide com a área do ressoador. Portanto, entre 600 a $400 \mathrm{~nm}$, reduz-se o consumo de potência de 126 fJ/bit para 84 fJ/bit. Apesar da resposta em profundidade de modulação ser penalizada em relação ao ressoador de maior largura, que variou de $-0,7 \mathrm{~dB}$ para -1,56 dB, este é um desempenho ainda superior ao melhor obtido para a primeira configuração de modulador. Portanto, se considerada como tolerável a penalização do desempenho desta figura de mérito, obtêm-se um dispositivo mais eficiente não só por seu consumo de potência reduzido, mas também por sofrer menores limitações em relação à taxa de modulação máxima por sua largura de banda, que é aproximadamente 2,4 vezes maior que o ressoador com largura de $600 \mathrm{~nm}$. Isso, por sua vez, além de aumentar a taxa de modulação máxima que o dispositivo pode suportar, reduz a influência da temperatura na variação da ressonância, que causa gastos energéticos adicionais.

Por fim, esta análise nos permite concluir que adotar ressoadores de larguras maiores permite maximizar a eficiência do dispositivo em profundidade de modulação. Entretanto, esta configuração compromete outras figuras de mérito do modulador, como o consumo de potência por bit, largura de banda, além reduzir o gap de separação para a condição de acoplamento crítico.

Portanto, ao se projetar esta configuração de modulador, a largura de ressoador mais eficiente é obtida ao se fazer um balanço das perdas e ganhos para as diferentes figuras de mérito. Uma vez que seja tolerável a redução de sua profundidade de modulação e do FSR, a adoção de largura menores para o ressoador apresenta vantagens, pois oferece um dispositivo com menor gasto energético, maior potencial em operar a taxas de modulação mais rápidas (aumento da largura de banda) e, por apresentar um gap de separação maior para a condição de acoplamento crítico, torna-se um dispositivo de mais fácil fabricação. 


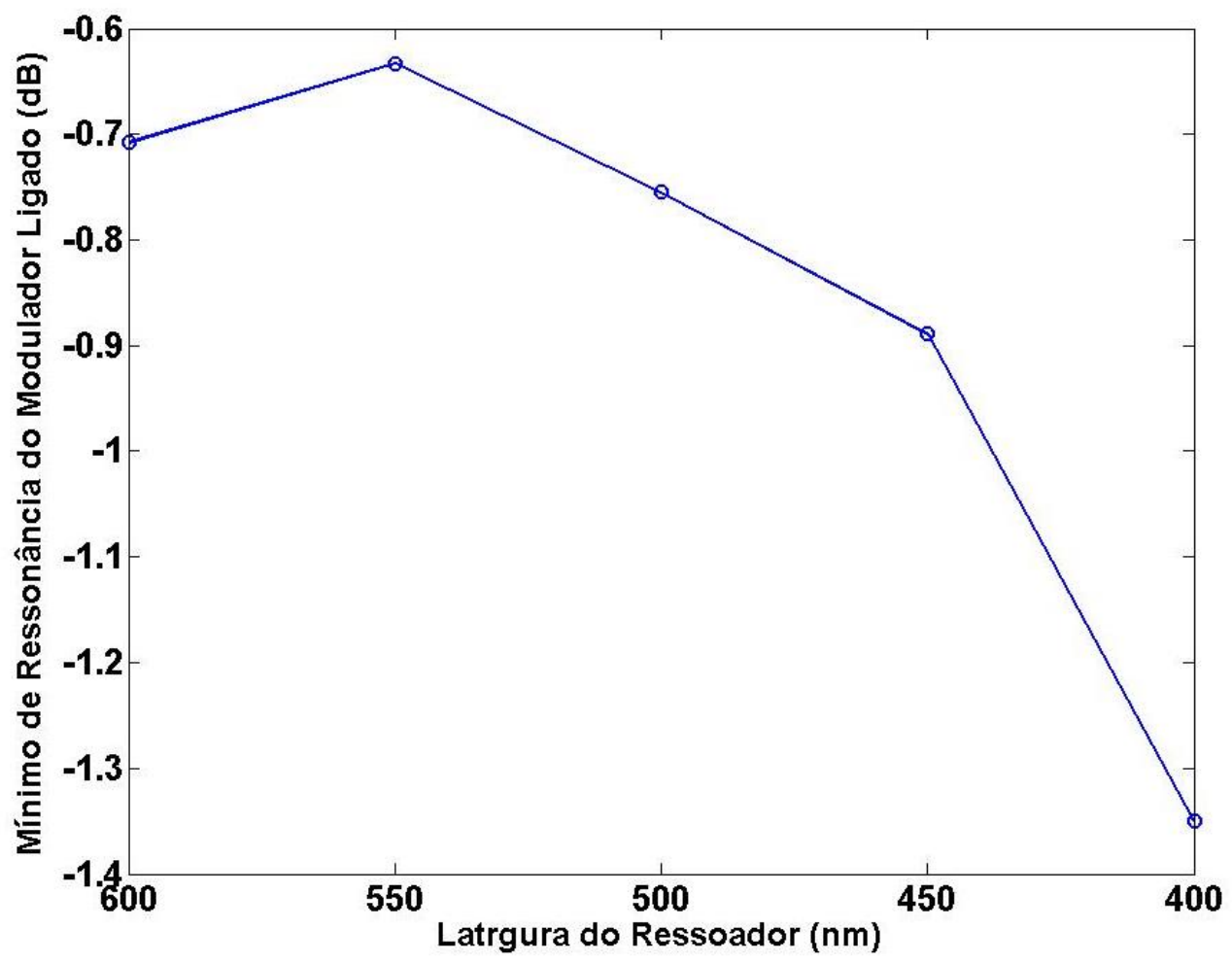

Figura 27 - Mínimo de transmissão do modulador ligado em função da largura W.

Fonte: Autor.

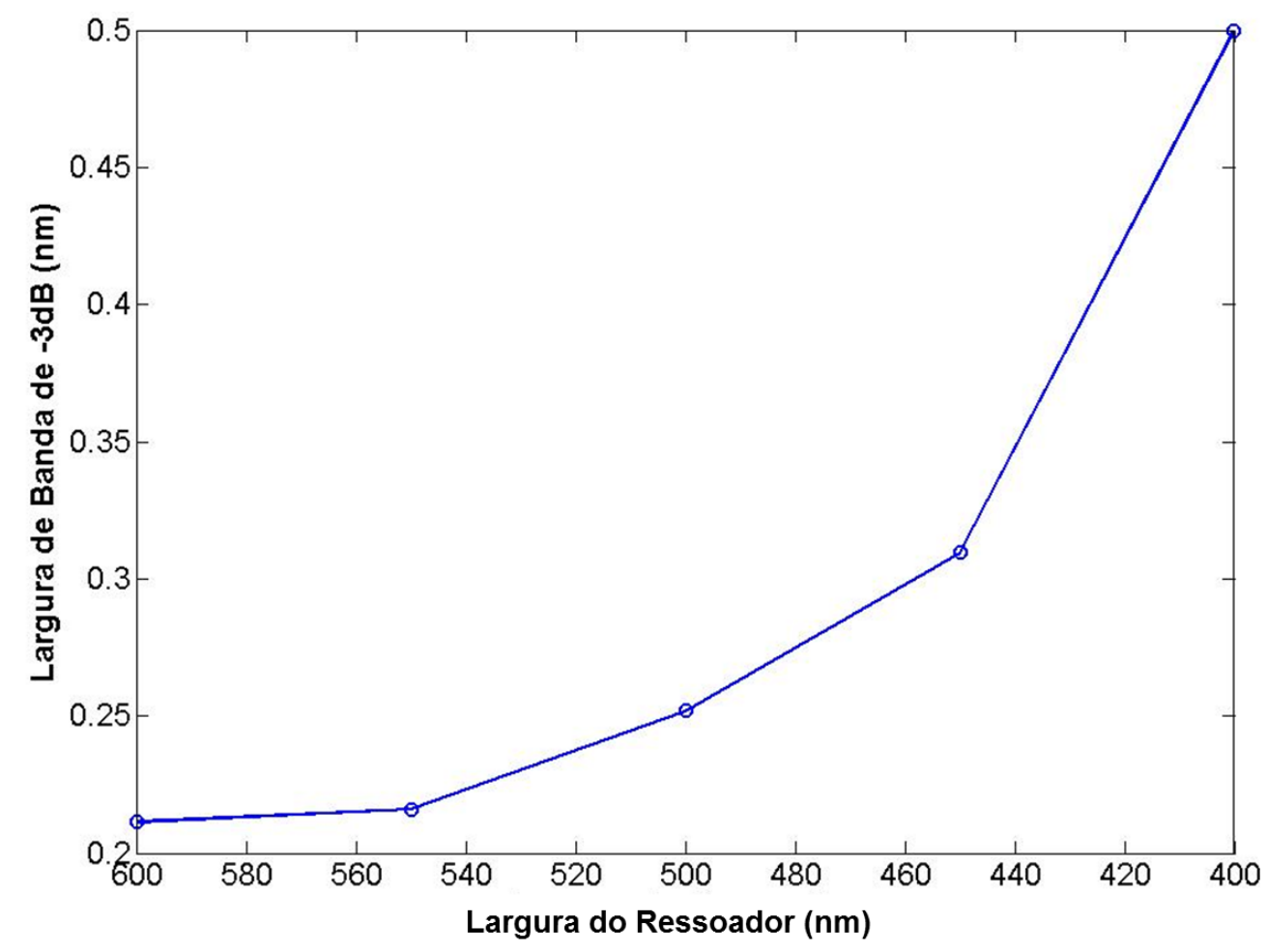

Figura 28 - Largura de banda do modulador para o acoplamento crítico em função da largura W. Fonte: Autor. 


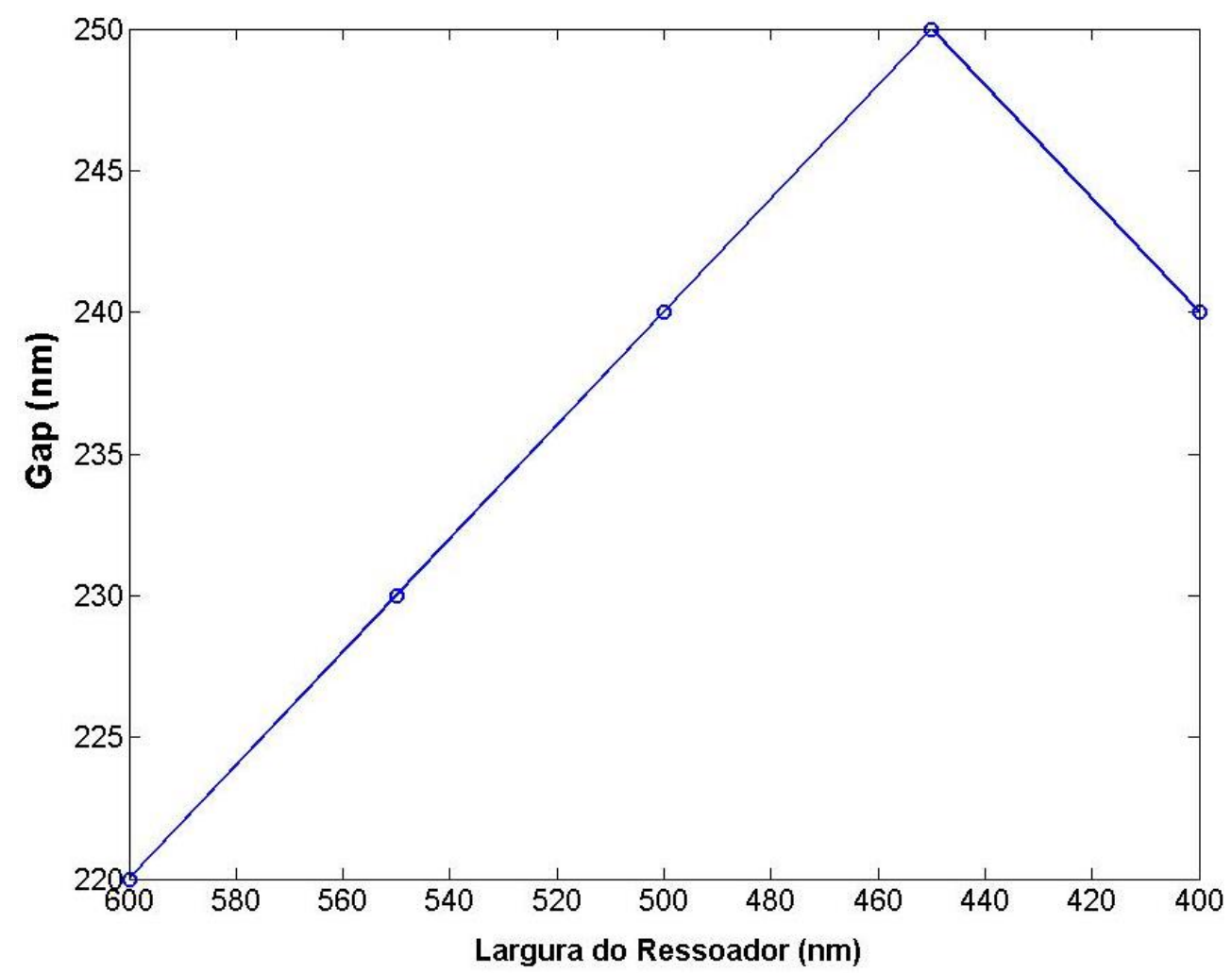

Figura 29 - Separação g entre o ressoador e o barramento para o acoplamento crítico em função da largura W. Fonte: Autor.

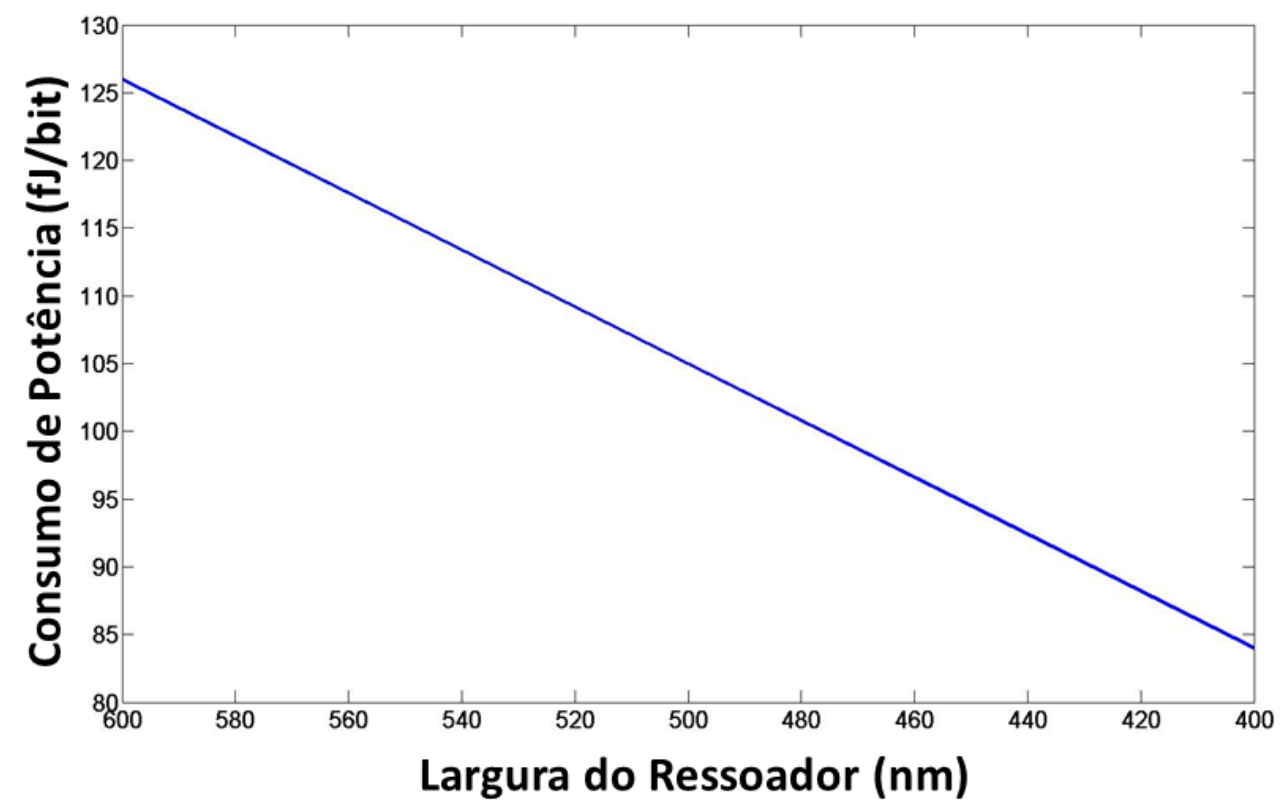

Figura 30 - Consumo de potência em função da largura W.

Fonte: Autor. 


\section{CONCLUSÕES}

Neste trabalho, investigou-se numericamente a resposta espectral de ressoadores cujo raio externo foi fixado em 2,58 $\mu \mathrm{m}$, para dois tipos de moduladores de eletro-absorção baseados em grafeno. No primeiro, a condição de acoplamento crítico foi ajustada para o caso de um ressoador cuja condutividade óptica foi definida para um potencial químico correspondente a $0,3 \mathrm{eV}$ e, no segundo caso, de 0,5 eV. As figuras de mérito, bem os parâmetros geométricos otimizados (considerando ressoadores de maior largura) das duas configurações de moduladores investigadas são expostas em comparação às obtidas por Midrio et al. [20] na Tabela 3.

Tabela 3 - Comparação entre os moduladores das configurações 1,2 e da obtida por Midrio et al.

\begin{tabular}{|c|c|c|c|}
\hline \multicolumn{4}{|c|}{ Comparação Entre os Moduladores Otimizados } \\
\hline & $\begin{array}{c}\text { Modulador } \\
1\end{array}$ & Modulador 2 & Midrio \\
\hline $\begin{array}{l}\text { Mín. de Ressonância do Estado } \\
\text { Ligado (dB) }\end{array}$ & $-1,73 \mathrm{~dB}$ & $-0,73$ & $-0,48$ \\
\hline Largura de Banda-3dB (nm) & 1,42 & 0,22 & ---- \\
\hline Footprint $\left(\mu \mathrm{m}^{2}\right)$ & 25 & 25 & 100 \\
\hline FSR (nm) & 40 & 40 & ----- \\
\hline $\begin{array}{l}\text { Tensão de Variação } \\
\text { Ligado/desligado(V) }\end{array}$ & $\begin{array}{c}\text { 0,9(Desligado), } \\
\text { 2,6 (ligado) }\end{array}$ & $\begin{array}{l}\text { 0,9(ligado),2,6 } \\
\text { (Desligado) }\end{array}$ & $\begin{array}{c}\text { 0,9(Desligado) } \\
\text { 2,6 (Ligado) }\end{array}$ \\
\hline $\begin{array}{c}\text { Consumo de Potência } \\
\text { (fJ/bit) }\end{array}$ & 126,25 & 26,25 & 60 \\
\hline$\theta_{\text {graf }}$ & $75^{\circ}$ & $360^{\circ}$ & $116^{\circ}$ \\
\hline w1 (nm) & 340 & 340 & 400 \\
\hline $\mathbf{W}(\mathbf{n m})$ & 600 & 600 & 400 \\
\hline $\operatorname{Gap}(n m)$ & 220 & 100 & 100 \\
\hline Raio Externo $(\mu \mathrm{m})$ & 2,58 & 2,58 & 5,2 \\
\hline
\end{tabular}

Para a primeira configuração de modulador, mostrou-se que é possível minimizar a degradação da resposta em profundidade de modulação para ressoadores com este raio externo, compensando o aumento das perdas por curvatura com a adoção de moduladores de maior largura e aumentando o acoplamento de energia do barramento ao ressoador (com a diminuição da largura do barramento) ligado/desligado do modulado. Além disso, a redução de suas dimensões permitiu 
(em comparação com Midrio) um modulador com um consumo de potencia bastante reduzido e um FSR mais largo.

Para o segundo modulador, com o ajuste do acoplamento crítico para um potencial químico representando menores perdas, obteve-se um dispositivo com uma resposta ainda melhor em profundidade de modulação, permitindo uma configuração com maior potencial de miniaturização do dispositivo, considerando um determinado patamar nesta figura de mérito. Apesar da redução da largura de banda e do aumento do consumo de potencia por bit em comparação à primeira configuração de modulador, ainda é possível considerar um dispositivo de baixo consumo energético e sem limitações significativas em sua taxa de modulação [9], [12], [13], com a vantagem adicional de ser um dispositivo de mais fácil fabricação, uma vez que a sintonia do acoplamento crítico ocorre para gaps mais largos e por sua estrutura ser completamente coberta com grafeno, permitindo uma fabricação menos sujeita a imprecisões.

For fim, conclui-se, neste trabalho, que apesar das dificuldades em se obter estes dispositivos em dimensões reduzidas sem que isto comprometa a sua resposta em profundidade de modulação, é possível minimizar esta degradação com ajustes geométricos na estrutura, a fim de reduzir as perdas por curvatura do ressoador e aumentar o acoplamento de energia com o barramento. Também, pode-se ajustar a variação da condutividade óptica do dispositivo de forma otimizada, possibilitando uma maximização do contraste nas perdas do modulador entre seus estados ligado e desligado.

\subsection{Perspectivas Futuras}

As investigações feitas neste trabalho permitem um direcionamento para definir os ajustes necessários destes moduladores tendo como objetivo a redução de suas dimensões sem que isto comprometa o desempenho do dispositivo, referente à sua profundidade de modulação. Como perspectivas futuras, além dos ajustes geométricos já definidos, pretende-se investigar, por meio de variações no potencial químico, a configuração energética mais favorável e que também represente uma redução da tensão de chaveamento, considerando sempre a manutenção da resposta em profundidade de modulação a patamares adequados para o funcionamento eficiente do modulador. Outra importante perspectiva aberta para estes ressoadores está na aplicação como dispositivos de sensoriamento, especialmente para a detecção de gases, tendo em vista que já foi demonstrada a grande sensibilidade do grafeno na variação de sua condutividade quando em contato com alguns gases, mesmo em concentrações relativamente baixas [54]. 


\section{REFERÊNCIAS BIBLIOGRÁFICAS}

[1] C. Kitano, "Aplicação da abordagem de domínio espectral para análise de moduladores eletroópticos integrados", (Tese de Doutorado), São José dos Campos: Instituto Tecnológico de Aeronáutica, 441 pp., 2001.

[2] C. del Río Campos and Paloma R. Horche (2012). Effects of Dispersion Fiber on CWDM Directly Modulated System Performance, Optical Fiber Communications and Devices, Dr Moh. Yasin (Ed.), ISBN: 978-953-307-954-7.

[3] E. Shamonina and L. Solymar, "Waveguide electrooptic modulators", IEEE Transactions on Microwave Theory and Techniques, vol. MTT-30, no. 8, pp. 1121-1137, August 1982.

[4] Y. Tang, "Study on electroabsorption modulators and grating couplers for optical interconnects", (Doctoral Thesis), Sweden: School of Information and Communication Technology, 92 pp., 2010.

[5] R. A. Soref, B. R. Bennett, "Electrooptical effects in silicon", IEEE Journal of Quantum Electronics, vol. QE-23, no. 1, pp. 123-129, January 1987.

[6] G. T. Reed, G. Mashanovich, F. Y. Gardes, and D. J. Thomson, "Silicon optical modulators", Nature Photonic, vol. 4, pp. 518-526, August 2010.

[7] G. Gupta, "Microring resonator based filters and modulators: optical coupling control and applications to digital communications", (Doctoral Thesis), University of Southern California, 187 pp., 2008.

[8] Y. Li, "Silicon micro-ring resonator device design for optical interconnect systems", (Doctoral Thesis), University of Southern California, 110 pp., 2013.

[9] Dong P, Liao S, Feng D, Liang H, Zheng D, Shafiiha R, Kung CC, Qian W, Li G, Zheng X, Krishnamoorthy AV, Asghari M., "Low Vpp, ultralow-energy, compact, high-speed silicon electrooptic modulador," Opt. Express, vol. 17, no. 25, pp. 22484-90, Dec. 2009.4309-4315 (2008). 
[10] Hiren Thacker, Ivan Shubin, Ying Luo, Kannan Raj, John E. Cunningham, and Ashok V. Krishnamoorthy, "25Gb/s 1V-driving CMOS ring modulator with integrated thermal tuning," Opt. Express 19, 20435-20443 (2011)

[11] Xi Xiao, Hao Xu, Xianyao Li, Yingtao Hu, Kang Xiong, Zhiyong Li, Tao Chu, Yude Yu, and Jinzhong $\mathrm{Yu}$, "25 Gbit/s silicon microring modulator based on misalignment-tolerant interleaved PN junctions," Opt. Express 20, 2507-2515 (2012)

[12] Hui Yu, Diqing Ying, Marianna Pantouvaki, Joris Van Campenhout, Philippe Absil, Yinlei Hao, Jianyi Yang, and Xiaoqing Jiang, "Trade-off between optical modulation amplitude and modulation bandwidth of silicon micro-ring modulators," Opt. Express 22, 15178-15189 (2014).

[13] Wesley D. Sacher, and Joyce K. S. Poon "Dynamics of microring resonator modulators," Opt. Express, vol. 16, Issue 20, pp. 15741-15753, 2008.

[14] A. K. Geim, and K. S. Novoselov, “The rise of graphene”, Nature Materials, vol. 6, pp. 183191, March 2007.

[15] M. Liu, X. Yin, E. Ulin-Avila, B. Geng, T. Zentgraf, L. Ju, F. Wang, and X. Zhang, “A graphene-based broadband optical modulator", Nature Materials, vol. 474, pp. 64-67, June 2011.

[16] Z. Lu and W. Zhao, "Nanoscale electro-optic modulators based on graphene-slot waveguides", J. Opt. Soc. Am. B, vol. 29, no. 6, June 2012.

[17] G. Gu and Z. Xie, "Modulation doping of graphene: An approach toward manufacturable", Applied Physics Letters, vol. 98, pp. 083502-1-083502-3, 2011.

[18] S. J. Koester and M. Li, "High-speed waveguide-coupled graphene-on-graphene optical modulators,” Appl. Phys. Lett. 100, 171107 (2012).

[19] K. Kim, J.-Y. Choi, T. Kim, S.-H. Cho, and H.-J. Chung, "A role for graphene in siliconbased semiconductor devices”, Nature, vol. 476, pp. 338-344, November 2011. 
[20] M. Midrio, S. Boscolo, M. Moresco, M. Romagnoli, C. Angelis, A. Locatelli, and A.-D. Capobianco, "Graphene-assisted critically-coupled optical ring modulator", Optics Express, vol. 20, no. 21, pp. 23144-23155, October 2012.

[21] Ciyuan Qiu, Weilu Gao,Robert Vajtai, Pulickel M. Ajayan, Junichiro Kono, and Qianfan $\mathrm{Xu}$, "Efficient Modulation of $1.55 \mu \mathrm{m}$ Radiation with Gated Graphene ona Silicon Microring Resonator”, Nano Lett., 2014, 14 (12), pp 6811-6815.

[22] J. E. Padilha de Sousa, "Nanodispositivos baseados em grafeno" (Tese de Doutorado), São Paulo: Instituto de Física, 186 pp., 2012.

[23] H. W. Kroto, J. R. Heath, S. C. O’Brien, R. F. Curl, and R. E. Smalley, "C 60 : Buckminsterfullerene", Nature, vol. 318, pp. 162-163, November 1985.

[24] A. J. C. Chaves, "Estudo das propriedades eletrônicas e ópticas do grafeno e projeto de um modulador em amplitude" (Trabalho de Conclusão de Curso de Graduação), São José dos Campos: Instituto Tecnológico de Aeronáutica, 173 pp., 2011.

[25] Y. Liu, B. Xie, Z. Zhang, Q. Zheng, and Z. Xu, "Mechanical properties of graphene papers", Journal of the Mechanics and Physics of Solids, vol. 60, Issue 4, pp. 591-605, April 2012.

[26] C. Lee. X. Wei, J. W. Kysar, and J. Hone, "Measurement of the elastic properties and intrinsic strength of monolayer graphene”, Science, vol. 321, pp. 385-388, July 2008.

[27] A. A. Balandin, S. Ghosh, W. Bao, I. Calizo, D. Teweldebrhan, F. Miao, and C. N. Lau, "Superior thermal conductivity of graphene", Nano Letters, vol. 8, no. 3, pp. 902-907, January 2008

[28] J.-C. Charlier, P. C. E. J. Zhu, A. C. Ferrari, "Electron and phonon properties of graphene”, Topics Appl. Physics, vol. 111, pp. 673-709, 2008.

[29] L. Britnell, "Electronic Trasport properties of Graphene-Based Heterostructures", (Doctoral Thesis), University of Manchester, 111 pp., 2012. 
[30] F. Bonaccorso, Z. Sun, T. Hasan, and A. C. Ferrari, "Graphene photonics and optoelectronics", Nature Photonics, vol. 4, pp. 611-622, September 2010.

[31] R. R. Nair, P. Blake, A. N. Grigorenko, K. S. Novoselov, T. J. Booth, T. Stauber, N. M. R. Peres, and A. K. Geim, "Fine structure constant defines visual transparency of graphene," Science, vol. 320, 1308, 2008.

[32] T. Kampfrath, L. Perfetti, F. Schapper, C. Frischkorn, and M. Wolf, "Strongly coupled optical phonons in the ultrafast dynamics of the electronic energy", Physical Review Letters, vol. 95, pp. 187403-1-187403-4, October 2005.

[33] S. Pyo, J.-W. Baik, S.-H. Cho and Y.-S. Kim, "Measurement of the optical conductivity of graphene”, Physical Review Letters, vol. 101, pp. 196405-1- 196405-4, November 2008.

[34] F. Xia, T. Mueller, Y.-M. Lin, A. Valdes-Garcia, and P. Avouris, "Ultrafast graphene photodetector", Nature Nanotechnology, vol. 4, pp. 839-843, December 2009.

[35] G. W. Hanson, "Dyadic Green's functions and guided surface waves for surface conductivity model of graphene”, J. Appl. Phys., vol. 103, 064302-1-064302-8, 2008.

[36] V. P. Gusynin, S. G. Sharapov, and J. P. Carbotte, "Magneto-optical conductivity in Graphene", J. Phys.: Condens. Matter, vol. 19, 026222, 2007.

[37] A. Vakil and N. Engheta, “Transformation optics using graphene," Science 332, 1291-1294 (2008).

[38] J. Ward and O. Benson, "WGM microresonators: sensing, lasing andfundamental optics with microspheres," Laser Photonics Rev 5, 553-570 (2011).

[39] P. Debye, "Der Lichtdruck auf Kugeln von beliebigem Material", Ann.

[40] C. G. B. Garrett, W. Kaiser, and W. L. Bond,'Stimulated emission into optical whispering gallery modes of spheres”, Phys. Rev. 124, 1807-1809 (1961). 
[41] Oraevsky, A.N. "Whispering-gallery waves", Quantum Electron. 32, 377-400 (2002).

[42] V. S. Ilchenko and A. B. Matsko, "Optical resonators with whispering-gallery modes Part II: Applications," Ieee J Sel Top Quant 12, 15-32 (2006).

[43] Wim Bogaerts, Peter De Heyn, Thomas Van Vaerenbergh, Katrien DeVos, Shankar Kumar Selvaraja, Tom Claes, Pieter Dumon, Peter Bienstman, Dries Van Thourhout, and Roel Baets "Silicon Microring Resonators," Laser Photonics Rev. 6, No. 1, 47-73 (2012)

[44] A. Yariv, "Universal relations for coupling optical power between microresonators and dieletric wavegudes”, Electronics Letters, vol. 36, no. 4, pp. 321-322, February 2000.

[45] A. Yariv, "Critical coupling and its control in optical waveguide-ring resonator systems", IEEE Photonics Technology Letters, vol. 14, no. 4, pp. 483-485, April 2002.

[46] Michele Moresco, Marco Romagnoli, Stefano Boscolo, Michele Midrio, Matteo Cherchi, Ehsan Shah Hosseini, Douglas Coolbaugh, Michael R. Watts, and Birendra Dutt, "Method for characterization of Si waveguide propagation loss," Opt. Express 21, 5391-5400 (2013)

[47] S. Xiao, M. H. Khan, H. Shen, and M. Qi, "Compact silicon microring resonators with ultralow propagation loss in the C band," Opt. Express 15(22), 14467-14475 (2007).

[48] C. D. Salzberg and J. J. Villa, "Infrared Refractive Indexes of Silicon, Germanium and Modified Selenium Glass", J. Opt. Soc. Am., 47, 244-246 (1957)

[49] I. H. Malitson, "Interspecimen Comparison of the Refractive Index of Fused Silica", J. Opt. Soc. Am. 55, 1205-1208 (1965)

[50] I. H. Malitson and M. J. Dodge, "Refractive Index and Birefringence of Synthetic Sapphire", J. Opt. Soc. Am. 62, 1405 (1972)

[51] M. Soltani, Q. Li, S. Yegnanarayanan, and A. Adibi, "Toward ultimate miniaturization of high Q silicon traveling-wave microresonators", Optics Express, vol. 18, no. 19, pp. 19541-19557, September 2010. 
[52] Hagness, S.G., Rafizadeh D., Ho S.T, Taflove A., "FDTD microcavity simulations: design and experimental realization of waveguide-coupled single-mode ring and WG mode disk resonators",J. Lightwave Techn vol. 15, no. 11, pp. 2154-2165, 1997

[53] Q. Xu, D. Fattal, and R. G. Beausoleil, "Silicon microring resonators with 1.5- $\mu$ m radius," Opt. Express 16, 4309-4315 (2008).

[54] L. Hultman, A. Lloyd Spetz, R. Yakimova, "Epitaxially grown graphene based gas sensors for ultra-sensitive NO2 detection," Sensors and Actuators B: Chemical, Volume 155, Issue 2, 20 July 2011, Pages 451-455 